\title{
The 30 October 2020, Mw 7.0, Samos Earthquake: Aftershock Relocation, Slip Model, Coulomb Stress Evolution and Estimation of Shaking
}

\section{Konstantinos Lentas}

National Observatory of Athens: Ethnikon Asteroskopeion Athenon

Charikleia Gkarlaouni

National Observatory of Athens: Ethnikon Asteroskopeion Athenon

Nikos Kalligeris

National Observatory of Athens: Ethnikon Asteroskopeion Athenon

NIKOLAOS S. MELIS ( $\square$ nmelis@noa.gr)

National Observatory of Athens: Ethnikon Asteroskopeion Athenon https://orcid.org/0000-0002-89664449

\section{Research Article}

Keywords: Body waves, Earthquake location, Earthquake source observations, Fault slip, Seismicity

Posted Date: May 24th, 2021

DOl: https://doi.org/10.21203/rs.3.rs-534400/v1

License: (9) This work is licensed under a Creative Commons Attribution 4.0 International License. Read Full License

Version of Record: A version of this preprint was published at Bulletin of Earthquake Engineering on October 26th, 2021. See the published version at https://doi.org/10.1007/s10518-021-01260-4. 


\title{
The 30 October 2020, $M_{W}$ 7.0, Samos earthquake: aftershock relocation, slip model, Coulomb stress evolution and estimation of shaking
}

\author{
Lentas K. • Gkarlaouni Ch. · Kalligeris \\ N. - Melis N.S.
}

Received: date / Accepted: date

\begin{abstract}
We study the major $M_{W}$ 7.0, 30 October 2020, Samos earthquake and its aftershocks, by calculating improved locations using differential travel times and waveform cross-correlations. We image the rupture of the mainshock using local strong motion data, and we examine the Coulomb stress evolution prior to the mainshock, as well as the coseismic stress changes. Lastly, we estimate the produced shaking using all the available information from strong motion data and testimonies. Earthquake relocations reveal the activation of the E-W oriented, Kaystrios fault, in the North basin of Samos with a possible extension to the West. The kinematic rupture inversion suggests non-uniform bilateral rupture on a $\sim 60 \mathrm{~km} \times \sim 20 \mathrm{~km}$ fault area, with the main rupture propagating towards the West and maximum slip up to approximately $2.5 \mathrm{~m}$. Improved locations of the aftershock sequence are anti-correlated with areas of maximum slip on the fault surface. Similarly, the Coulomb stress change calculations show that only off-fault earthquake clusters are located within lobes of increasing positive static stress changes. This observation is consistent with assuming a fault area of either uniform slip, or variable slip according to the obtained slip model. Both scenarios indicate typical stress patterns for a normal fault with $\mathrm{E}-\mathrm{W}$ orientation, with stress lobes of positive $\triangle C F F$ increments
\end{abstract}

K. Lentas

National Observatory of Athens, Institute of Geodynamics, Lofos Nymfon, 11810, Athens, Greece

Ch. Gkarlaouni

National Observatory of Athens, Institute of Geodynamics, Lofos Nymfon, 11810, Athens, Greece

N. Kalligeris

National Observatory of Athens, Institute of Geodynamics, Lofos Nymfon, 11810, Athens, Greece

N.S. Melis

National Observatory of Athens, Institute of Geodynamics, Lofos Nymfon, 11810, Athens, Greece 
expanding in E-W orientation. In the case of the variable slip model, both negative and positive stress changes show slightly larger values compared to the uniform slip model. Finally, Modified Mercalli Intensities based on the fault model obtained in this study indicate maximum intensity (VII+) in the North Samos island. Spectral acceleration values at $0.3 \mathrm{~s}$ period also demonstrate the damaging situation at Izmir.

Keywords Body waves - Earthquake location · Earthquake source observations · Fault slip · Seismicity

\section{Introduction}

On October 30, 2020, at 11:51 UTC, a major $M_{W} 7.0$ earthquake occured offshore the north coast of Samos island in the eastern Aegean Sea, in close proximity with Asia Minor coast, causing the death of two people in Vathi (Greece) and 115 people in Izmir (Turkey) due to severe building collapse. The earthquake caused heavy damages which resulted in a number of 19 and more than 1030 injuries in Samos island and Turkey, respectively (GEER, 2020). A variety of geological effects such as coastal uplifts, ground fractures, ground deformation, were reported after the earthquake occurrence and attracted multiple scientific working groups in situ. A moderate tsunami was generated that mainly impacted the northern coast of Samos and the SW coastline of Izmir Province, Turkey (Dogan et al., 2020). In Samos, runup exceeded $1.8 \mathrm{~m}$ in the town of Karlovasi causing minor damages, whereas the low-elevation waterfront of Vathi was impacted by a series of waves with maximum overland flow depth reaching $\sim 1 \mathrm{~m}$ (Dogan et al., 2020). Along the Aegean coastline of Turkey, a maximum wave runup of $3.8 \mathrm{~m}$ was measured in Akarca and flow depth values as high as $1.4 \mathrm{~m}$ were recorded in the worst-hit Kaleici region of Sigacik (Dogan et al., 2021). Tsunami warning messages were issued within 11 minutes after the earthquake by all three Tsunami Service Providers operating in the Eastern Mediterranean under the NorthEastern Atlantic, Mediterranean and connected seas Tsunami Warning System (NEAMTWS) of IOC UNESCO, and were followed by tsunami-ongoing messages following the detection of the tsunami through several tide gauges installed in the Aegean Sea (Dogan et al., 2020).

A few hours after the mainshock the strongest $M 5.3$ aftershock followed in close epicentral distance from the mainshock (Figure 1). According to the fault plane solutions reported by various agencies (Table S1 in the Supplementary material) both earthquakes signify normal faulting, which is in agreement with the seismotectonic regime (see also Section 2).

Historical archives indicate that the broader area of Samos has been occasionally struck by destructive earthquakes with the first record around 200 $\mathrm{BC}$ to be found on ancient inscriptions which describe Samos island suffering from damages due to a strong earthquake (Papazachos and Papazachou, 2003). There is an absence of information for hundreds of years until the $18^{\text {th }}$ century. 
There is evidence for nine earthquakes with estimated magnitude $M \geq 6.0$ until 1955 when the $M$ 6.9 Samos destructive earthquake occurred (Figure 1). Furthermore, the island has been affected by strong earthquakes in the northern Aegean and western Turkey which induced damages and losses at Samos along with significant tsunamis (Altinok et al., 2005; Melis et al., 2020). In recent times, microseismicity in the area of Samos and Kusadasi has been investigated with the deployment of a temporary network by Tan (2013) where dense earthquake clustering was evident. The adjacent 2005, $M_{W} 5.8$, moderate magnitude seismic sequence to the South of Karaburun peninsula has also been studied (Benetatos et al., 2006; Melis and Konstantinou, 2006). The significance of earthquake interaction through stress transfer in the broader area and the evolution of stresses due to strong events has been investigated by Paradisopoulou et al. (2010), as well as for the broader western Turkey since 1900, the northeastern Aegean Sea (Nalbant et al., 1998) and the Northern Aegean Sea (Papadimitriou and Sykes, 2001; Rhoades et al., 2010). Nevertheless, previous studies have not considered stress effects on the Samos 2020, causative fault.

In this study we attempt to shed some light on the characteristics of the $M_{W}$ 7.0, Samos earthquake, rupture history, as well as its aftershock sequence and its relation to the tectonics of the study area. Moreover, we investigate the mechanisms of stress transfer prior to the occurrence of the mainshock, and we assess the impact of Coulomb stress changes on the evolution of the aftershock activity.

\section{Study area and its seismotectonic setting}

The study area is situated in the eastern edge of the Aegean arc within the transition zone between the fast moving Aegean and the Anatolia microplate where deformation is transferred into the fast moving Aegean Sea, as deduced from GPS and seismological data (Papazachos, 1999). The broader area has been repeatedly struck by destructive historical earthquakes which are related to active seismogenic faults, built in a complex seismotectonic setting. The broader Aegean area undergoes widespread NNW-SSE extension orthogonal to the subduction of the eastern Mediterranean plate under the Aegean microplate (Papazachos and Comninakis, 1971). The westward extrusion of Anatolia plate and the prolongation of the North Anatolia Fault (NAF) into the Aegean Sea, which started $5 \mathrm{Ma}$ ago further reinforced the existing extensional forces (McKenzie, 1972). The Aegean microplate accommodates a southwestward movement relative to the stable Eurasia with a velocity rate of 32-35 mm/yr (LePichon et al., 1995; McClusky et al., 2000). Dextral strike slip faulting is dominant in the Northern Aegean as revealed by tectonics and fault plane solutions (Taymaz et al., 1991; Kiratzi, 2003). The trend of the extensional axis has gradually been rotated from NE-SW to NNE-SSW giving formation to new structures and causing the older NW-SE and NE-SW trending faults to acquire a strike slip component (Kissel and Laj, 1988). Currently, 
the extensional axis strikes in an almost N-S direction, according to geodetic measurements (Armijo et al., 1996) and fault plane solutions for strong earthquakes (Papazachos et al., 1998).

Back arc tectonics along with Tertiary volcanism are the dominant characteristics of the Aegean and coasts of western Asia Minor and have given rise to the formation of several neotectonic basins (Ikaria, Samos basins). In the Western Anatolian Extension Province, which is also governed by N-S extension a significant number of elongated E-W grabens like Gediz, Kucuk Menderes and Buyuk Menderes grabens have been developed (Sengör et al., 1984) along with offshore and onshore N-S to NE-SW steeply dipping oblique slip faults especially in Kusadasi peninsula and Izmir gulf owing a transpressional character (Ocakoğlu et al., 2005). According to the same authors in this area E-W compression in this area causes the N-S trending reverse faults, NE-SW dextral and NW-SE left-lateral strike slip faults, like Karaburun fault. Onshore seismotectonic research in Samos island by Mountrakis et al. (2003) highlighted the existence of active normal faults which shape the northern and southern coasts of the horst-like tectonics of the island and bound the Quaternary basins. NNW-SSE basins were initially formed by low angle detachment zones but NE-SW extension in Miocene imposed a high angle faulting. The successive rotation of the stress field from NE-SW to NNE-SSW resulted in the formation of new E-W normal high angle faults with the NW-SE and NESW ones to be reactivated by acquiring a strike slip component. The active fault databases of Gredass (Caputo and Pavlides, 2013) and GEM (Styron and Pagani, 2020) present the Kaystrios normal fault dipping offshore to the north of Samos island with a slip rate of $1.0 \mathrm{~mm} / \mathrm{yr}$ (Pavlidis et al., 2009). Regarding offshore seismotectonic investigation (Lykousis et al., 1995) suggest that strike slip deformation is active at the eastern part of the asymmetric Ikarian basin between Ikaria and Samos Islands as also proposed by Stiros et al. (2000). The bathymetry analysis by Nomikou et al. (2021) suggested the existence of an E-W normal fault bounding Samos basin from the south with an average dip $45^{\circ}$ and total throw $650 \mathrm{~m}$ since early Pleistocene, whereas slopes get steeper to the western part of the island mostly related to the NE-SW Ikaria margin.

\section{Data}

For the study of the mainshock as well as its aftershock sequence we combined parametric phase arrivals and waveform data. Details on the availability, temporal and space distribution of the data being used are given below.

\subsection{Parametric phase arrival data}

We downloaded hypocentral parameters and all the available phase arrival times of $P$ and $S$ phases up to $250 \mathrm{~km}$ in epicentral distance for all the earthquakes within our study area with magnitude $M \geq 2.0$, using the web services 
of the European-Mediterranean Seismological Centre (EMSC, https://www . seismicportal.eu/fdsn-wsevent.html, database last accessed March 2021), as it combines data from different providers within hours after an earthquake has occured. Details on the search parameters are shown in Table 1. This search yielded parametric data for 2,122 earthquakes with 67,775 associated $P$ and $S$ phase arrivals.

Figure 2a shows the spatial distribution of the seismicity and seismic stations being used in the current study. The associated phase arrivals are mainly manually picked from the permanent seismic stations of the Hellenic Unified Seismic Network (HL,HT,HA,HP,HC, National Observatory Of Athens, 1997; Aristotle University Of Thessaloniki Seismological Network, 1981; University Of Athens, 2008; University Of Patras, 2000; Technological Educational Institute Of Crete, 2006), coordinated by the Institute of Geodynamics, National Observatory of Athens (NOA-IG), Greece, the Kandilli Observatory And Earthquake Research Institute, Boğaziçi University (KO, Kandilli Observatory And Earthquake Research Institute, Boğaziçi University, 1971) and and the Turkish National Seismic Network (TU, Disaster And Emergency Management Authority, 1990), operated by the Disaster and Emergency Management Authority (AFAD).

\subsection{Waveform data}

Along with parametric phase arrivals we used three-component continuous recordings from the seismic networks mentioned in Section 3.1 in order to calculate differential travel times. Each waveform's start time was defined as the earthquake's origin time and the end time was set to $20 \mathrm{~s}$ past the theoretical $S$ arrival time based on the ak135 velocity model (Kennett et al., 1995). Moreover, we downloaded three-component continuous recordings of strong motion waveform data (ITSAK Institute Of Engineering Seimology Earthquake Engineering, 1981; National Observatory Of Athens, 1997; Kandilli Observatory And Earthquake Research Institute, Boğaziçi University, 1971; Disaster And Emergency Management Authority, 1990) for the mainshock, up to $200 \mathrm{~km}$ in epicentral distance, as well as a station at Samos island (SAMA) operating in trigerring mode (NOA accelerograph station) to carry out a kinematic slip inversion. More details about processing and calculations will be given in Section 4.

\subsection{Macroseismic observations and input data for shaking estimation}

The "Did You Feel It" (DYFI) testimonies reported to EMSC (https:// seismicportal.eu/eventdetails.html?unid=20201030_0000082), along with Peak Ground Acceleration (PGA) values obtained from strong motion data (see also, Askan et al., 2021) were used for the estimation of Modified Mercalli Intensity (MMI) maps. This data is being used at NOA in a routine manner, 
under SeisComP3 monitoring software (Helmholtz-Centre Potsdam-GFZ German Research Centre For Geosciences and GEMPA GmbH, 2008). A module scwfparam (https://www. seiscomp.de/doc/apps/scwfparam.html?highlight= scwfparam) is in operation to measure peak ground acceleration (PGA), peak ground velocity (PGV) and pseudo absolute acceleration elastic response spectrum (PSA) in periods $0.3 \mathrm{~s}, 1.0 \mathrm{~s}$ and $3.0 \mathrm{~s}$ (see Section 4.4 for more details).

\section{Methodology}

In the current Section we discuss the details of processing and methods applied in order to: (i) relocate the main event and its aftershock sequence, (ii) determine a kinematic slip model for the mainshock, and (iii) to study the stress evolution in the area of interest.

\subsection{Earthquakes relocation}

With the majority of the seismicity located offshore at the north of Samos, only a few stations are located in the close proximity of the epicentres $(<10 \mathrm{~km})$ which is key to accurate earthquake locations (e.g., Bondar and McLaughlin, 2009). Moreover, the fact that most of the aftershocks following the mainshock are of small magnitude $(\mathrm{M}<3.0)$, large azimuthal and secondary azimuthal gaps are often closely associated with the picking of very few phase arrival observations (see Figure 3 and Figure S1 in the Supplementary material).

In order to improve the locations of the existing catalogue (see Section 3.1), we applied a double-difference location technique (Waldhauser and Ellsworth, 2000 ) by calculating differential travel times $(t t)$ obtained from both catalogue data and waveform cross-correlations. Considering two neighbouring seismic events $i$ and $j$ with hypocentral parameters $\left[\varphi_{i} \lambda_{i} h_{i} t_{i}\right]^{T}$ and $\left[\begin{array}{llll}\varphi_{j} & \lambda_{j} & h_{j} & t_{j}\end{array}\right]^{T}$, respectively, the double-difference problem for any $n$ phase observation relative to the two events $i$ and $j$ can be defined as:

$$
\frac{\partial t t_{n}^{i j}}{\partial m} \Delta m^{i j}=\left(t t_{n}^{i}-t t_{n}^{j}\right)^{o b s}-\left(t t_{n}^{i}-t t_{n}^{j}\right)^{c a l}
$$

where $\Delta m^{i j}=\left[\begin{array}{llll}\Delta d \varphi^{i j} & \Delta d \lambda^{i j} \quad \Delta d h^{i j} \quad \Delta d t^{i j}\end{array}\right]^{T}$ represents perturbations in the model space $(m)$ which is defined by the relative hypocentral parameters between the two events $i$ and $j$, and the second part of equation 1 represents the differential travel time residuals. Equation 1 can be used to form a system of linear equations for each station pair which can be solved by means of least squares in an iterative way.

By linking as many neighbouring events together as possible (typically thousands) within small distances of a few kilometers, high resolution relative hypocentre locations can be achieved. In our case, we set the maximum separation distance to $10 \mathrm{~km}$ and the minimum number of links per pair to six, when at least four phase pairs are available. This setup yielded 18,096 event 
pairs with $153,301 P$ phase and 55,303 $S$ phase differential travel time pairs. We then calculated cross-correlation differential travel times based on 694,001 seismograms, after removing the mean and applying a zero phase bandpass filter from $1 \mathrm{~Hz}$ to $10 \mathrm{~Hz}$ to each waveform. Only phase pairs with a correlation coefficient above 0.7 were considered (Schaff and Waldhauser, 2005; Waldhauser and Schaff, 2008) as a balance for the tradeoff between reliability and a high number of observations, resulting in 9,324 event pairs with 22,683 $P$, and 3,271 $S$ cross-correlation pairs (Figure 4).

Using the 1D velocity model of Akyol et al. (2006), and adopting a $V_{P} / V_{S}$ ratio of 1.73 (Figure $2 \mathrm{~b}$ ), both phase picks and cross-correlation differential times were combined in a dynamically weighted double-difference inversion giving more weight to catalogue phase data in the first stages of the inversion, whereas control is passed to cross-correlation differential times in the last stages allowing the cross-correlation data to constrain only event pairs with separations smaller than $5 \mathrm{~km}$.

\subsection{Kinematic slip model}

In order to calculate a kinematic rupture model for the mainshock, we applied the technique developed by Gallovič et al. (2015). The displacement wavefield $u$ in space $(r)$ and time $(t)$ is described by the representation theorem:

$$
u(r, t)=\iint_{S} \Delta u(\xi, \tau) G(\xi, \tau ; r, t) d \xi d \tau
$$

where $G$ is the Green's function which contains the responses of point sources from subfaults distributed along the fault surface $S$, as described by the model. The term $\Delta u(\xi, \tau)$ represents the slip rate function in space $(\xi)$ and time $(\tau)$, which is parameterised by overlapping Dirac functions distributed along the fault surface. This type of formulation imposes no constraints on the nucleation point, the rupture velocity, or the shape of the slip rate function. As a result, the inverse problem consists of a large number of model parameters, namely, samples of the slip velocity as a function of spatial coordinates and time which are linearly related to the wavefield. The inverse problem is then solved by applying smoothing and a non-negativity constraint on the slip rates as regularisation.

In the current study, we used three-component strong motion data (Figure $2 \mathrm{a}$, see also Section 3.2), removed the mean, filtered the accelerograms between $0.05 \mathrm{~Hz}$ and $0.5 \mathrm{~Hz}$ and converted it to displacement. Moreover, for the station SAMA in Samos island, where the accelerograph is installed in a public building and oriented in parallel to the walls of the building, we rotated the two horizontal recordings to N-S and E-W directions prior to the processing mentioned above. Finally, based on the results from the relative locations (see Section 5.1) we set the fault surface measuring $60 \mathrm{~km}$ along strike and $20 \mathrm{~km}$ along dip and we calculated the Green's functions based on the Global Centroid Moment Tensor model (GCMT, https : //www.globalcmt.org/, database last 
accessed March 2021, Dziewonski et al., 1981; Ekström et al., 2012) using the Earth's structure extracted from CRUST2.0 velocity model (Bassin et al., 2000) with reference to the location of the main earthquake (Figure 2b), as this velocity model was built by combining both travel times and waveform data (surface wave dispersion measurements and normal modes).

\subsection{Coulomb stress transfer}

Changes in the stress field arise due to the coseismic stress changes induced by the occurrence of strong earthquakes along with the interseismic long-term stress accumulation which is accommodated on major faults and is driven from relative plate motions. In the case of Samos sequence, the stress state was investigated prior to the mainshock by investigating the successive stress changes imposed by the occurrence of strong earthquakes in the surrounding area $(M \geq 6.5)$ and the changes during the occurrence of the $M_{W} 7.0$ mainshock. The methodology that was followed relies on the elastic rebound theory, according to which the stress released in an area existed prior to the event and the applied technique follows Deng and Sykes (1997). For the calculations of the interseismic strain accumulation the "virtual dislocation" concept was introduced according to which the released coseismic stress preexists in the brittle part of the crust and is determined by assuming the backward fault slip. The Coulomb Failure Function criterion examines the conditions under which failure occurs on rocks when shear stress exceeds rock strength (Scholz, 2002). Changes in Coulomb Failure Function $(\triangle C F F)$ depend on changes in shear stress, $\Delta \tau$ and normal stress, $\Delta \sigma$, resolved onto the earthquake fault plane according to:

$$
\Delta C F F=\Delta \tau+\mu^{\prime} \Delta \sigma
$$

where $\mu^{\prime}$ is the apparent coefficient of friction. Positive $\triangle C F F$ values denote a high likelihood for future failure, therefore locations with advanced stress changes indicate areas close to rupture, whereas negative values indicate that fault failure is prevented. Subsequent earthquakes preferentially occur on locations with positive increments whereas negative values are considered areas of seismic quiescence described as shadow zones. The term $\mu^{\prime}$ describes the effect of the pore pressure change due to pore fluid and for dry materials ranges between 0.5 and 0.8 (Harris, 1998).

For calculating $\triangle C F F$, source models for large earthquakes are constrained to approximate the rupture geometry. Despite their heterogeneity, faults can be simply approximated with planar rectangular geometric structures, which dip into the brittle part of the crust. The geometrical parameters such as the fault length and width, the co-seismic horizontal $\left(u_{S S}\right)$ and along dip $\left(u_{D S}\right)$ slip and the fault plane solution (strike, dip and rake) adequately describe the rectangular rupture models and are used as an input for stress change evaluation. The selection of these parameters is crucial for the definition of the stress field since the variation of these parameters strongly affects the final stress pattern. The geometrical parameters are deduced from the available geological or 
seismological information and in the absence of this information, parameters are computed with the application of empirical relationships relating earthquake moment magnitude with fault length and average displacement. The ones proposed for normal faults by Papazachos et al. (2004) regarding length, $L$ (equation 4) and the average coseismic displacement, $u$ (equation 5) for dip slip continental faults were used in this study:

$$
\begin{aligned}
& \log L=0.50 M-1.86 \\
& \log L=0.59 M-2.30 \\
& \log u=0.82 M-3.71 \\
& \log u=0.68 M-2.82
\end{aligned}
$$

In cases of instrumental recordings where the seismic moment $\left(M_{o}\right)$ is known, the average coseismic displacement, was directly calculated from equation 6 :

$$
M_{o}=G \bar{u} w L=G \bar{u} S
$$

where $G$ is the shear modulus in the seismic source, estimated approximately equal to $3.3 \times 10^{11} d y n \times \mathrm{cm}^{-2}$ (Stein et al., 1997), $\bar{u}$ is the average displacement $S$ and corresponds to the fault area. Fault width, $w$, was obtained from the equation $w=h / \sin \delta$, where $\delta$ corresponds to the fault dip and $h$ is the downdip distance from the upper to the lower edge of the fault always taking into consideration the value of the aspect ratio (fault length over width, $L / w$ ). The width of the seismogenic part of the crust for which $\triangle C F F$ were calculated, was determined from the distribution of the relocated earthquake foci at depth and ranges between $3-14 \mathrm{~km}$.

\subsection{Shakemap calculations}

ShakeMap calculations were derived by combining PGA, PGV, PSA (at $0.3 \mathrm{~s}$, $1.0 \mathrm{~s}$ and $3.0 \mathrm{~s}$ ) values computed using the swfparam module in SeisComP3 and the DYFI testimonies collected by EMSC. We attempted to estimate and map the shaking of the $M_{W}$ 7.0, Samos earthquake, using the United States Geological Survey (USGS) ShakeMap4 (Worden, 2016) standard procedure. PGA values were converted to MMI following Worden et al. (2012), which satisfies shallow crustal events in Greece (Margaris et al., 2021). Site effects were taken into account using the $V_{s} 30$ gridded layer produced by Stewart et al. (2014) and made available at the USGS ShakeMap repository and github (https://usgs . maps . arcgis. com/apps/webappviewer/index. html?id=8ac19bc334f747e486550f32837578e1, https://github.com/usgs/earthquake-global_vs30/tree/master/Greece), combined with the Ground Motion Model (GMM) of Boore et al. (2020). The location and dimensions of the fault plane were based on the slip model obtained in the current study using the technique presented in Section 4.2, which corresponds to the best fitting double-couple model from GCMT. 


\section{Results}

\subsection{Relative locations}

Relative locations were obtained following the procedures described in Section 4.1 after experimenting with different setup parameters and weighting schemes. In fact, in some cases high damping was needed to stabilise the inversion, as expressed by the ratio of the largest to smallest eigenvalue of the system (condition number). This might be an indication of weak links between events and/or the presence of data outliers, possibly due to the fact that the majority of the seismic events in our set are located offshore where the density of the seismic stations in the close proximity of the epicentres is not ideal. A way to overcome this requires more links between event pairs in order to form continuous clusters, changes in the weighting of the catalogue and crosscorrelation differential travel time data, or even the generation of differential time data sets that allows for more neighbours for each event by taking into account more distant events. Nevertheless, this can be a balancing act between the resolution of the relocations and the number of relocated events.

We achieved acceptable condition numbers and we obtained relative locations for 1357 out of 2122 seismic events by combining catalogue phase picks and cross-correlation differential travel times (Figure 5). Sparse earthquakes initially located off the main cluster which lies offshore the north shore of Samos island were rejected (Figure 6a) as these events did not meet the requirements set regarding the minimum links per pair and/or maximum separation (see also Section 4.1). Moreover, event pairs associated with similar wave trains showing high correlation coefficients $(>0.7)$ yielded a higher density of earthquakes located in a narrower zone along the Kaystrios fault in the Samos basin (Figures 6b and 6c).

Figure 7 shows the evolution of the relocation process every time a different weighting scheme was applied in the inversion, carrying out 25 iterations in total. When the catalogue data and cross-correlation differential travel times were equally weighted, distinct earthquake clusters formed as early as in the $10^{\text {th }}$ iteration. Essentially, the inversion converged approximately at the $20^{\text {th }}$ iteration when catalogue phase data are down-weighted and cross-correlation differential travel times almost entirely control the inversion.

Figure 8 provides information regarding the quality of the event pairs constrained by cross-correlation data and how it relates to event separation. In general, travel time residuals are centred around zero seconds following a normal distribution and the RMS residuals have the tendency to increase with increasing event offset as expected. This increase with offset distance may be explained as a result of scattering along the ray path and/or discrepancies in the source mechanisms for each event pair.

The onset of the Samos earthquake sequence was marked with the occurrence of the $M_{W} 7.0$ mainshock, which was followed by the strongest aftershock $M 5.2$ a few hours later and in a very close distance. The stem diagram of Figure $9 \mathrm{a}$ shows the temporal evolution of the seismic sequence for the initial 
earthquake catalogue reported from EMSC for earthquakes with magnitude $M \geq 2.0$. Dense earthquake occurrence was observed within the first 15 days of November 2020, while by the end of the study period only 10 moderate events with magnitude $M \geq 4.5$ occurred. For a clear investigation of spacetime earthquake relations distinct colours are assigned to the most significant spatial clusters (Figures 9b and 9c). Seismic activity expanded equally to the West and to the East of the main shock, along an elongated zone offshore, North of Samos island. Synchronous seismic activity appeared to the West by forming two clusters. The most numerous cluster (in red) shows a quite diffused distribution of epicentres with an increased activity within the first 10 days, which coincides with the activity and duration of the smaller blue cluster. Some activity of small magnitude earthquakes bursts to the East simultaneously, but it is not E-W aligned. Some hours after the mainshock, seismic activity migrated to the eastern coast of the island (in green) and two seismic bursts also appeared to the northeast (yellow and magenta), in the proximity of the Turkish coast. Seismic rate is considerably decreased all over the area, approximately 15 days after the mainshock.

In order to investigate the seismic faults activated by the mainshock and its aftershocks we examine the cross-sections of Figure 5. Cross-sections A and $\mathrm{B}$ are oriented along strike to the Kaystrios fault, whilst, the rest are oriented perpendicular to it. All cross-sections are $5 \mathrm{~km}$ in width and those that are parallel slightly overlap to each other.

Along strike (E-W) cross-sections (Figure 10) cover almost the entire seismicity in the study area and show earthquake clusters at a total length of $60 \mathrm{~km}$ approximately, with the mainshock's epicentre located $40 \mathrm{~km}$ from the West (A1) and $20 \mathrm{~km}$ from the East (A2). The vast majority of the relocated earthquakes are observed at depths ranging from $3 \mathrm{~km}$ to $15 \mathrm{~km}$. Four distinct clusters are formed along this direction, with the largest observed at the close proximity of the mainshock and the largest aftershock ( $M 5.2)$ hypocentres. Cross-section B which is located slightly to the South, offers a clearer view to these distinct earthquake clusters, suggesting the activation of possible parallel seismic faults to the main Kaystrios fault. The cluster located to the Western part covered by the cross-sections A and B, could be considered as a result of a possible extension of the Kaystrios fault to the West, as suggested by fault mechanisms (Figure S2 in the Supplementary material).

North-South oriented cross-sections (Figure 10) indicate that the main cluster observed at the Samos basin is associated with the Kaystrios fault, which is rather shallow dipping for a normal fault $\left(\sim 40^{\circ}\right)$, in agreement with the earthquake fault plane solutions in the area. Some minor activity may be associated with the presence of other smaller parallel seismic faults, suggested by the similarity of source mechanisms (Figure S2 in the Supplementary material). In general, sharp images of relocated seismicity, especially as shown in $\mathrm{C}$ and $\mathrm{D}$ cross-sections, revealed a possible system of listric faults in the Samos basin, dipping to the North.

The earthquake cluster observed at the East coast of Samos is not associated with the North-dipping Kaystrios fault and may be explained by the 
activation of other seismic faults in the area with steep dipping angles (see cross-sections B and F in Figure 10). Since the seismicity of this cluster is of rather low mangnitude $(\sim 3.0)$, there is lack of source mechanisms which could reveal the characteristics of their associated sources, and hence, it is not safe to draw any conclusions at this point regarding this earthquake cluster prior to further investigation.

\subsection{Slip model}

Using the relocated hypocentral solution obtained for the mainshock in Section 5.1, we carried out a kinematic slip inversion described in Section 4.2 in order to determine its slip model. Based on the distribution of the relocated aftershock sequence we assumed a planar fault for simplicity, with a fault rupture area of $60 \mathrm{~km} \times 20 \mathrm{~km}$. The nucleation point was placed $20 \mathrm{~km}$ from the West boundary along strike, and $8 \mathrm{~km}$ in the up-dip direction (see also cross-section A at Figure 10). Several source models determined for this earthquake (Table S1 in the Supplementary material) show a rotation angle (Kagan, 1991) up to $\sim 30^{\circ}$ which is typical among source models obtained using different data and techniques (e.g., Lentas et al., 2019). Despite these variations within source parameters based on the nucleation point or centroid based solutions, we used the best fitting double couple solution from the Global CMT (Dziewonski et al., 1981; Ekström et al., 2012) as an average representation of the source. We used the seismic moment determined by the GCMT model and we set the source duration twice the GCMT half-duration (7.6 s), as being a good approximation for the total rupture time (Duputel et al., 2013; Lentas et al., 2013). The GCMT assumes a triangular source time function with halfduration determined by a constant stress drop scaling relation, proportional to the seismic moment. Table 2 summarises the input parameters used in the kinematic slip inversion.

Unlike synthetic tests, real case applications usually suffer from non-uniform station azimuthal coverage or data quality issues. Our case is no exception regarding the station coverage due to the topography of the study area, where stations to the west are sparse and far from the epicentre (green triangles in Figure 2a). Hence, we tried to overcome this issue by slightly down-weighting near-by stations at the east and up-weighting more distant stations to compensate for the geometrical spreading of wave amplitudes. Figure 11 compares the data against synthetic waveforms with respect to the calculated slip model. Synthetic displacement seismograms show very good fit against observed data in most cases, especially for the stations closest to the epicentre (up to 100 $\mathrm{km}$ ). Nevertheless, the station located at Tinos island (TNSA) may suffer from timing errors, thus, it was strongly down-weighted. Some discrepancies between the amplitude fit of waveform data and CRUST 2.0 synthetics may be improved by the use of a more accurate velocity model for the area.

Figure 12 shows the rupture evolution and the composite slip model obtained for the mainshock. Within the first three seconds the rupture propa- 
gated asymmetrically in the up-dip direction, mainly towards the East, whereas, in the next four seconds (4-8 s) it propagated simultaneously up-dip and downdip. Next, the rupture is characterised by westward propagation, with the maximum slip observed up-dip (Figure 12a). Individual slip rate functions (Figure $12 \mathrm{~b}$ ) indicate a more prominent slip patch in the up-dip direction, whereas, down-dip propagation was slightly shorter in time. Slip towards the East is almost negligible, whilst, slip in the West fades out at the $14^{\text {th }}$ second, with just a very short episode of rupture (pulse-like) in the last second. However, this might be just an artifact, since no matter how we set the total rupture time in the inversion, the ending is always ambiguous, possibly due to the fact that the station coverage to the West is sparse. Nonetheless, based on the assumed source duration (15 s) and fault dimensions, the obtained seismic moment $\left(4.01 \times 10^{19} \mathrm{Nm}\right)$ from our slip model agrees well with that of the GCMT.

\subsection{Coulomb stress evolution}

\subsubsection{Stress state prior to Samos 2020 earthquake}

Stress accumulation on the causative Samos fault before the 2020 earthquake was investigated by incorporating the interseismic deformation along the fault according to its slip rate and the coseismic $\triangle C F F$ due to the occurrence of the known historical earthquakes in the vicinity of the study area. Uncertainties related to estimated magnitude and location of historical earthquakes along with lack of data alter the real stress state prior to the earthquake. For the purposes of the study, strong earthquakes reported after 1881 when the devastating Chios-Cesme earthquake occurred are considered reliable to be involved in the stress field reconstruction. Six earthquakes with magnitude $M \geq 6.5$ have struck the study area from 1881 until present most of which regard normal fault plane solutions, shown in Figure 1 and further described in Papazachos and Papazachou (2003). Information on the parameters used for approximating the source models and the determination of their coseismic stress pattern is given in Table 6 . Coseismic stress changes caused by the occurrence of each earthquake were computed according to the source properties described in Table 6 but resolved onto the dipping plane of Samos fault (according to the GCMT solution (see Table S1 in the Supplementary material), which is the receiver fault (planar calculations at $8 \mathrm{~km}$ depth are shown in Figure S3 in the Supplementary material). Shear modulus and Poisson's ratio are fixed at $3.3 \times 10^{5}$ bar and 0.25 , respectively.

Figure 13 subplots exhibit the successive evolutionary state results for the receiver fault. Results incorporate the cumulative effect due to the tectonic loading according to the slip rate and the progressive coseismic changes. Before 1881 stress is presumed to be zero. Figure 13a shows the stress impact of the 1881 earthquake which occurred at $55 \mathrm{~km}$ distance from Samos epicentre on an antithetic fault zone (Figure S3a in the Supplementary material) and induces 
slight positive stress increments on the fault zone. The 1883 Cesme earthquake to the North of Samos sheds a wide stress shadow over the north dipping Samos fault plane (Figure S3b in the Supplementary material) prohibiting rupture along the receiver Samos fault (Figure 13b) while interseismic loading on fault is considered infinitesimal. The 1904 earthquake south of Samos (Figure S3c in the Supplementary material) which probably is related with the activation of the south dipping Pythagorion fault bounding southern Samos coasts produced a broad N-S area with negative $\triangle C F F$ increment on Samos island but induced a stress enhancement along the antithetic Samos fault plane by raising stress changed more than 1 bar (Figure 13c).

Figure 13d shows notable stress disturbances due to the 1928 Torbali earthquake to the northeast of Samos epicentral area, resulting in a positive stress lobe E-W oriented (Figure S3d in the Supplementary material) which further imposed a positive stress enforcement on Samos receiver fault (Figure 13d). The result is attributed additionally to the interseismic loading impact along fault for 47 years. Stress changes induced by the $1949 M$ 6.7 Chios-Karaburun earthquake in a $100 \mathrm{~km}$ distance from the 2020 epicentre caused positive stress changes mainly to the western Kuruburun peninsula (Figure S3e in the Supplementary material). However, its strong positive contribution to the stress increase along Samos fault is shown in Figure S3e in the Supplementary material where stress changes exhibit, are patched with $\triangle C F F$ values more than 2 bars. No significant impact on the overall stress state is observed along dip on Samos fault, after the occurrence of the 1955 Balat earthquake on the south dipping normal fault, in the western coast of Turkey (Figure 13f) no matter its proximity to the epicentral area of Samos (Figure S3f in the Supplementary material).

The cumulative effect of the coseismic stress changes for the given rupture models along with the estimated aseismic deformation shows a progressive stress built-up along Samos causative fault, which indicates a future failure promotion. A planar view at $8 \mathrm{~km}$ depth presents the stress state before the occurrence of the 2020 earthquake in a planar fault view according to which, bright zones are formed to the fault area northern than Samos as well as to the east and west of Samos island (Figure 14) mainly due to the collaborative contribution of the 1881, the 1902 and the 1955 strong earthquakes.

\subsubsection{Samos 2020 earthquake Coseismic Coulomb stress Changes}

Coulomb stress changes due to the Samos mainshock were calculated with the use of the uniform and finite fault models determined by this study. The GCMT solution which signifies a pure normal fault $\left(-90^{\circ}\right.$ rake) striking $276^{\circ}$ with $34^{\circ}$ dip was employed for constructing the rupture model. In the first case, the source fault zone was approximated with a rectangular plane $35 \mathrm{~km}$ long and $20 \mathrm{~km}$ wide, which coincides with the area of maximum slip and the length of the aftershock zone, and is slightly smaller than the fault rupture length estimated using the empirical scaling relation (equation $4, L=43 \mathrm{~km}$ ). Average slip was defined according to equation 6 for $M_{o}=4.01 \times 10^{19} \mathrm{Nm}$ 
determined by the slip inversion analysis with an along dip component $\left(u_{D S}\right)$ equal to $1.64 \mathrm{~m}\left(u_{S S}=0\right)$.

$\triangle C F F$ was calculated for three different horizontal layers of the seismogenic zone at $5 \mathrm{~km}$ (Figure 15a), $8 \mathrm{~km}$ (Figure 15c) and $10 \mathrm{~km}$ depth (Figure $15 \mathrm{e})$ where the majority of hypocentres is found. The stress pattern is typical for a normal fault shedding a broad stress shadow in a N-S direction where potential rupture is prohibited for a similar faulting type. Stress lobes with positive $\triangle C F F$ increments expand in an $\mathrm{E}-\mathrm{W}$ trend, and enhance stress changes over the Ikaria - Samos basin and the coasts of Turkey and Menderes basin to the West. Most of the aftershocks, including the strongest aftershock (Figure 15c) lie along the main dislocation plane and they are concentrated at the central and the western part of the shadow zone. Visual inspection ascertains a good correlation between seismicity and spatial distribution of the positive stress values only for the off-fault seismicity clusters. The western cluster is entirely located within the bright zones, whereas the cluster to the southeast is not fully explained by the distribution of stress resolved onto the north dipping plane and is probably attributed to the activation of a secondary faulting type. The cluster is effectively explained by the Coulomb stress evolutionary model, with the majority of the recent seismicity located where increasing positive static stress changes are calculated.

In the case of the fault finite model, a $60 \mathrm{~km}$ long and $20 \mathrm{~km}$ wide and $1 \mathrm{~km} \times 1 \mathrm{~km}$ gridded fault plane was introduced in order to investigate the determined slip patches across the entire rupture zone. Stress was calculated for the depth of $5 \mathrm{~km}, 8 \mathrm{~km}$ and $10 \mathrm{~km}$ shown in the Figures 15b, 15d and $15 \mathrm{f}$ along with the seismicity for the corresponding depths. The shadow zone is expanded as expected but with patches of positive stress changes are observed to the east of the aftershock at $8 \mathrm{~km}$ and at $10 \mathrm{~km}$ depth. Both negative and positive stress changes experience larger values compared with the uniform slip model. For investigating the correlation of the earthquakes with the given rupture model six cross-sections were plotted following the cross-section definitions provided in Figure 5, where $\triangle C F F$ changes are projected onto vertical planes (Figure 16). Earthquake hypocentres in $10 \mathrm{~km}$ range are additionally plotted. A1-A2 and B1-B2 profiles run the entire zone in an ENE-WSW direction. The southern profile shows that the hypocentres are embedded into the shadow zone, whereas the two zone terminations especially the eastern part where seismicity is dense, exhibit positive stress increments. To the North of the zone (B1-B2) the shadow zone is thinner but also coincides with the hypocentral distribution. N-S sections indicate a positive correlation between hypocentres and stress distribution to the eastern fault edge where increased $\triangle C F F$ is found especially for seismicity between $8 \mathrm{~km}$ and $10 \mathrm{~km}$ depth, as shown in sections D1-D2 and E1-E2. Section F1-F2 encompasses the southeastern cluster which seems not to be favoured by a stress pattern resolved on the north-dipping dip slip fault. 


\subsection{Estimation of shaking}

Modified Mercalli Intensities (MMI) with emphasis given to the epicentral area are shown in Figure 17, where the maximum expected intensity (VII+) is observed in the North of the Samos island, following the location of the rupture area. In fact, the NW part of the island suffered greater damage, as many rural villages were devastated, where old and poor quality stone masonry structures did not withstand the shaking. In general, this coincides with the results of the expected intensity calculations. Moreover, we note high values of $\sim 25 \% \mathrm{~g}$ PSA at $0.3 \mathrm{~s}$ period (spectral acceleration at $0.3 \mathrm{~s}$ ) in the city of Izmir, which are expected to affect the high rise buildings in the greater vicinity. The latter combined with the amplification of the ground motion due to the basin soil conditions could explain the collapse of the buildings in this area, where the greater number of fatalities was observed.

The above trend is also evident in static maps of macroseismic intensity (MMI), peak ground acceleration (PGA), peak ground velocity (PGV) and pseudo-spectral acceleration (PSA) at $0.3 \mathrm{~s}, 1.0 \mathrm{~s}$ and $3.0 \mathrm{~s}$ periods, which are shown in Figures S4-S9 in the Supplementary material. Diagrams of the fitted Ground Motion model (Boore et al., 2020) also demonstrate excellent fit to PGA, PGV and PSA from strong motion data, whilst converted values from testimonies are somewhat explained by the model (see Figures S10-S12 in the Supplementary material).

\section{Discussion and Conclusions}

In the current study we analysed the major $M_{W}$ 7.0, October 30, 2020, Samos earthquake, and its aftershock sequence. We relocated the mainshock relative to its aftershocks, using differential travel times from phase catalogue and waveform cross-correlation data (Waldhauser and Ellsworth, 2000), covering a broad time period of four months. We carried out a kinematic slip inversion (Gallovič et al., 2015) for the mainshock and we examined the evolution of Coulomb stress transfer (Deng and Sykes, 1997) as a result of the main earthquake, using a uniform slip model based on a simple planar fault, as well as using the fault slip distribution that we obtained from our kinematic slip inversion. Finally, based on the rupture are determined from our slip model, we estimated the shaking in the epicentral area by combining strong motion data and DYFI EMSC-testimonies.

Improved relative locations of the mainshock and the aftershock activity were obtained by combining catalogue and waveform cross-correlation data based on the hypocentres downloaded from the EMSC database, and the use of a 1D velocity model (Akyol et al., 2006) for the broad area of the East Aegean Sea. The EMSC is expected to offer an acceptable basis of initial hypocentral solutions, as it combines phase arrival data from various sources, which are being used in the relocated EMSC hypocentres. Other studies also suggest the determination of absolute locations prior to the relocation using 
differential travel times and the calculation of a more appropriate $1 \mathrm{D}$ velocity model for the study area when working with local stations (i.e., Matrullo et al., 2013; Konstantinou, 2018; Konstantinou et al., 2020). This also offers the advantage of calculating station corrections which reflect unmodelled 3D structure and can lead to lower station time residuals. This is evident as phase arrival data in local epicentral distances is very sensitive to lateral heterogeneities as the rays are mostly up-going. Nevertheless, synthetic tests based on velocity models with substantial differences, have shown that relative locations based on linearised double-difference equations can still converge close to the true locations (Waldhauser and Ellsworth, 2000). This is also enhanced by the use of cross-correlation differential travel times which are very effective in relocating repeating earthquakes. In fact, hypocentral separation is one of the key factors in accurate relocations of seismic events using double-difference and cross-correlation methods (Waldhauser and Schaff, 2008).

The relative locations of the earthquakes in our dataset revealed sharper images of the main tectonic characteristics of the fault area, which extends 60 $\mathrm{km}$ along strike $\left(\sim 270^{\circ}\right)$, and approximately $20 \mathrm{~km}$ along dip direction. Fault plane solutions of the mainshock and aftershocks are in excellent agreement with the orientation of the Kaystrios fault in the Samos basin. Moreover, the available source models suggest dip angles that range from $30^{\circ}$ to $55^{\circ}$ and indicate a possible system of parallel lystric faults in the Samos basin. This is also in agreement with morphotectonic studies (i.e., Nomikou et al., 2021) which support the existence of an E-W normal fault in the Samos basin with an average dip of $45^{\circ}$.

Using the improved hypocentral solution of the mainshock obtained from the double-difference relocation, and the best fitting double-couple solution from the Global CMT, we parameterised the fault area defined by the relative locations of the aftershock sequence, accordingly, and we attempted to calculate a kinematic slip model for the mainshock using displacement data from local strong motion stations.

The model space of linear slip inverse problems is characterised by a large number of model parameters, which typically leads to non-unique solutions of finite-fault source models (Zhang et al., 2014). As such, slip inversions are ill-posed problems that require some kind of regularisation in order to stabilise the inversion. The latter is usually implemented by applying non-linear constraints, such as positivity and/or spatialtemporal smoothing in order to damp any arising artifacts (Gallovič and Zahradník, 2011). Since spatial smoothing is strongly affected by station coverage and weighting, it is important to be implemented in a way that equalises the effect of nearby and distant stations (Gallovič and Zahradník, 2011; Gallovič et al., 2015). For example, nearest stations which typically have larger amplitudes compared to distant stations, can introduce biases to the obtained slip model, in a similar manner that non-uniform station azimuthal coverage can lead to false unilateral rupture propagation towards the azimuth with the highest station density. Moreover, data noise and/or inappropriate velocity models can further give rise to spurious effects and small-scale heterogeneities in the obtained slip model. 
After careful weighting of the waveform data in our kinematic slip inversion, we imaged the bilateral rupture of the mainshock within the first four seconds, as well as the main westward propagation towards the ending of the rupture, suggesting two main episodes of rupture which are also evident in the obtained moment rate function. Patches of maximum slip in our model are anticorrelated with the spatial distribution of the relocated aftershocks as expected (e.g., Konca et al., 2007; Kim and Dreger, 2008; Sladen et al., 2010), and the main cluster of the aftershock sequence around the mainshock, seems to lie on the fault area with the minimum slip (Figure 18). Only a small cluster to the West is associated with moderate slip, which might be an indication of a false slip patch due to unmodelled 3D structure in the inversion, non-uniform station azimuthal coverage, or a more complex rupture that cannot be fully explained by the assumption of a planar seismic fault. Joint inversions of seismic and geodetic data could possibly provide a more robust slip model (i.e., Sladen et al., 2010).

Coulomb Stress analysis was carried out in order to investigate the stress state on fault before the 2020 Samos earthquake as well as the coseismic stress disturbances and its impact on the spatial evolution of the aftershock activity. The evolution of the stress field included the cumulative impact of coseismic stress changes of six strong earthquakes with magnitude $M \geq 6.5$ beginning with the 1881 Chios - Cesme earthquake and the aseismic deformation on the fault. We assumed that loading on Kaystrios fault which was simply approached as a rectangular fault source, $36 \mathrm{~km}$ long and $20 \mathrm{~km}$ wide, is accommodated with a moderate rate equal to $1 \mathrm{~mm} / \mathrm{yr}$ obtained from seismotectonic information (Pavlidis et al., 2009). Before the 1881 earthquake occurrence, stress on fault was zero, which means that all the energy along the fault is released and starts building up from the beginning, gradually affected by nearby strong earthquakes. In all cases the stress field is resolved onto the properties of the Samos receiver fault. The fault plane solutions regard pure normal and oblique normal faults dipping to the North and to the South. The shadow zone that was cast after the 1883 event is recovered by the 1904 earthquake at South Samos which increased the $\triangle C F F$ values for more than 1 bar. After this point positive stress changes are reinforced on the fault, moving the fault closer to failure even if the earthquakes responsible for the corresponding stress changes have occurred on antithetic south-dipping faults like the 1928 or the 1955 earthquakes (see also Table 6). After the last strong earthquake in 1955 the entire fault zone is characterised by positive stress increments with patches of stress with more than 2 bars as shown at the cross-section and the surface fault projection.

Static stress changes influence the location and timing of subsequent strong earthquakes or aftershock activity (Scholz, 2002). Positive correlations between Coulomb stress changes induced by a mainshock and the distribution of aftershock hypocentres has been generally affirmed (King et al., 1994; Parsons, 2002). In our case, the investigation between the main shock coseismic stress changes and the locations of the aftershock activity was performed by modelling coseismic stress changes both for a uniform slip $36 \mathrm{~km}$ long fault and 
a variable slip $60 \mathrm{~km}$ long fault zone. In both cases the vast majority of the aftershock locations is spatially distributed over the elongated shadow zone with high negative stress changes which is shed along fault strike and denotes the rupture area. Due to the pattern of the stress field, which is typical for a pure normal fault, the clusters which evolved at the terminations of the faults are located within the stress bright lobes. Especially the off fault seismicity at the western edge of the Kaystrios fault (red colour) is totally embedded within the bright zone and favoured by stress enhancement, as also the calculation of $\triangle C F F$ at the foci of the earthquakes show. The stress field analysis based on the variable slip model is significant because it sufficiently explains the existence of the majority of aftershocks at the eastern part of the rupture zone, since it coincides with the existence of a patch with positive stress increments, which probably have triggered microseismicity. The cluster in green which is located at the southern part of the seismogenic fault cannot be fully explained by the stress pattern, probably because its activation is attributed to a fault with different fault properties. Calculations for a stress field resolved for a N-S fault with dextral strike slip component as seismotectonic investigation indicates for the broader area, explain more clearly the existence of the activity.

Our analysis of the major $M_{W}$ 7.0, Samos earthquake, and its aftershock sequence, revealed the activation of the E-W oriented, Kaystrios normal fault in the North basin of the Samos island. The obtained slip model, as well as the Coulomb stress changes due to the mainshock, are in agreement with the improved relative locations of the aftershocks, suggesting that the main rupture propagated mostly to the West. The estimated shaking in the epicentral area explained the observed severe damage to the NW part of Samos, as well as the collapse of buildings in the city of Izmir, further enhanced by the local soil conditions. 


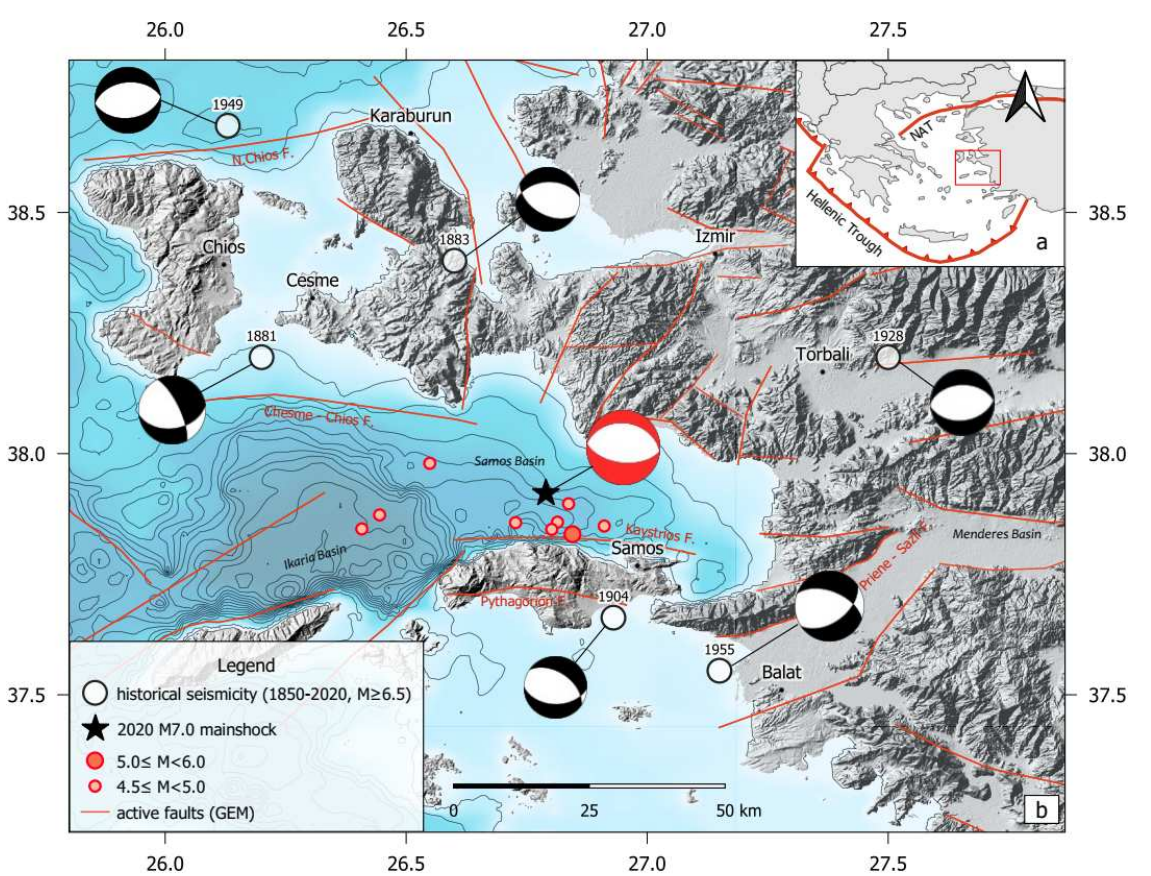

Fig. 1 a: General map of the study area (enclosed by the red rectangle) within the Aegean regime in respect to the main seismotectonic features of the North Anatolian Trough (NAT) and the Hellenic Trough; b: Seismotectonic map with the approximate locations of the most significant historical earthquakes $(M \geq 6.5)$ since 1850 obtained from the historical catalogue of Papazachos and Papazachou (2003) along with their inferred fault plane solutions (details are given in Table 6). Plotted with the black star is the 2020 Samos mainshock along with the Global CMT best fitting double-couple fault plane solution, whereas the circles in red outline refer to the strongest earthquakes which occurred within four months of aftershock activity. Main active faults as reported in the GEM active fault database (Styron and Pagani, 2020) are also depicted. 
$\mathbf{a}$

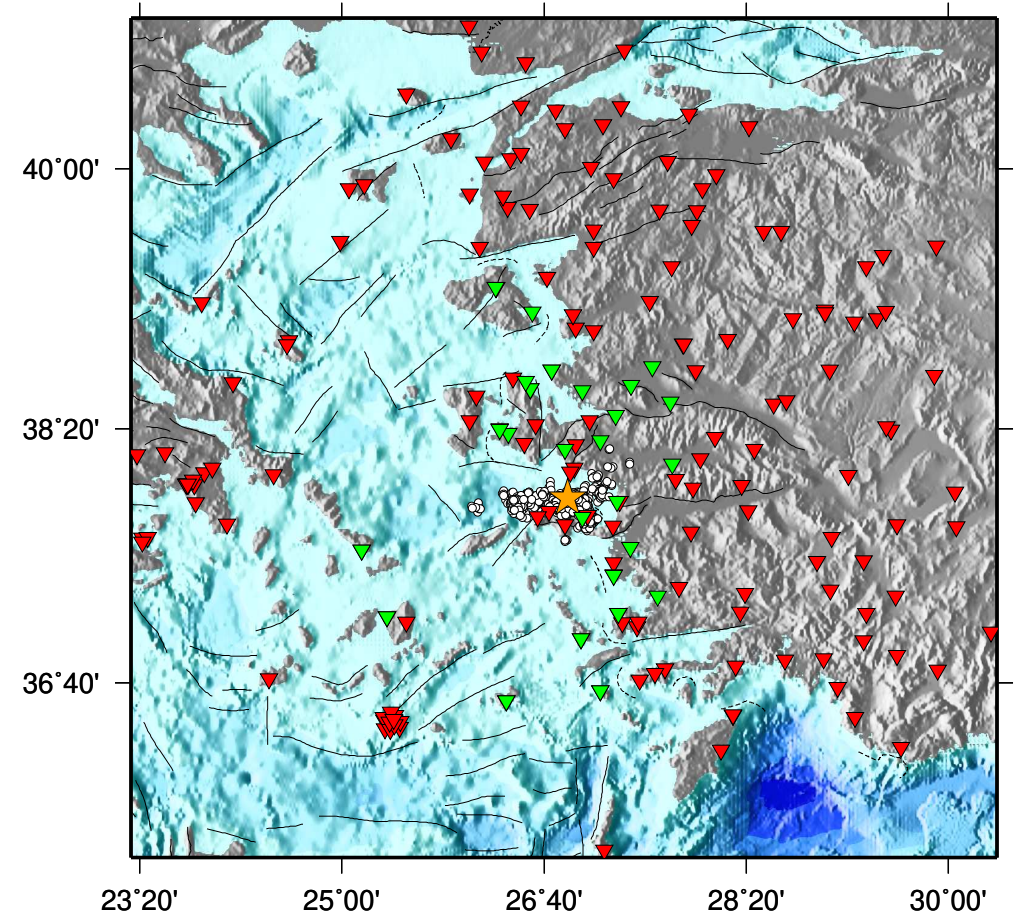

b

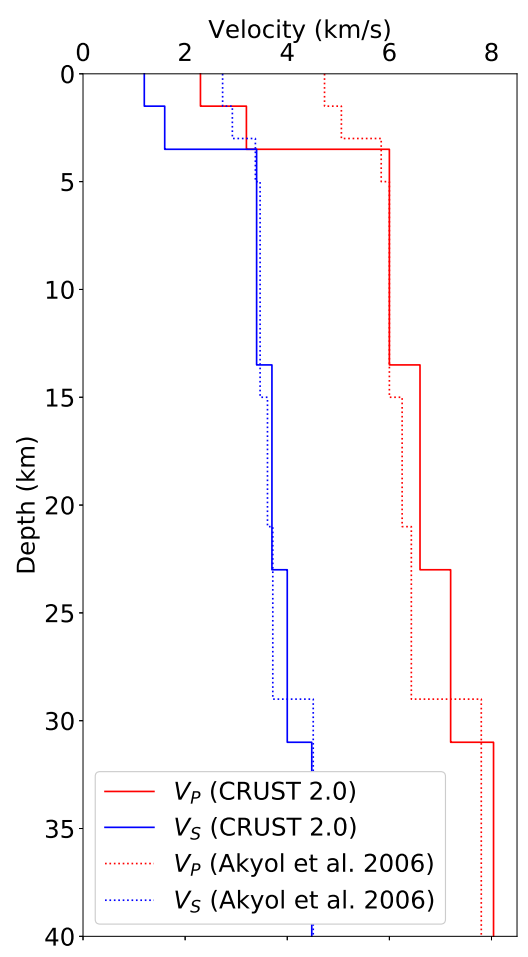

Fig. 2 a: Map showing the spatial distribution of the seismic stations used in the current study with respect to the mainshock (orange star) and its aftershock sequence (white circles). Red inverse triangles show stations which have been used in earthquake relative locations, whilst green inverse triangles represent stations equipped with accelerographs whose recordings have been used to determine the mainshock's slip model; b: comparison of 1D velocity models used for the earthquake relative locations (Akyol et al., 2006), and Earth's structure used for the determination of the mainshock's slip model, which is extracted from CRUST $2.0,3 \mathrm{D}$ velocity model (Bassin et al., 2000), with respect to the $2^{\circ} \times 2^{\circ}$ cell, with reference to the mainshock's epicentre. 

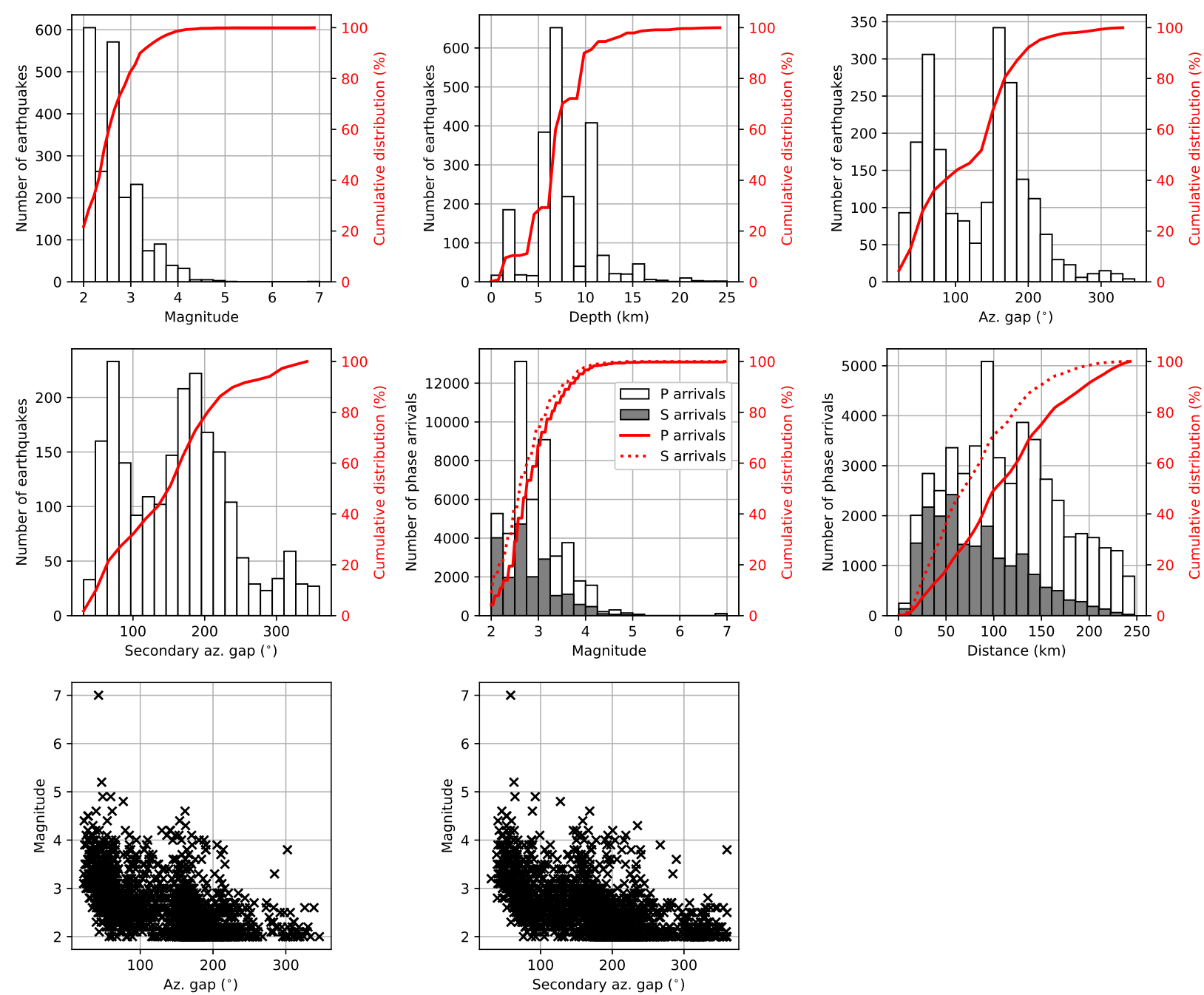

Fig. 3 Histograms and scatter plots showing the distribution of magnitudes, depths, azimuthal gaps, and number of phase arrivals in the parametric data used in the current study, as well as the association of azimuthal gaps with magnitude. Red lines in histograms indicate the cumulative distribution. 


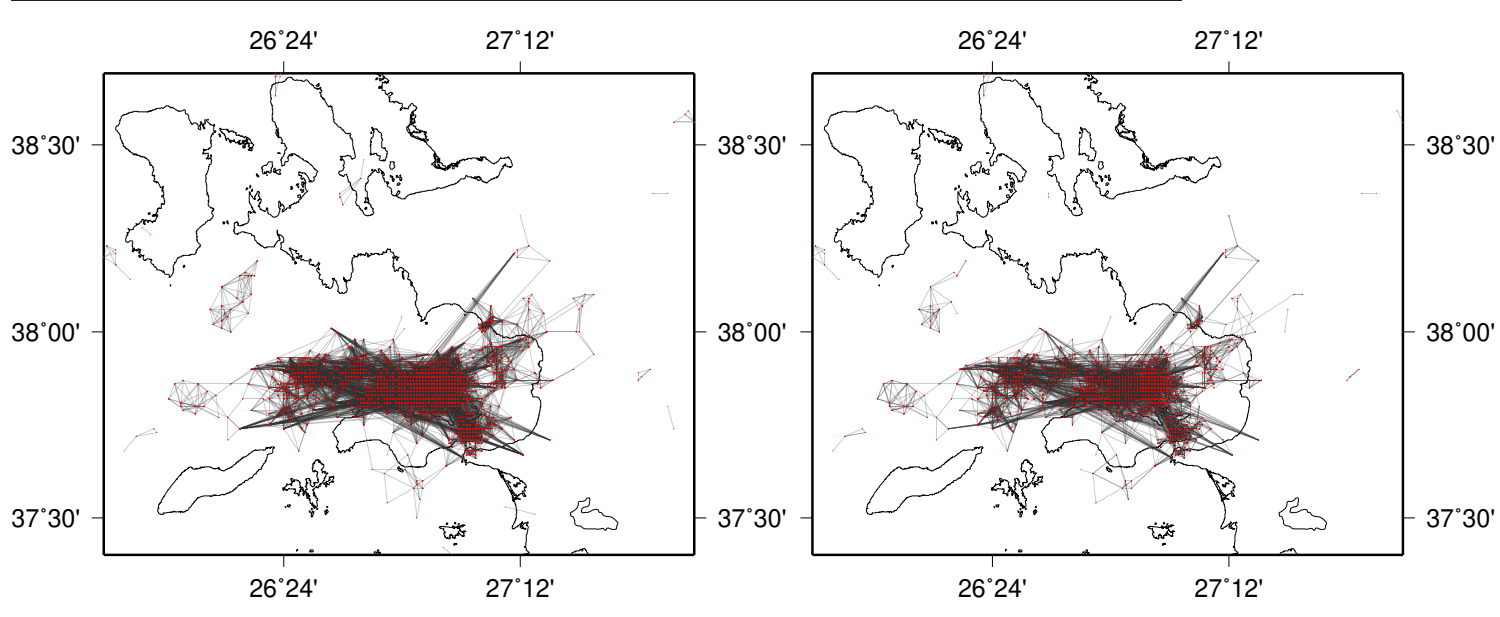

Fig. 4 Maps showing the links of event pairs based on the earthquake catalogue used for the relative locations (left) and the links based on waveform cross-correlations (right). 


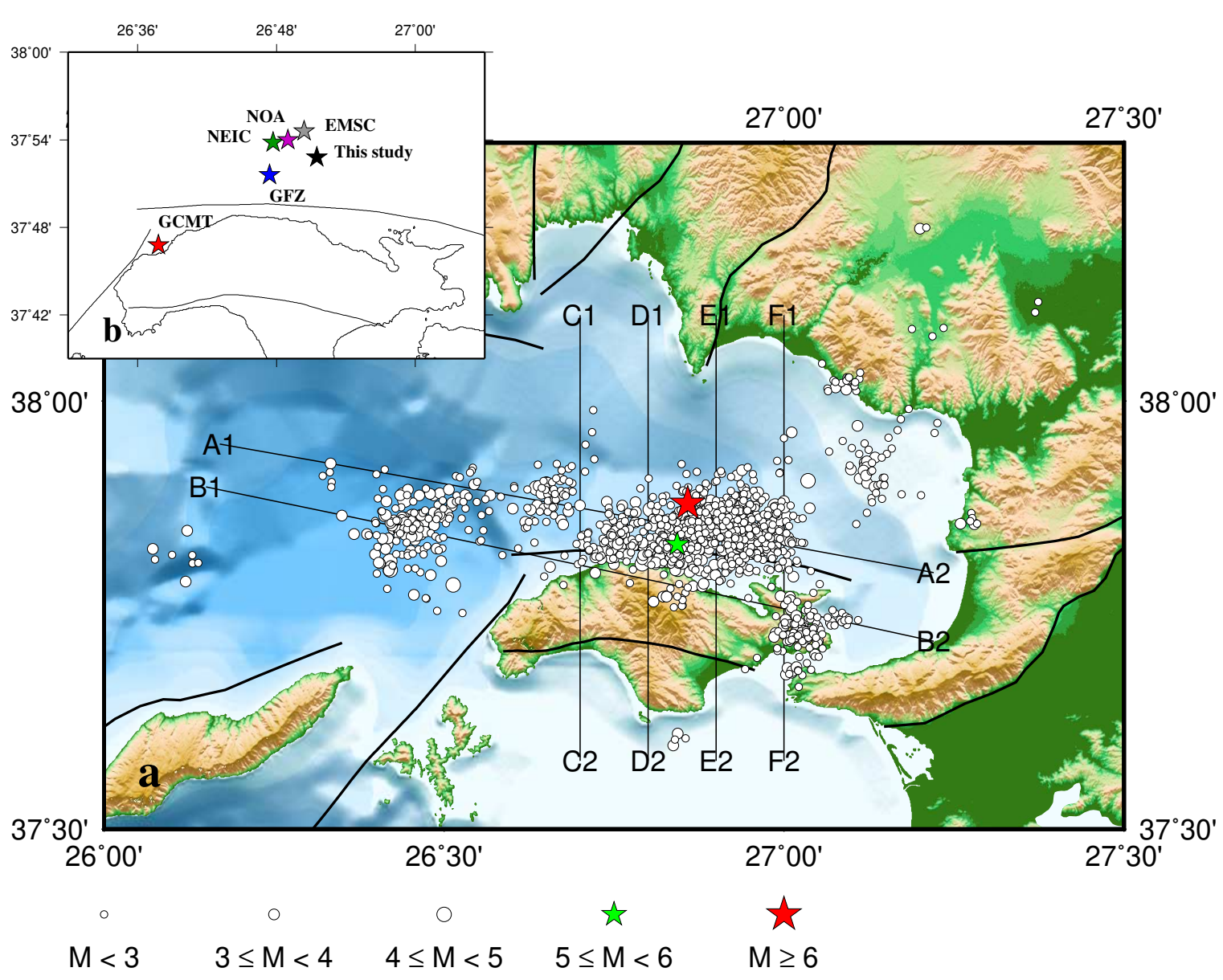

Fig. 5 a: Map showing relative locations based on differential travel times from catalogue and waveform cross-correlation data. Black thick lines represent surface traces of the main seismic faults by the GEM active fault database (Styron and Pagani, 2020). Black thin lines show cross-sections analysed in Figure 10; b: Comparison of available epicentres for the mainshock (GCMT: Global CMT, NEIC: National Earthquake Information Center, GFZ: Helmholtz Centre Potsdam, German Research Centre For Geosciences, EMSC: EuropeanMediterranean Seismological Centre, NOA: National Observatory of Athens) against the relocated epicentre obtained in the current study. 


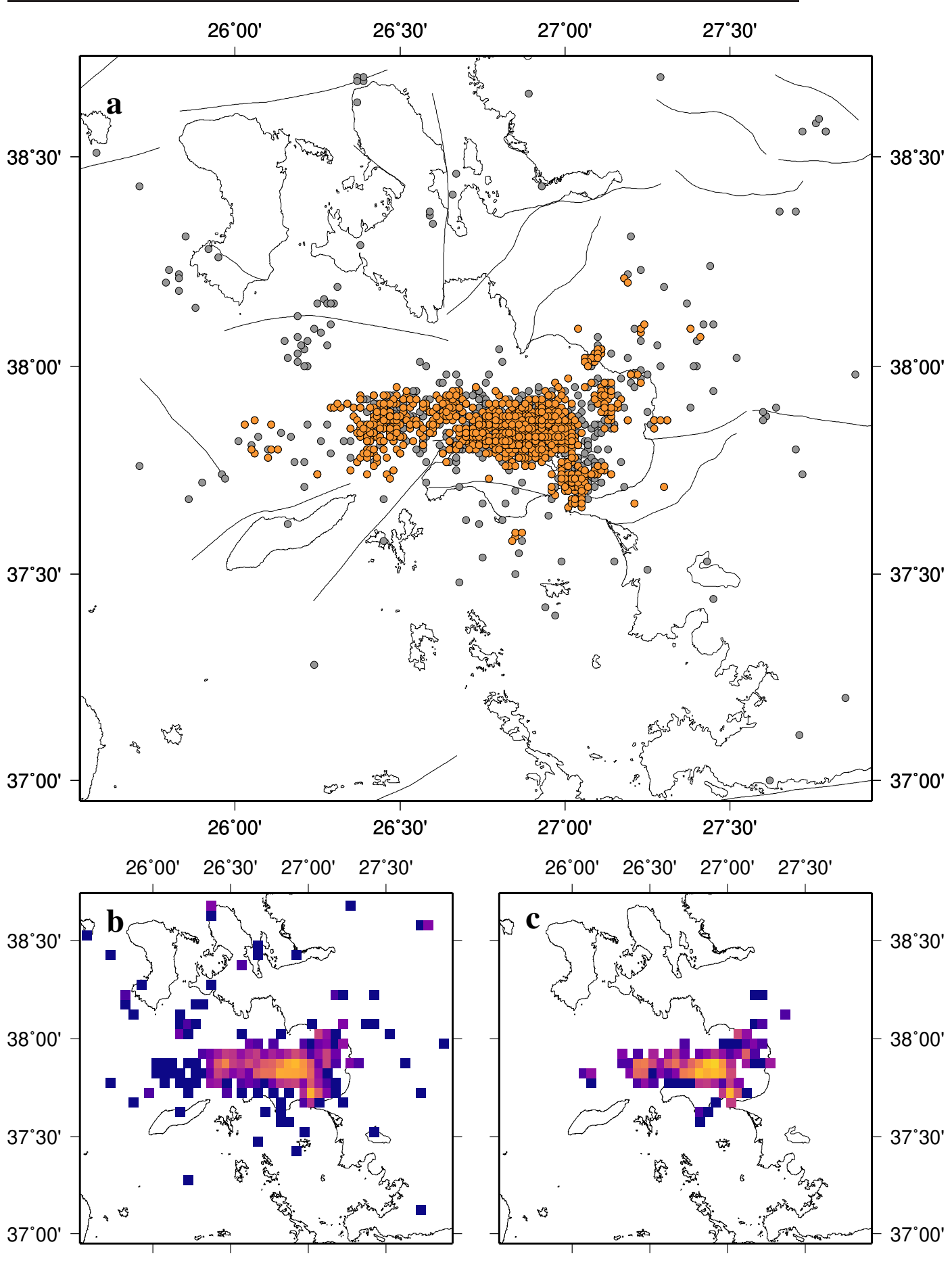

Number of earthquakes

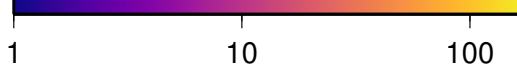

Fig. 6 a: Map showing epicentre locations for all the earthquakes downloaded from EMSC (grey circles) and those that were relocated using differential travel times from catalogue and waveform cross-correlation data (orange circles); b: map showing the spatial distribution of earthquake density before the relocation on a $5 \mathrm{~km} \times 5 \mathrm{~km}$ grid; and c: same as in b but using the relocated epicentres. 

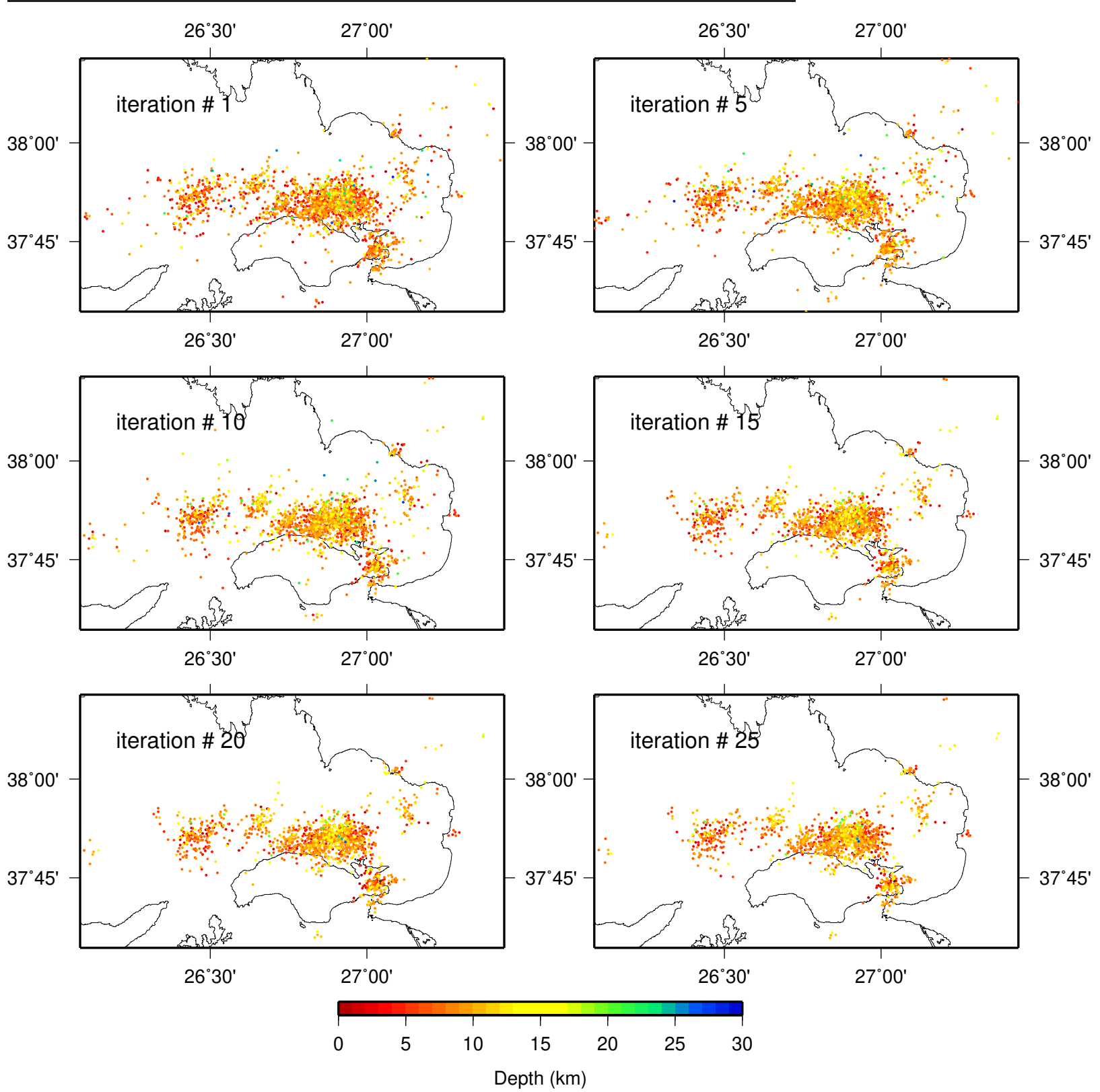

Fig. 7 Maps showing the progress of the relocation inversion every five iterations when a different weighting scheme was applied to the data. 

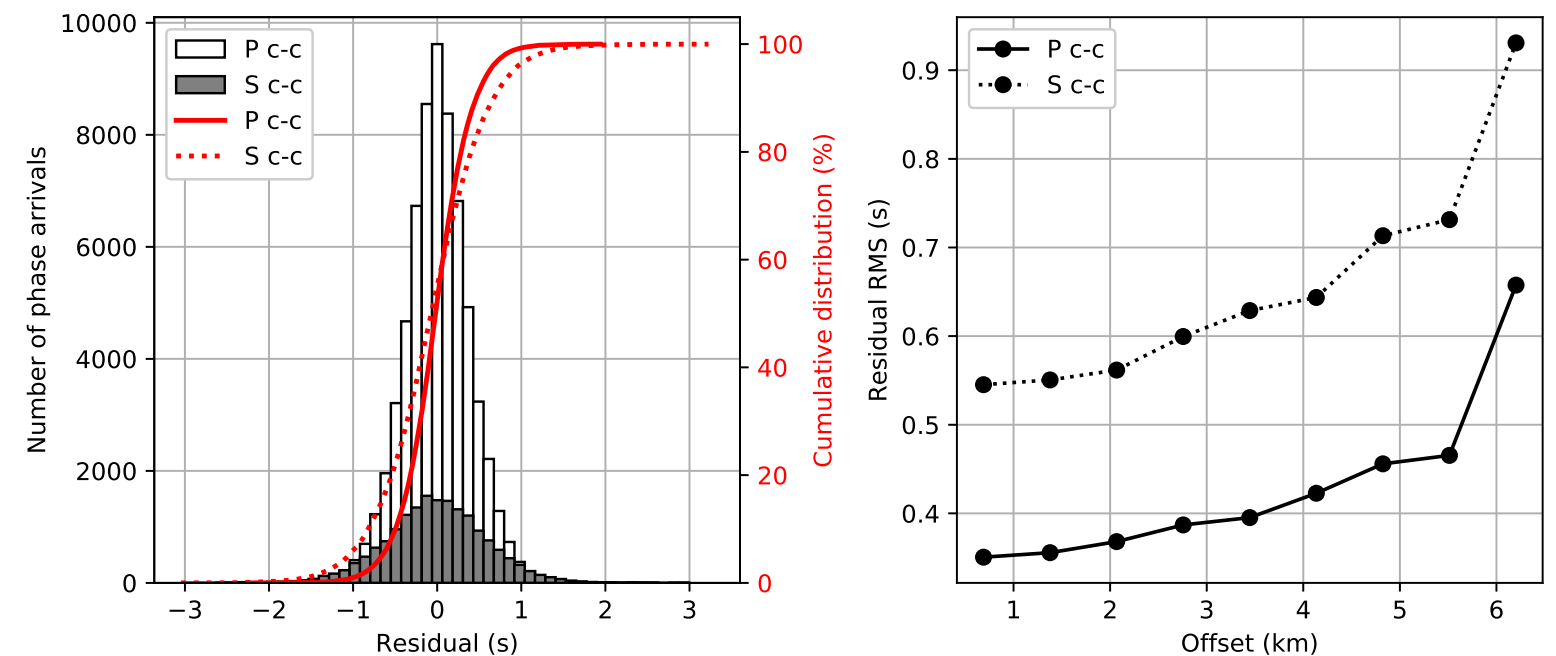

Fig. 8 Histograms showing the distribution of $P$ (white) and $S$ (grey) cross-correlation differential travel time residuals (left). Red solid and dotted lines represent the cumulative distributions, respectively. RMS travel time residuals against the interevent distance for $P$ (solid line) and $S$ (dotted line) cross-correlation data are plotted in the right hand side. 

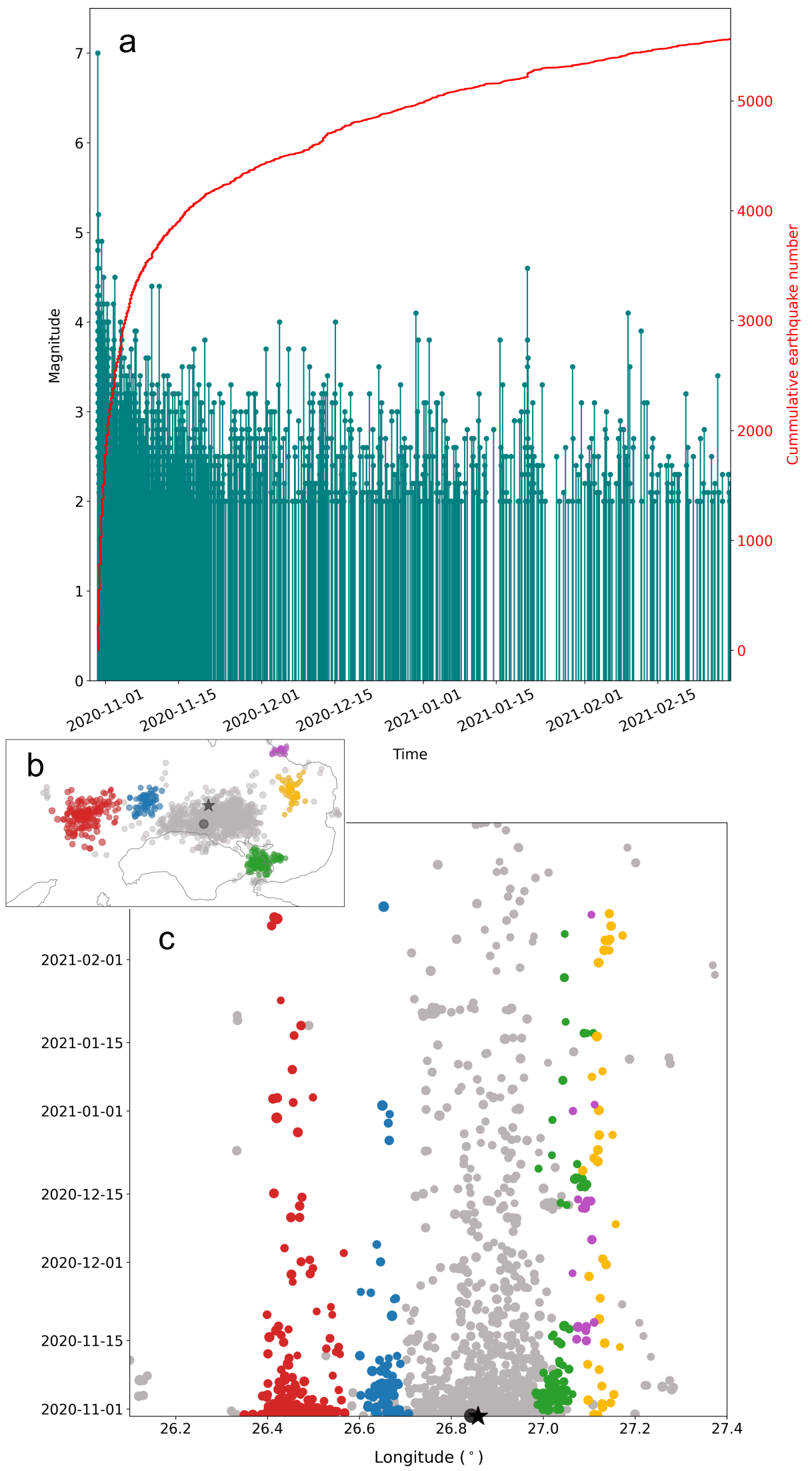

Fig. 9 a: Temporal distribution of the reported seismicity for the study area, used as input to the relocation analysis from 30-10-2020 to 01-03-2021 along with the cumulative number of earthquakes in red colour; b: Map view of the relocated seismicity; and c: Spatial-temporal diagram of the relocated seismicity projected in E-W orientation. Different colouring is used to highlight distinctive earthquake clusters both in the map view and the space-time plot. 

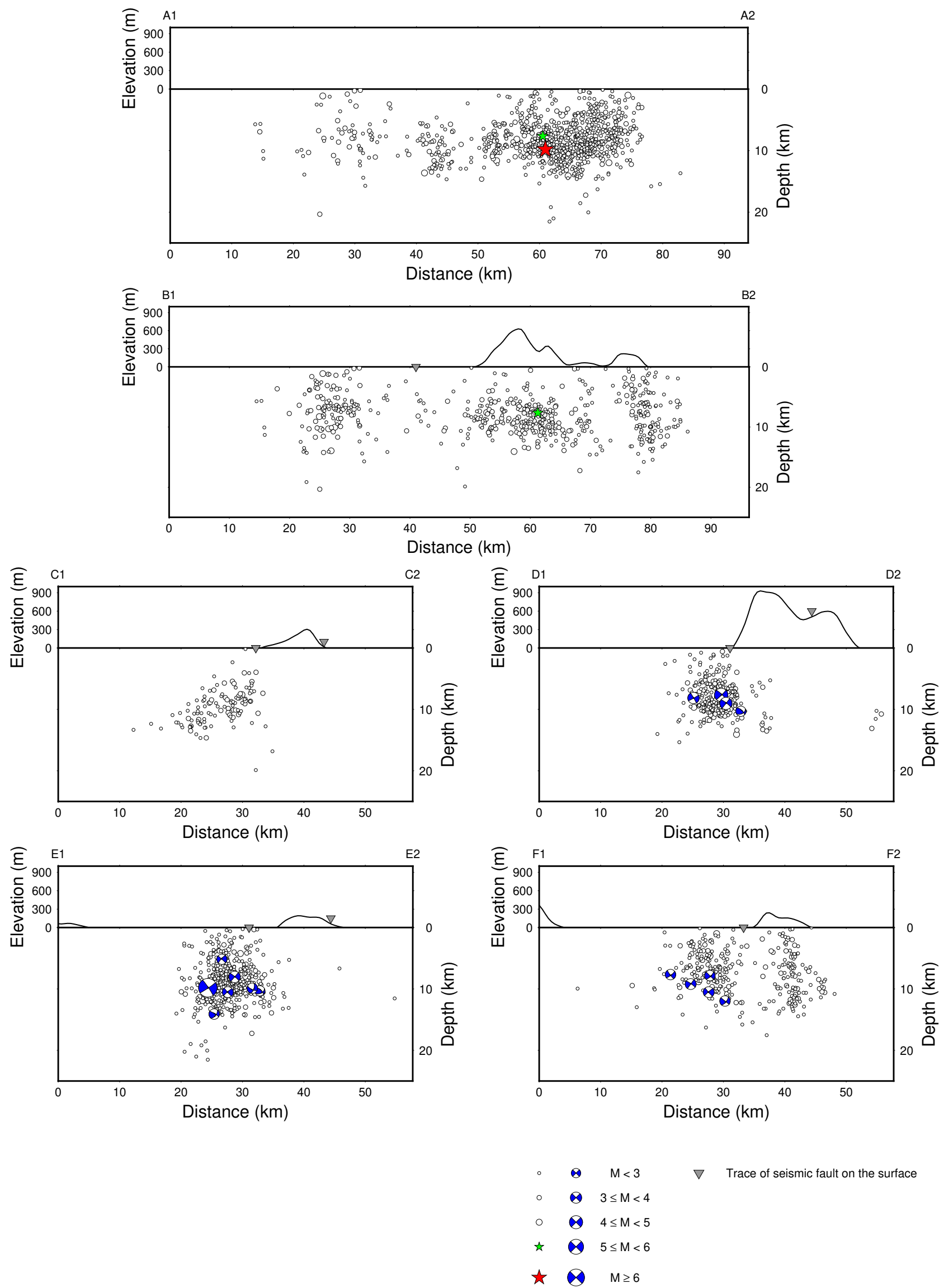

Fig. 10 Cross-sections of the relocated hypocentres shown in the map of Figure 5. Available source mechanisms are also plotted in the cross-sections (C-F) oriented perpendicular to the main seismic faults in the study area. The width of each cross-section is set to $5 \mathrm{~km}$. Grey triangles indicate the surface traces of Kaystrios and Pythagorio seismic faults. 


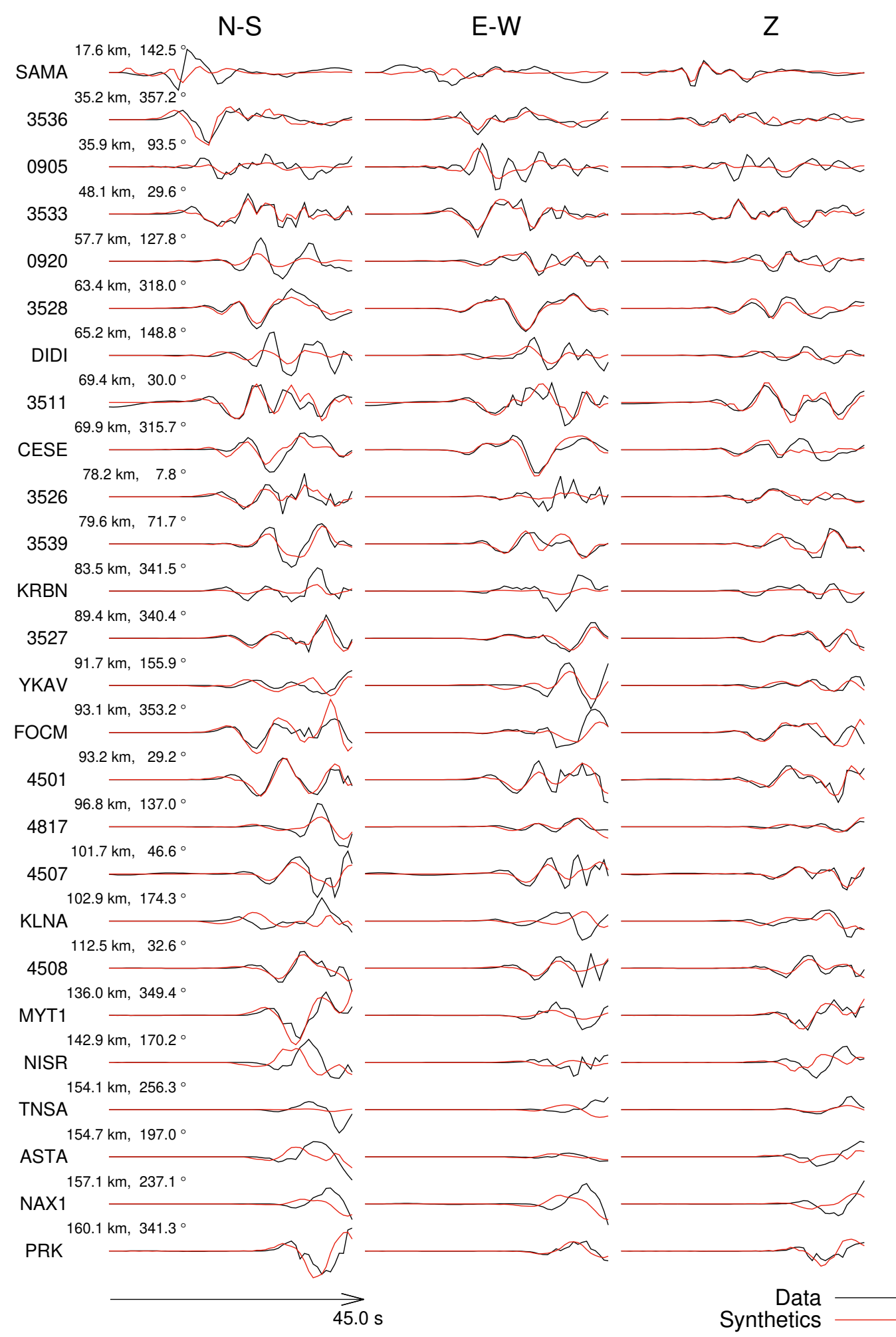

Fig. 11 Three component displacement waveform data (black) compared to synthetics based on the obtained slip model (red) for each station used in the kinematic slip inversion for the mainshock. 
$\mathbf{a}$

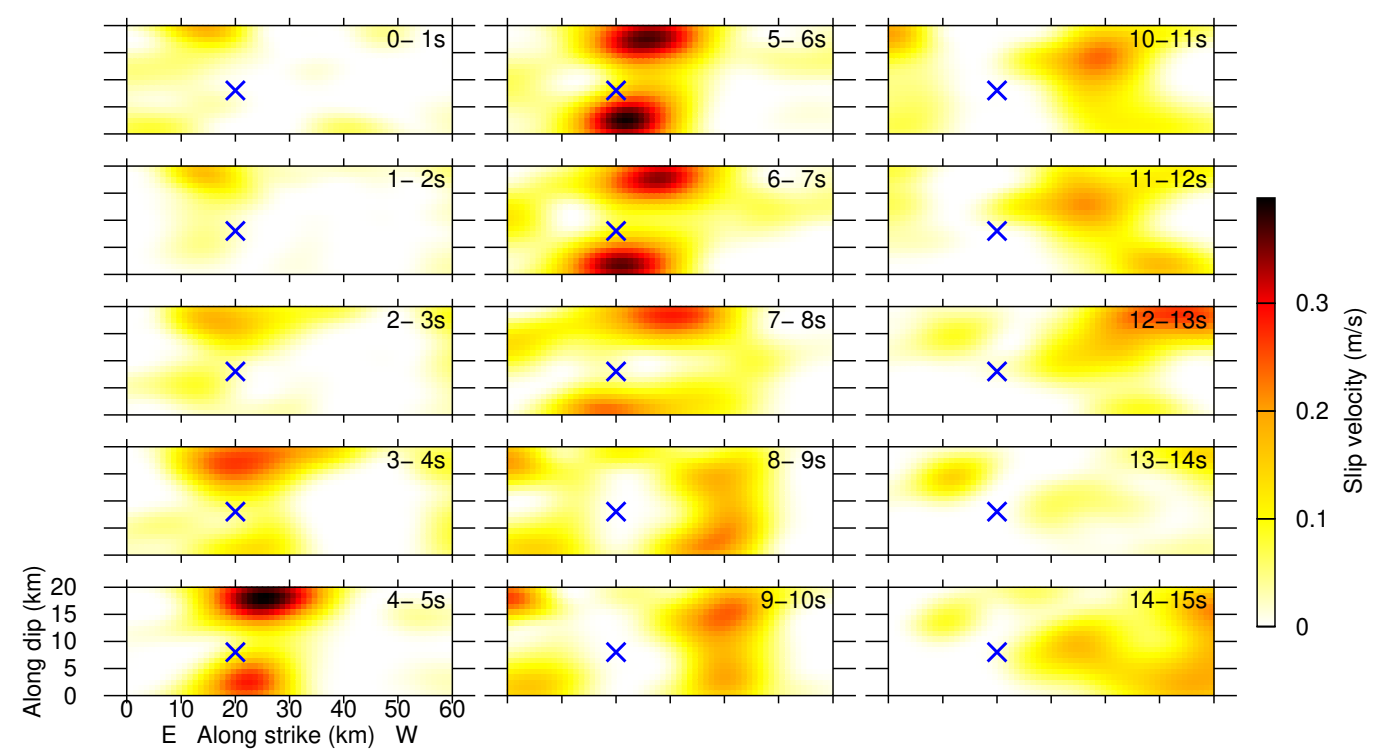

$\mathbf{b}$

EAST

WEST

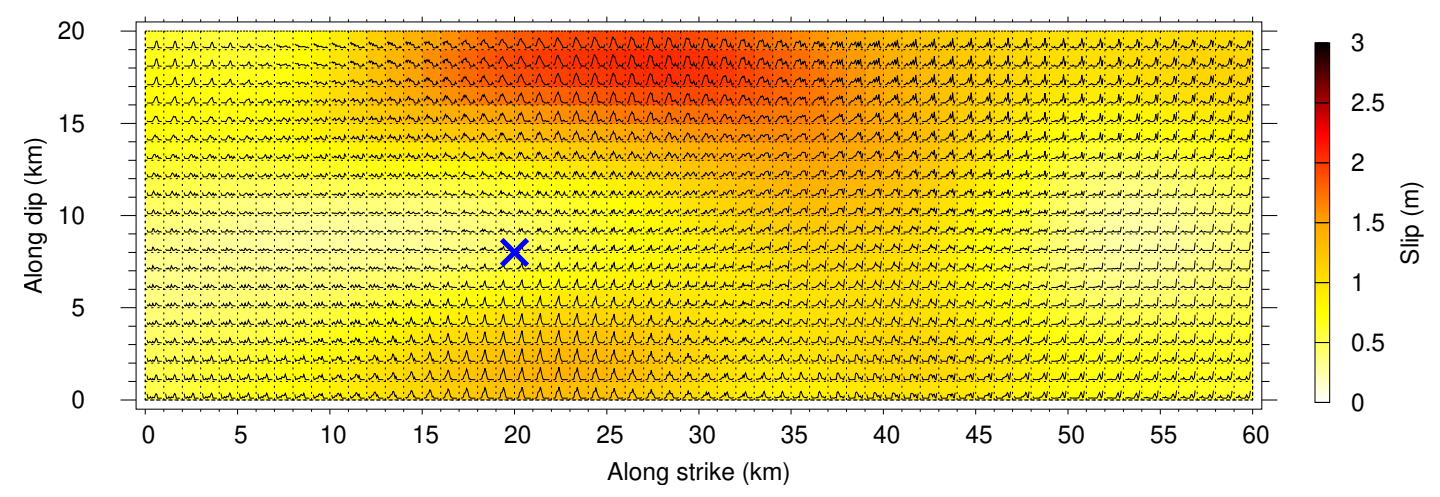

Fig. 12 a: Snapshots at $1 \mathrm{~s}$ time intervals showing the rupture evolution of the mainshock obtained from the kinematic inversion described in Section 4.2. The blue cross indicates the rupture nucleation point; b: composite slip model for the mainshock based on the slip history in a. Individual slip rate functions for each $1 \mathrm{~km} \times 1 \mathrm{~km}$ subfault are also shown. Details for the parameterisation of the kinematic slip inversion are given in Table 2 . 


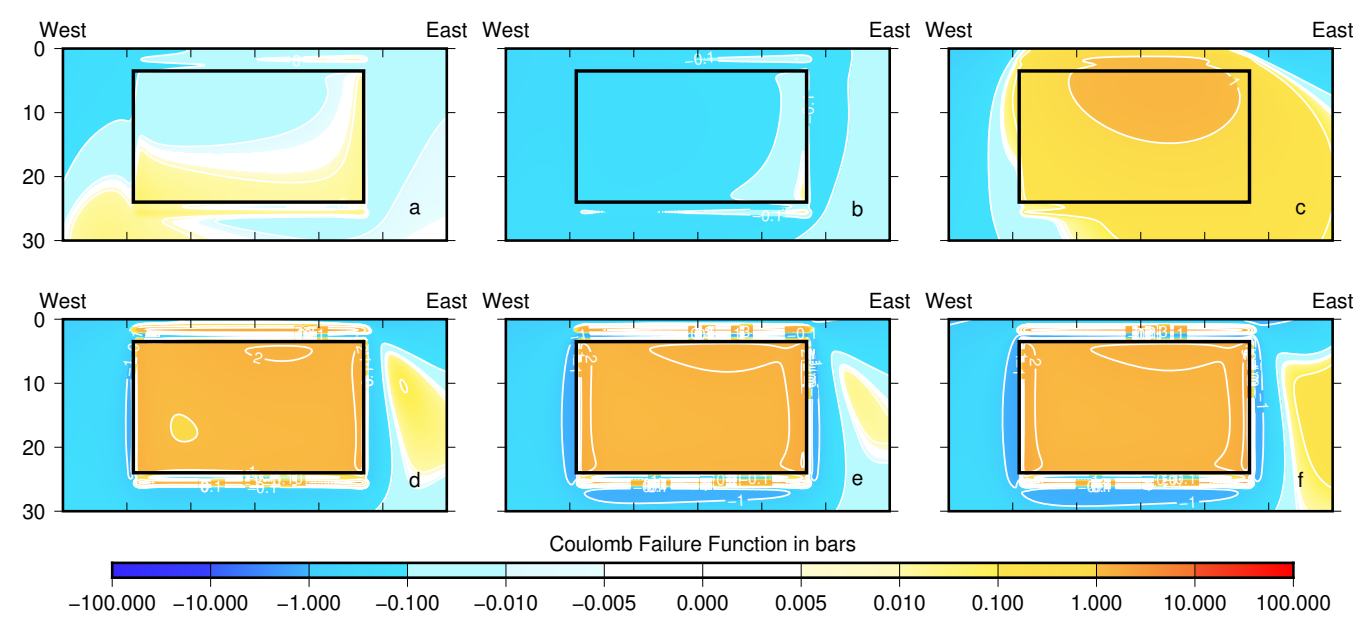

Fig. 13 The accumulated $\triangle C F F$ resolved onto the Kaystrios fault due to the successive tectonic loading and the coseismic stress changes impact due to a: the 1881 Chios-Cesme earthquake; b: the 1883 Cesme earthquake; c: the 1904 earthquake south of Samos; d: the 1928 Torbali earthquake; e: the 1949 Chios-Karaburun earthquake and f: the 1955 Balat earthquake. The fault geometry is represented with a black rectangle. 


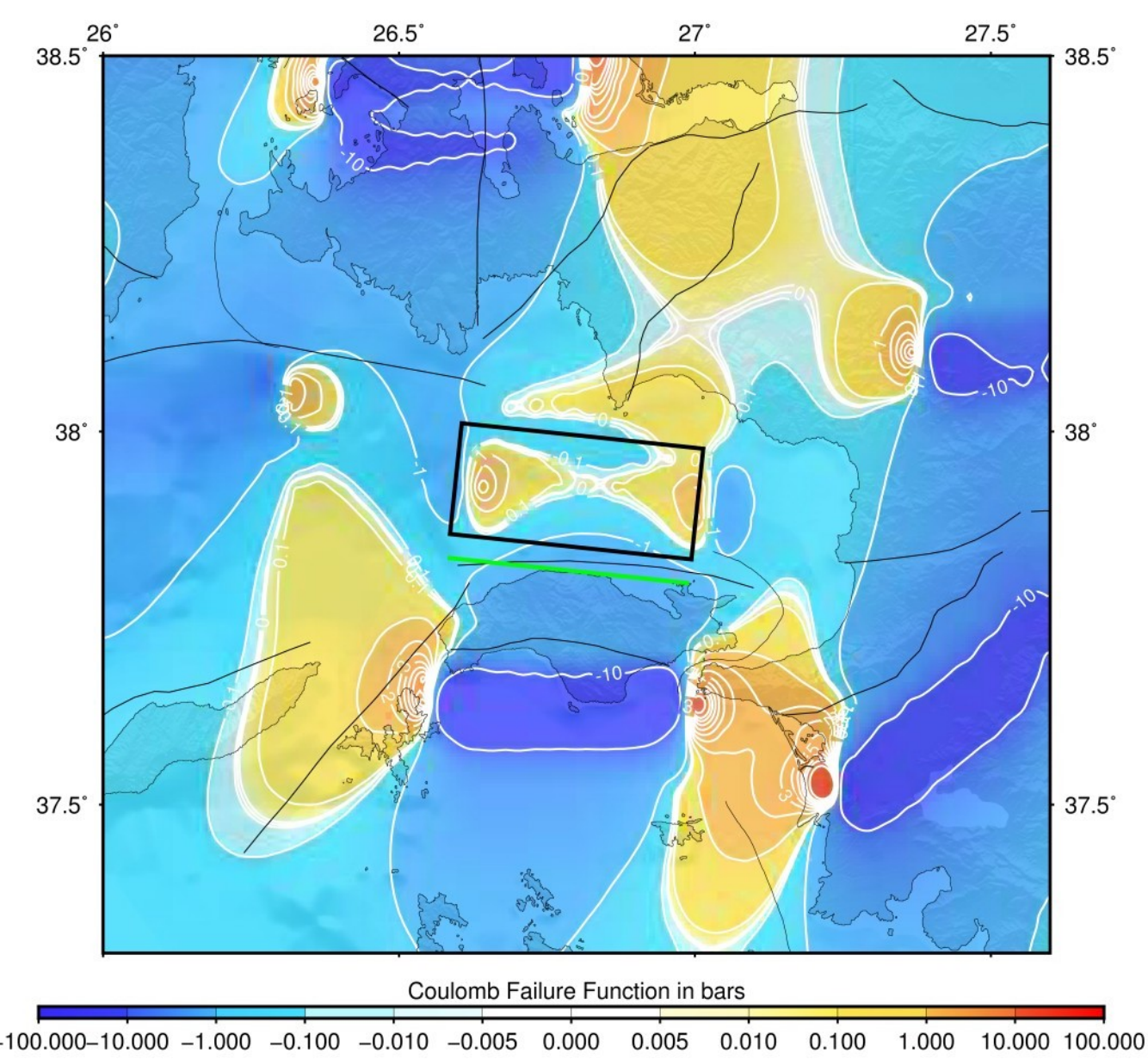

Fig. 14 Stress field changes imposed by the strong earthquake occurrence and the stress loading along the Kaystrios fault, in a surface projection at $8 \mathrm{~km}$ depth. The fault is represented with a black rectangle and the fault plane projection on the surface is shown as a green line. 

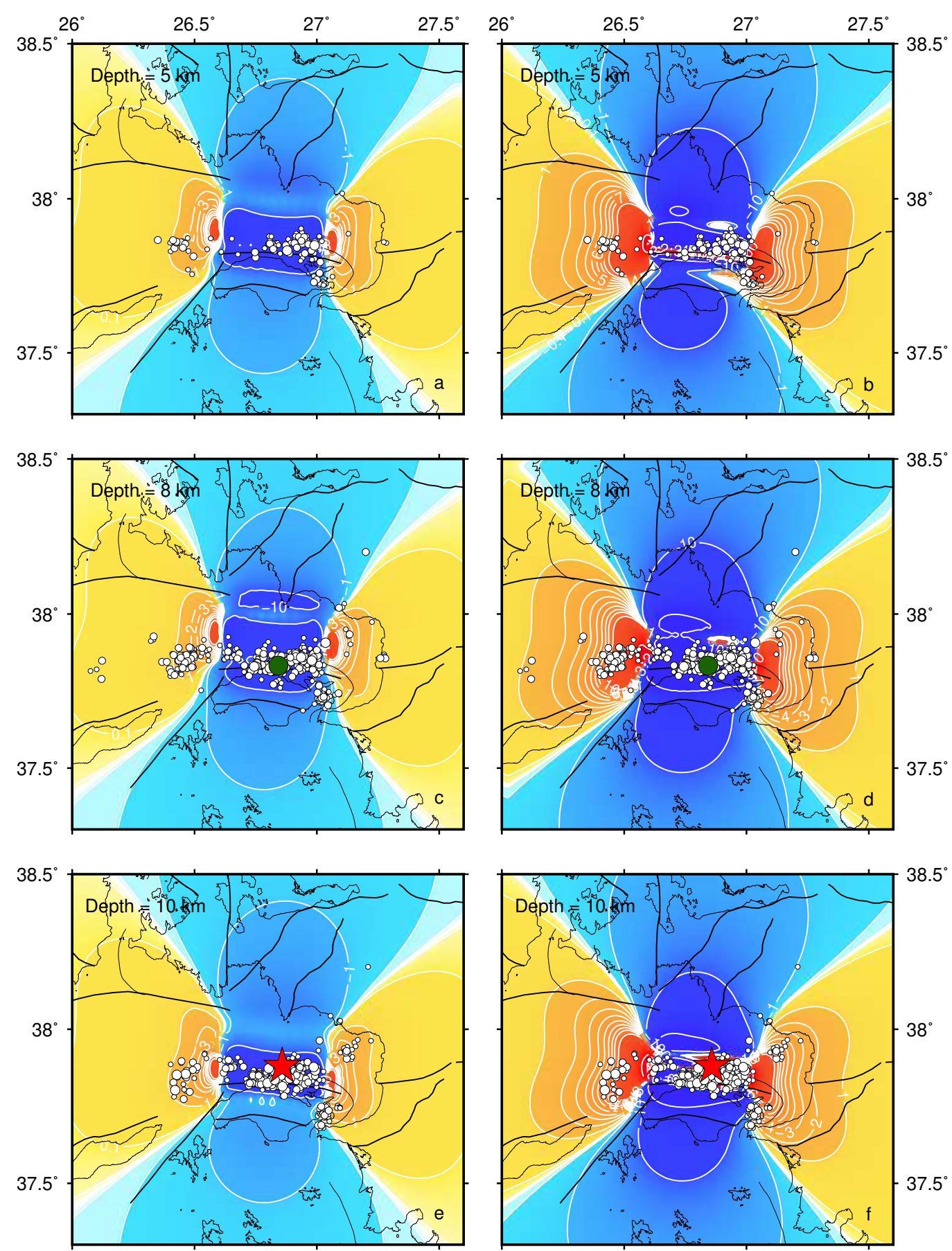

Coulomb Failure Function in bars

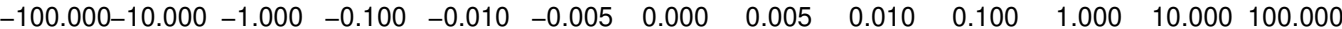

Fig. 15 a: Coseismic stress changes for the uniform slip model at the horizontal layer at 5 $\mathrm{km}$ depth; b: Coseismic stress changes for the variable slip model at $5 \mathrm{~km}$ depth; c: Coseismic stress changes for the uniform slip model at $8 \mathrm{~km}$ depth; d: Coseismic stress changes for the variable slip model at $8 \mathrm{~km}$ depth; e: Coseismic stress changes for the uniform slip model at $10 \mathrm{~km}$, and f: Coseismic stress changes for the variable slip model at $10 \mathrm{~km}$ depth. 

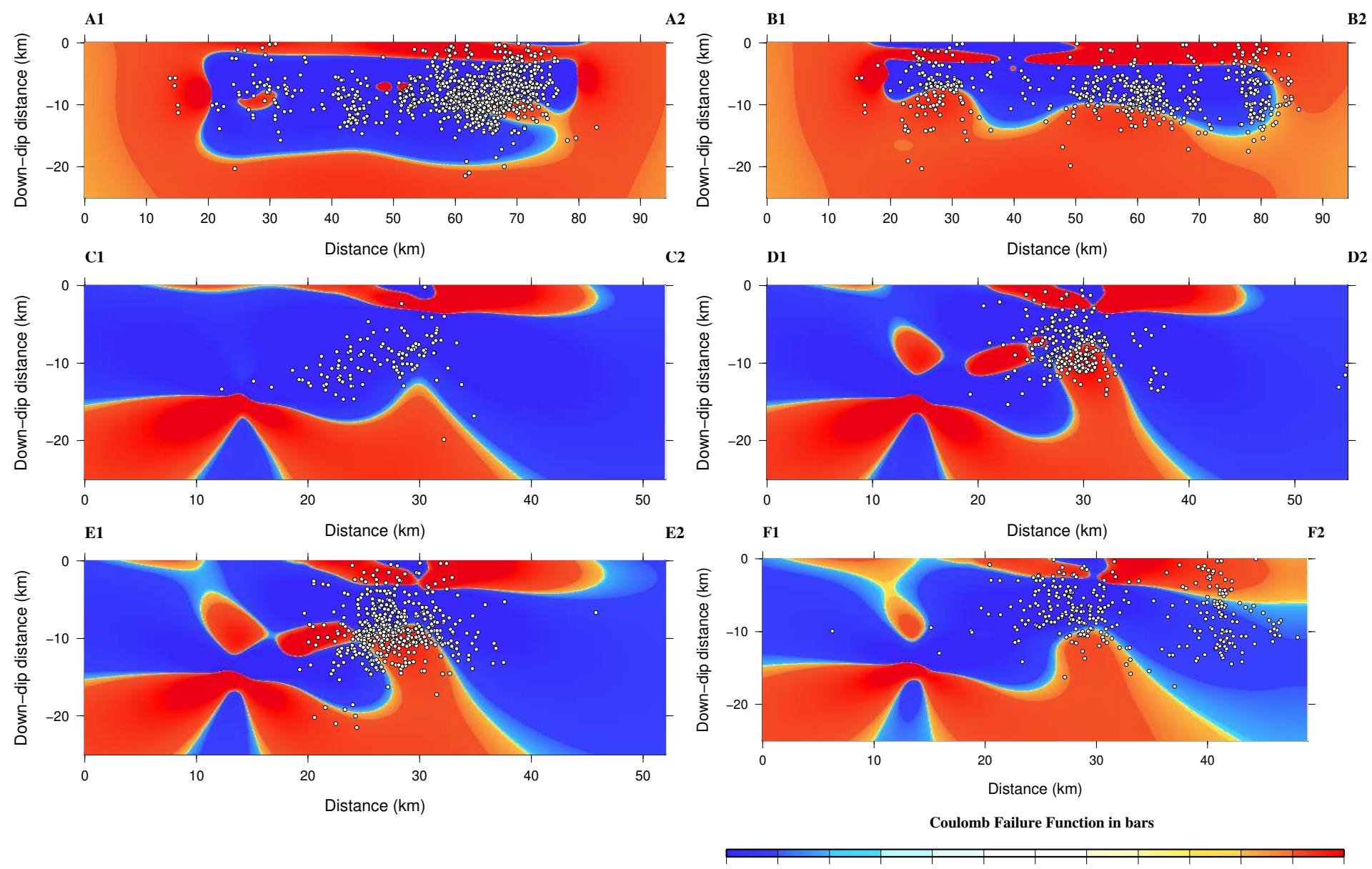

Fig. 16 Cross-sections of $\triangle C F F$ along vertical planes according to the cross-sections in Figure 5 . White circles represent the relocated seismicity. 


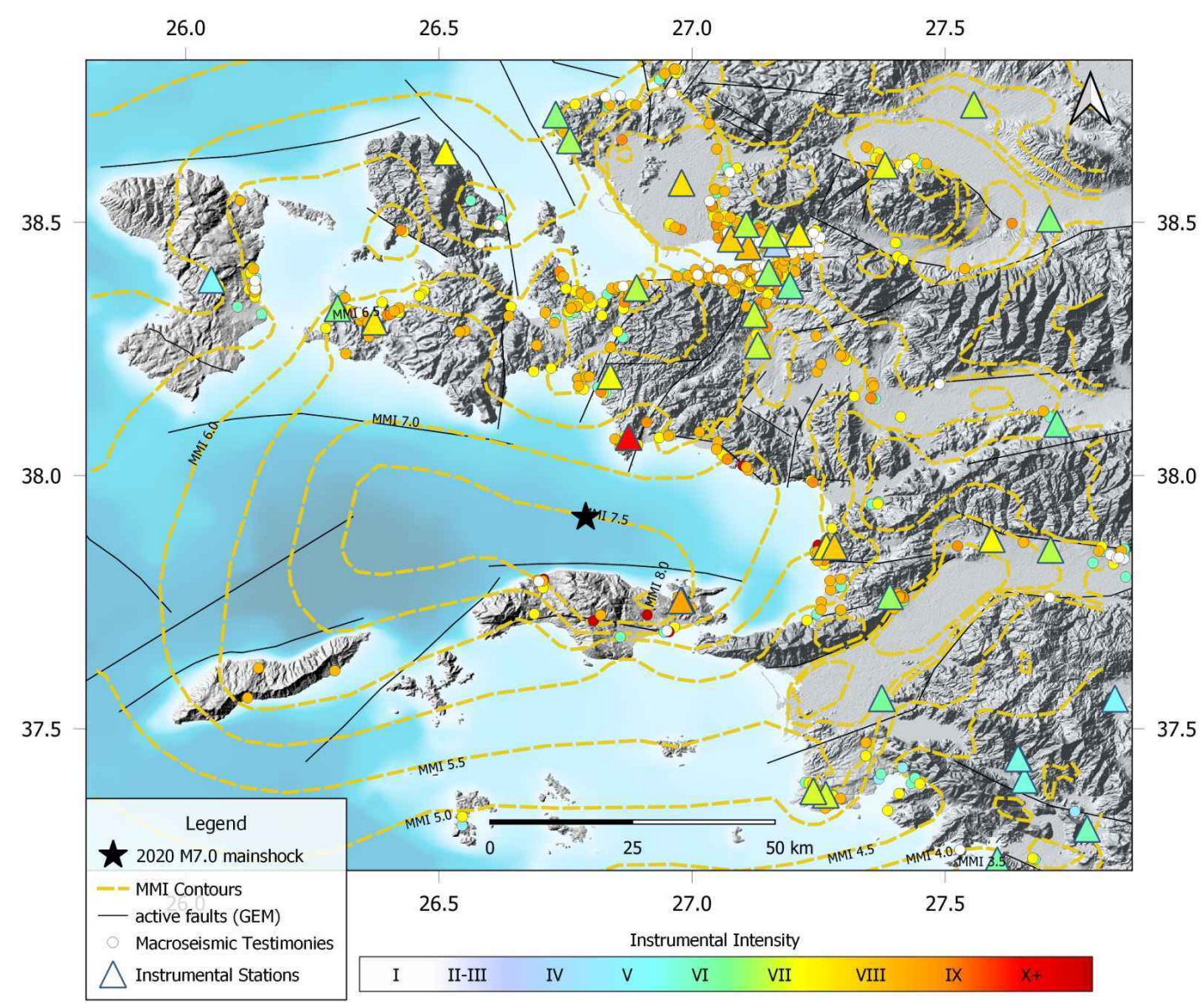

Fig. 17 Estimated intensity MMI contours using the resulted rupture model, strong motion maximum PGA values at recorded stations converted to MMI and EMSC collected testimonies. Filled triangles correspond to recorded stations and filled circles to EMSC testimonies. Colour following USGS MMI ShakeMap legend. 

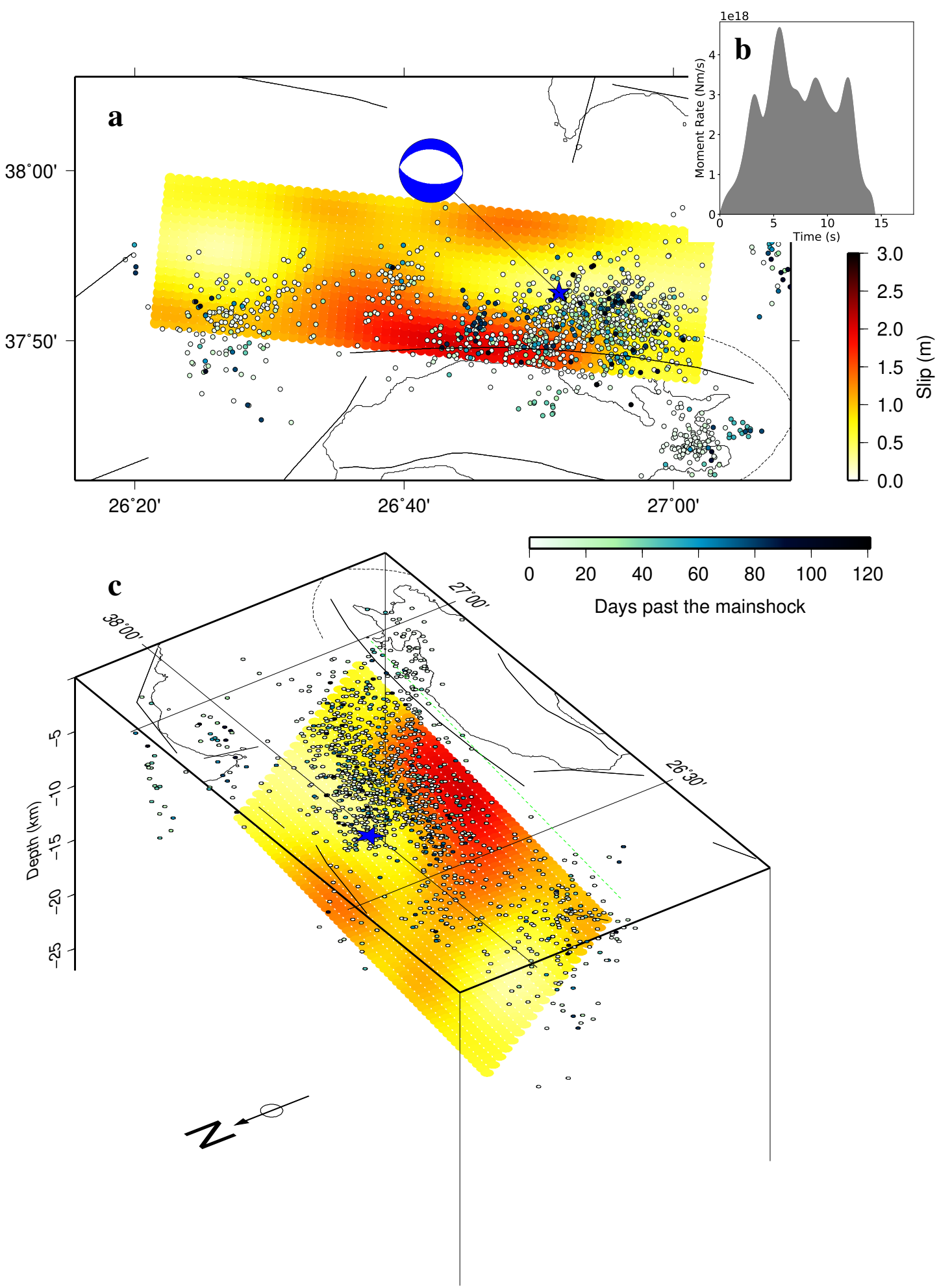

Fig. 18 a: Map showing the slip model distribution in relation to the Kaystrios fault and the location of the mainshock (blue star). The GCMT best fitting double couple solution used for the determination of the slip model is also shown on the map. The relative locations of the aftershock sequence are shown as black dots; b: moment rate function determined from the kinematic slip inversion for the mainshock; c: same as in a, but in 3D plot. The surface trace of the planar fault assumed in the slip model inversion is shown in green for reference. 
Table 1 Table summarising the spatio-temporal search parameters in this study.

\begin{tabular}{ccc}
\hline & Min. & Max. \\
\hline Time UTC & $2020-10-3000: 00: 00$ & $2021-03-0100: 00: 00$ \\
Latitude $\left(^{\circ}\right)$ & 37.00 & 38.70 \\
Longitude $\left(^{\circ}\right)$ & 25.50 & 28.00 \\
Depth $(\mathrm{km})$ & 0.00 & 25.00 \\
\hline
\end{tabular}


Table 2 Input parameters and parameterisation for the kinematic slip inversion.

\begin{tabular}{lr}
\hline Parameters & Values \\
\hline Origin time & $2020-10-3011: 51: 25.43$ \\
Nucleation point geographical coordinates $(\varphi, \lambda)$ & $37.88^{\circ}, 26.86^{\circ}$ \\
Nucleation point depth $(h)$ & $9.81 \mathrm{~km}$ \\
Fault dimensions $(L, W)$ & $60.00 \mathrm{~km}, 20.00 \mathrm{~km}$ \\
Nucleation point position (from NE fault edge) & Along strike: $20.00 \mathrm{~km}$, Up-dip: $8.00 \mathrm{~km}$ \\
Coordinates of the fault rectangle & Top (East) $37.80^{\circ}, 27.03^{\circ}$ \\
as projected to the surface $(\varphi, \lambda)$ & Top (West) $37.85^{\circ}, 26.36^{\circ}$ \\
& Bottom (East) $37.94^{\circ}, 27.05^{\circ}$ \\
Fault mechanism $(\varphi, \delta, \lambda)$ & Bottom (West) $37.99^{\circ}, 26.38^{\circ}$ \\
Scalar Moment $\left(M_{o}\right)$ & $276^{\circ}, 34^{\circ},-90^{\circ}$ \\
Slip rate duration & $3.86 \times 10^{19} \mathrm{Nm}$ \\
Waveform frequency range (displacement) & $15 \mathrm{~s}$ \\
& \\
\end{tabular}


Table 3 Information on the strong earthquakes $(M \geq 6.5)$ since 1881 (Date, Location, Magnitude, $M_{W}$ and their corresponding rupture models described by the fault plane solution (strike, dip, rake), the geometrical properties (Length, Width) and the two slip components, along fault strike $\left(u_{S S}\right.$, positive for sinistral slip) and along fault dip $\left(u_{D S}\right.$, positive for normal slip).

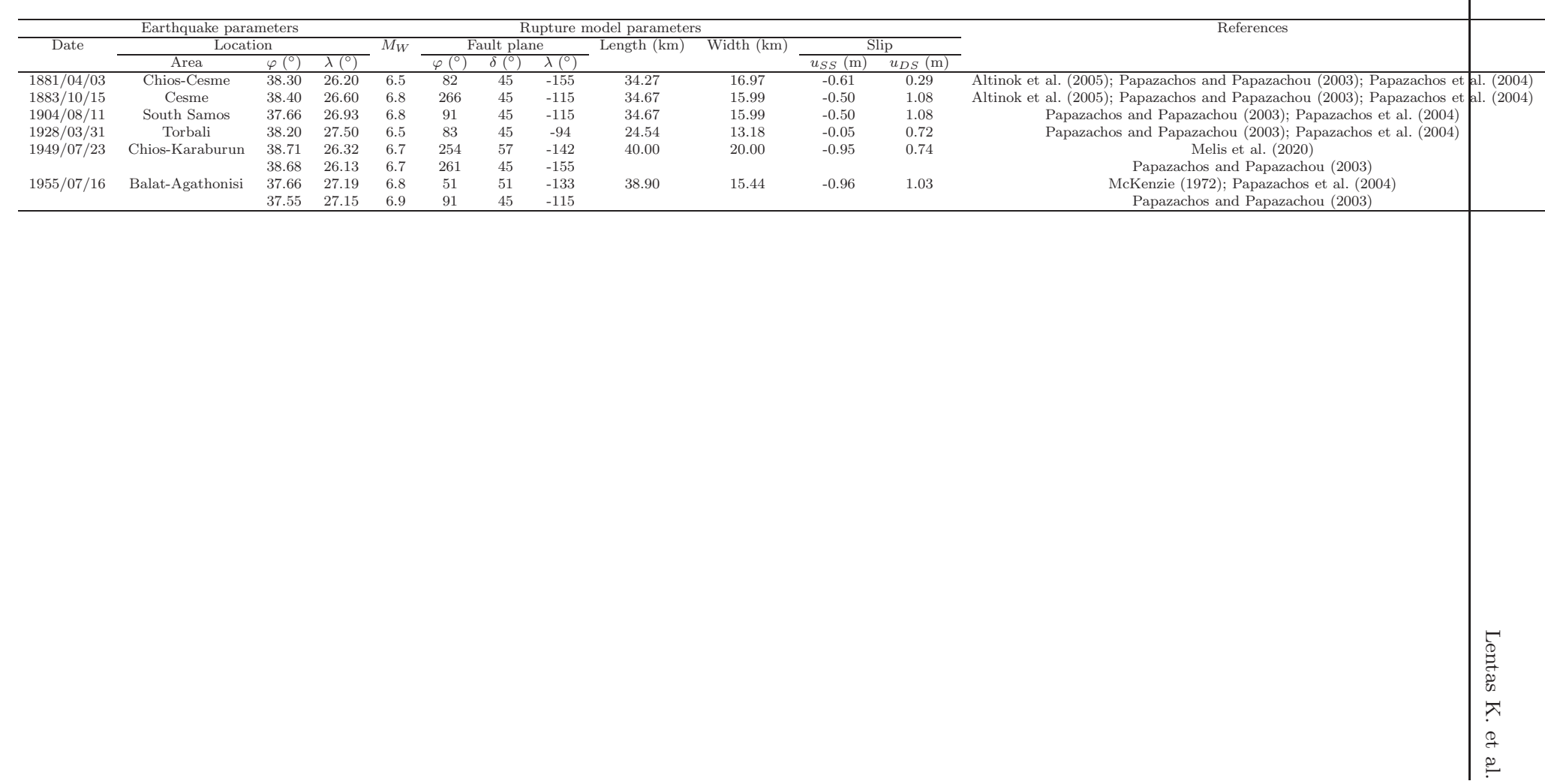


Acknowledgements The authors gratefully acknowledge the availability of seismograms from IRIS, Orfeus, and national data centres. This research was supported by the ARISTOTLEeENHSP (All Risk Integrated System TOwards Trans-boundary hoListic Early-warning - enhanced European Natural Hazards Scientific Partnership) Project (Contract ECHO/SER/2020/830887+830888). Stress tensors were calculated based on the Dis3D code (Erickson, 1987) and Coulomb 3.4 software (Toda et al., 2011). Waveform data access and processing was carried out using ObsPy (Beyreuther et al., 2010). USGS ShakeMap4 (Worden, 2016) was used to compute shaking. Figures were built using the Generic Mapping Tools (Wessel et al., 2013), QGIS (QGIS Development Team, 2021), and the Matplotlib python library (Hunter, 2007).

\section{Conflict of interest}

The authors declare that they have no conflict of interest.

\section{References}

Akyol N, Zhu L, Mitchell BJ, Sözbilir H, Kekovalı K (2006) Crustal structure and local seismicity in western anatolia. Geophysical Journal International 166(3):1259-1269, DOI 10.1111/j.1365-246x.2006.03053.x, URL https:// doi.org/10.1111/j.1365-246x.2006.03053.x

Altinok Y, Alpar B, Özer N, Gazioglu C (2005) 1881 and 1949 earthquakes at the chios-cesme strait (aegean sea) and their relation to tsunamis. Natural Hazards and Earth System Sciences 5(5):717-725, DOI 10.5194/ nhess-5-717-2005, URL https://doi .org/10.5194/nhess-5-717-2005

Aristotle University Of Thessaloniki Seismological Network (1981) Permanent regional seismological network operated by the aristotle university of thessaloniki. DOI 10.7914/SN/HT, URL http://www.fdsn.org/doi/10.7914/ $\mathrm{SN} / \mathrm{HT}$

Armijo R, Meyer B, King GCP, Rigo A, Papanastassiou D (1996) Quaternary evolution of the corinth rift and its implications for the late cenozoic evolution of the aegean. Geophysical Journal International 126(1):1153, DOI 10.1111/j.1365-246x.1996.tb05264.x, URL https://doi.org/10. 1111/j.1365-246x.1996.tb05264.x

Askan A, Gulerce Z, Roumelioti Z, Sotiriadis D, Melis N, Altindal A, and; Eyup Sopac BA, Karimzadeh S, Kalogeras I, Theodoulidis N, Konstantinidou K, Ozacar A, Kale O, Margaris B (2021) The samos island (aegean sea) m7.0 earthquake: Analysis and engineering implications of strong motion data. Bulletin of Earthquake Engineering This volume

Bassin C, Laske G, Masters TG (2000) The current limits of resolution for surface wave tomography in north america. EOS Trans AGU 81

Benetatos C, Kiratzi A, Ganas A, Ziazia M, Plessa A, Drakatos G (2006) Strike-slip motions in the gulf of siğaçik (western turkey): Properties of the 17 october 2005 earthquake seismic sequence. Tectonophysics 426(3-4):263279, DOI 10.1016/j.tecto.2006.08.003, URL https://doi.org/10.1016/j . tecto.2006.08.003 
Beyreuther M, Barsch R, Krischer L, Megies T, Behr Y, Wassermann J (2010) Obspy: A python toolbox for seismology. Seismological Research Letters 81:530-533, DOI 10.1785/gssrl.81.3.530

Bondar I, McLaughlin KL (2009) A new ground truth data set for seismic studies. Seismological Research Letters 80(3):465-472, DOI 10.1785/gssrl. 80.3.465, URL https://doi.org/10.1785/gssrl.80.3.465

Boore DM, Stewart JP, Skarlatoudis AA, Seyhan E, Margaris B, Theodoulidis N, Scordilis E, Kalogeras I, Klimis N, Melis NS (2020) A ground-motion prediction model for shallow crustal earthquakes in greece. Bulletin of the Seismological Society of America 111(2):857-874, DOI 10.1785/0120200270, URL https://doi.org/10.1785/0120200270

Caputo R, Pavlides S (2013) Greek database of seismogenic sources (gredass). DOI 10.15160/UNIFE/GREDASS/0200, URL http://gredass . unife.it

Deng J, Sykes LR (1997) Evolution of the stress field in southern california and triggering of moderate-size earthquakes: A 200-year perspective. Journal of Geophysical Research: Solid Earth 102(B5):9859-9886, DOI 10.1029/96jb03897, URL https://doi.org/10.1029/96jb03897

Disaster And Emergency Management Authority (1990) Turkish national seismic network. DOI 10.7914/SN/TU, URL http://www.fdsn.org/ networks/detail/TU/

Dogan G, Kalligeris N, Yalciner A, Charalampakis Mea (2020) Tsunami effects and performance of port structures (chapter 2). In: Seismological and Engineering Effects of the M 7.0 Samos Island (Aegean Sea) Earthquake, Ed: Onder Çetin, K., Mylonakis, G., Sextos, A. and Stewart, J.P., Geotechnical Extreme Events Reconnaissance Association: Report GEER-069

Dogan G, Yalciner A, Yuksel Y, Ulutaş E, Polat O, Güler I, Şahin C, Tarih A, Kânoğlu U (2021) The 30 october 2020 aegean sea tsunami: post-event field survey along turkish coast. Pure and applied geophysics pp 1-28

Duputel Z, Tsai VC, Rivera L, Kanamori H (2013) Using centroid time-delays to characterize source durations and identify earthquakes with unique characteristics. Earth and Planetary Science Letters 374:92-100, DOI 10.1016/ j.epsl.2013.05.024, URL https://doi.org/10.1016/j.epsl.2013.05.024

Dziewonski AM, Chou TA, Woodhouse JH (1981) Determination of earthquake source parameters from waveform data for studies of global and regional seismicity. Journal of Geophysical Research: Solid Earth 86(B4):28252852, DOI 10.1029/jb086ib04p02825, URL https://doi.org/10.1029/ jb086ib04p02825

Ekström G, Nettles M, Dziewoński A (2012) The global CMT project 2004-2010: Centroid-moment tensors for 13, 017 earthquakes. Physics of the Earth and Planetary Interiors 200-201:1-9, DOI 10.1016/j.pepi.2012.04.002, URL https://doi.org/10.1016/j.pepi.2012.04.002

Erickson L (1987) A three-dimensional dislocation program with applications to faulting in the earth: user's manual for DIS3D. Stanford, Stanford University

Gallovič F, Zahradník J (2011) Toward understanding slip inversion uncertainty and artifacts: 2. singular value analysis. Journal of Geophysical Re- 
search 116(B2), DOI 10.1029/2010jb007814, URL https://doi.org/10. 1029/2010jb007814

Gallovič F, Imperatori W, Mai PM (2015) Effects of three-dimensional crustal structure and smoothing constraint on earthquake slip inversions: Case study of the mw 6.32009 laquila earthquake. Journal of Geophysical Research: Solid Earth 120(1):428-449, DOI 10.1002/2014jb011650, URL https://doi.org/10.1002/2014jb011650

GEER (2020) Samos, greece earthquake impacts. DOI 10.18118/G6H088, URL http://geerassociation.org/administrator/components/com geer_reports/geerfiles/SamosIslandEarthquakeFinalReport.pdf

Harris RA (1998) Introduction to special section: Stress triggers, stress shadows, and implications for seismic hazard. Journal of Geophysical Research: Solid Earth 103(B10):24347-24358, DOI 10.1029/98jb01576, URL https: //doi.org/10.1029/98jb01576

Helmholtz-Centre Potsdam-GFZ German Research Centre For Geosciences, GEMPA GmbH (2008) The seiscomp seismological software package. DOI 10.5880/GFZ.2.4.2020.003, URL https://www. seiscomp.de/

Hunter JD (2007) Matplotlib: A 2d graphics environment. Computing In Science \& Engineering 9(3):90-95

ITSAK Institute Of Engineering Seimology Earthquake Engineering (1981) Itsak strong motion network. DOI 10.7914/SN/HI, URL http: //www . fdsn . org/doi/10.7914/SN/HI

Kagan YY (1991) 3-d rotation of double-couple earthquake sources. Geophysical Journal International 106(3):709-716, DOI 10.1111/j.1365-246x. 1991.tb06343.x, URL https://doi.org/10.1111/j.1365-246x.1991. tb06343.x

Kandilli Observatory And Earthquake Research Institute, Boğaziçi University (1971) Boğaziçi university kandilli observatory and earthquake research institute. DOI 10.7914/SN/KO, URL http://www.fdsn.org/doi/10.7914/ $\mathrm{SN} / \mathrm{KO}$

Kennett BLN, Engdahl ER, Buland R (1995) Constraints on seismic velocities in the earth from traveltimes. Geophysical Journal International 122(1):108 124, DOI 10.1111/j.1365-246x.1995.tb03540.x, URL https ://doi .org/10 . 1111/j.1365-246x.1995.tb03540.x

Kim A, Dreger DS (2008) Rupture process of the 2004 parkfield earthquake from near-fault seismic waveform and geodetic records. Journal of Geophysical Research 113(B7), DOI 10.1029/2007jb005115, URL https: //doi.org/10.1029/2007jb005115

King GCP, Stein RS, Lin J (1994) Static stress changes and the triggering of earthquakes. Bulletin of the Seismological Society of America 84(3):935953, https://pubs.geoscienceworld.org/bssa/article-pdf/84/3/ 935/2708368/BSSA0840030935.pdf

Kiratzi A (2003) Focal mechanisms of shallow earthquakes in the aegean sea and the surrounding lands determined by waveform modelling: a new database. Journal of Geodynamics 36(1-2):251-274, DOI 10.1016/ s0264-3707(03)00050-4, URL https ://doi .org/10.1016/s0264-3707 (03) 
00050-4

Kissel C, Laj C (1988) The tertiary geodynamical evolution of the aegean arc: a paleomagnetic reconstruction. Tectonophysics 146(1-4):183-201, DOI 10.1016/0040-1951(88)90090-x, URL https://doi.org/10.1016/ 0040-1951 (88) 90090-x

Konca AO, Hjorleifsdottir V, Song TRA, Avouac JP, Helmberger DV, Ji C, Sieh K, Briggs R, Meltzner A (2007) Rupture kinematics of the $2005 \mathrm{mw}$ 8.6 nias-simeulue earthquake from the joint inversion of seismic and geodetic data. Bulletin of the Seismological Society of America 97(1A):S307-S322, DOI 10.1785/0120050632, URL https://doi.org/10.1785/0120050632

Konstantinou K (2018) Estimation of optimum velocity model and precise earthquake locations in ne aegean: Implications for seismotectonics and seismic hazard. Journal of Geodynamics 121:143-154, DOI https://doi.org/10. 1016/j.jog.2018.07.005, URL https://www.sciencedirect.com/science/ article/pii/S0264370718300577

Konstantinou KI, Mouslopoulou V, Saltogianni V (2020) Seismicity and Active Faulting around the Metropolitan Area of Athens, Greece. Bulletin of the Seismological Society of America 110(4):1924-1941, DOI 10.1785/0120200039, URL https://doi.org/10.1785/0120200039, https ://pubs.geoscienceworld.org/bssa/article-pdf/110/4/1924/ 5114247/bssa-2020039.1.pdf

Lentas K, Ferreira AMG, Vallée M (2013) Assessment of SCARDEC source parameters of global large $(\mathrm{mw} \geq 7.5)$ subduction earthquakes. Geophysical Journal International 195(3):1989-2004, DOI 10.1093/gji/ggt364, URL https://doi.org/10.1093/gji/ggt364

Lentas K, Di Giacomo D, Harris J, Storchak DA (2019) The isc bulletin as a comprehensive source of earthquake source mechanisms. Earth System Science Data 11(2):565-578, DOI 10.5194/essd-11-565-2019, URL https: //essd. copernicus.org/articles/11/565/2019/

LePichon X, Chamot-Rooke N, Lallemant S, Noomen R, Veis G (1995) Geodetic determination of the kinematics of central greece with respect to europe: Implications for eastern mediterranean tectonics. Journal of Geophysical Research: Solid Earth 100(B7):12675-12690, DOI 10.1029/95jb00317, URL https://doi.org/10.1029/95jb00317

Lykousis V, Anagnostou C, Pavlakis P, Rousakis G, Alexandri M (1995) Quaternary sedimentary history and neotectonic evolution of the eastern part of central aegean sea, greece. Marine Geology 128(1-2):59 71, DOI 10.1016/0025-3227(95)00088-g, URL https://doi .org/10.1016/ 0025-3227 (95) 00088-g

Margaris B, Scordilis EM, Stewart JP, Boore DM, Theodoulidis N, Kalogeras I, Melis NS, Skarlatoudis AA, Klimis N, Seyhan E (2021) Hellenic strongmotion database with uniformly assigned source and site metadata for the period 1972-2015. Seismological Research Letters 92(3):2065-2080, DOI 10.1785/0220190337, URL https://doi.org/10.1785/0220190337

Matrullo E, De Matteis R, Satriano C, Amoroso O, Zollo A (2013) An improved 1-D seismic velocity model for seismological studies in the Cam- 
paniaLucania region (Southern Italy). Geophysical Journal International 195(1):460-473, DOI 10.1093/gji/ggt224, URL https://doi.org/10. 1093/gji/ggt224, https://academic.oup.com/gji/article-pdf/195/ 1/460/1638381/ggt224.pdf

McClusky S, Balassanian S, Barka A, Demir C, Ergintav S, Georgiev I, Gurkan O, Hamburger M, Hurst K, Kahle H, Kastens K, Kekelidze G, King R, Kotzev V, Lenk O, Mahmoud S, Mishin A, Nadariya M, Ouzounis A, Paradissis D, Peter Y, Prilepin M, Reilinger R, Sanli I, Seeger H, Tealeb A, Toksöz MN, Veis G (2000) Global positioning system constraints on plate kinematics and dynamics in the eastern mediterranean and caucasus. Journal of Geophysical Research: Solid Earth 105(B3):5695-5719, DOI 10.1029/1999jb900351, URL https://doi.org/10.1029/1999jb900351

McKenzie D (1972) Active tectonics of the mediterranean region. Geophysical Journal International 30(2):109-185, DOI 10.1111/j.1365-246x.1972.tb02351.x, URL https://doi.org/10.1111/j . 1365-246x.1972.tb02351.x

Melis NS, Konstantinou KI (2006) Real-time seismic monitoring in the greek region: An example from the 17 october 2005 east aegean sea earthquake sequence. Seismological Research Letters 77(3):364-370, DOI 10.1785/gssrl. 77.3.364, URL https://doi.org/10.1785/gssrl.77.3.364

Melis NS, Okal EA, Synolakis CE, Kalogeras IS, Kânoğlu U (2020) The chios, greece earthquake of 23 july 1949: Seismological reassessment and tsunami investigations. Pure and Applied Geophysics 177(3):12951313, DOI 10.1007/s00024-019-02410-1, URL https://doi.org/10.1007/ s00024-019-02410-1

Mountrakis D, Kilias A, Vavliakis E, Psilovikos A, Thomaidou E (2003) Neotectonic map of Samos Island (Agean Sea, Greece): implication of Geographical Information Systems in the Geological mapping. $4^{\text {th }}$ European Congress on Regional Geoscientific Cartography and Information Systems, Bologna, Italy, 11-13

Nalbant SS, Hubert A, King GCP (1998) Stress coupling between earthquakes in northwest turkey and the north aegean sea. Journal of Geophysical Research: Solid Earth 103(B10):24469-24486, DOI 10.1029/98jb01491, URL https://doi.org/10.1029/98jb01491

National Observatory Of Athens IOG (1997) National observatory of athens seismic network. DOI 10.7914/SN/HL, URL http://www.fdsn.org/doi/ $10.7914 / \mathrm{SN} / \mathrm{HL}$

Nomikou P, Evangelidis D, Papanikolaou D, Lampridou D, Litsas D, Tsaparas Y, Koliopanos I (2021) Morphotectonic analysis along the northern margin of samos island, related to the seismic activity of october 2020, aegean sea, greece. Geosciences 11(2):102, DOI 10.3390/geosciences11020102, URL https://doi.org/10.3390/geosciences 11020102

Ocakoğlu N, Demirbağ E, Kuşçu \{I (2005) Neotectonic structures in izmir gulf and surrounding regions (western turkey): Evidences of strike-slip faulting with compression in the aegean extensional regime. Marine Geology 219(2-3):155-171, DOI 10.1016/j.margeo.2005.06.004, URL https: 
//doi.org/10.1016/j.margeo.2005.06.004

Papadimitriou EE, Sykes LR (2001) Evolution of the stress field in the northern aegean sea (greece). Geophysical Journal International 146(3):747-759, DOI 10.1046/j.0956-540x.2001.01486.x, URL https://doi.org/10.1046/ j.0956-540x.2001.01486.x

Papazachos B, Papadimitriou E, Kiratzi A, Papazachos C, Louvari E (1998) Fault plane solutions in the aegean sea and the surrounding area and their tectonic implication. Bollettino Di Geofisica Teorica Ed Applicata 39:199218

Papazachos B, Scordilis E, Panagiotopoulos D, Papazachos C, Karakaisis G (2004) Global relations between seismic fault parameters and moment magnitude of earthquakes. Bulletin of the Geological Society of Greece 36(3):1482-1489

Papazachos BC, Comninakis PE (1971) Geophysical and tectonic features of the aegean arc. Journal of Geophysical Research 76(35):85178533, DOI 10.1029/jb076i035p08517, URL https://doi.org/10.1029/ jb076i035p08517

Papazachos BC, Papazachou CC (2003) The Earthquakes of Greece

Papazachos CB (1999) Seismological and GPS evidence for the aegean-anatolia interaction. Geophysical Research Letters 26(17):2653-2656, DOI 10.1029/ 1999g1900411, URL https://doi.org/10.1029/1999g1900411

Paradisopoulou PM, Papadimitriou EE, Karakostas VG, Taymaz T, Kilias A, Yolsal S (2010) Seismic hazard evaluation in western turkey as revealed by stress transfer and time-dependent probability calculations. Pure and Applied Geophysics 167(8-9):1013-1048, DOI 10.1007/s00024-010-0085-1, URL https://doi.org/10.1007/s00024-010-0085-1

Parsons T (2002) Global omori law decay of triggered earthquakes: Large aftershocks outside the classical aftershock zone. Journal of Geophysical Research: Solid Earth 107(B9):ESE 9-1-ESE 9-20, DOI 10.1029/ 2001jb000646, URL https://doi.org/10.1029/2001jb000646

Pavlidis S, Tsapanos T, Zouros N, Sboras S, Koravos G, Chatzipetros A (2009) Using active fault data for assessing seismic hazard: a case study from NE Aegean Sea, Greece. XVII ${ }^{\text {th }}$ Int Conf Soil Mech \& Geotechn Eng, 2-3 October 2009, Alexandria, Egypt

QGIS Development Team (2021) QGIS Geographic Information System. QGIS Association, URL https://www.qgis.org

Rhoades DA, Papadimitriou EE, Karakostas VG, Console R, Murru M (2010) Correlation of static stress changes and earthquake occurrence in the north aegean region. Pure and Applied Geophysics 167(8-9):10491066, DOI 10.1007/s00024-010-0092-2, URL https://doi.org/10.1007/ s00024-010-0092-2

Schaff D, Waldhauser F (2005) Waveform cross-correlation-based differential travel-time measurements at the northern california seismic network. Bulletin of the Seismological Society of America 95:2446-2461, DOI $10.1785 / 0120040221$ 
Scholz CH (2002) The Mechanics of Earthquakes and Faulting, 2nd edn. Cambridge University Press, DOI 10.1017/CBO9780511818516

Sengör AMC, Satir M, Akkök R (1984) Timing of tectonic events in the menderes massif, western turkey: Implications for tectonic evolution and evidence for pan-african basement in turkey. Tectonics 3(7):693707, DOI 10.1029/tc003i007p00693, URL https://doi.org/10.1029/ tc003i007p00693

Sladen A, Tavera H, Simons M, Avouac JP, Konca AO, Perfettini H, Audin L, Fielding EJ, Ortega F, Cavagnoud R (2010) Source model of the 2007mw8.0 pisco, peru earthquake: Implications for seismogenic behavior of subduction megathrusts. Journal of Geophysical Research 115(B2), DOI 10.1029/2009jb006429, URL https : //doi .org/10.1029/2009jb006429

Stein RS, Barka AA, Dieterich JH (1997) Progressive failure on the north anatolian fault since 1939 by earthquake stress triggering. Geophysical Journal International 128(3):594-604, DOI 10.1111/j.1365-246x.1997.tb05321.x, URL https ://doi.org/10.1111/j.1365-246x.1997.tb05321.x

Stewart JP, Klimis N, Savvaidis A, Theodoulidis N, Zargli E, Athanasopoulos G, Pelekis P, Mylonakis G, Margaris B (2014) Compilation of a local VS profile database and its application for inference of VS30 from geologicand terrain-based proxies. Bulletin of the Seismological Society of America 104(6):2827-2841, DOI 10.1785/0120130331, URL https://doi.org/10. $1785 / 0120130331$

Stiros S, Laborel J, Laborel-Deguen F, Papageorgiou S, Evin J, Pirazzoli P (2000) Seismic coastal uplift in a region of subsidence: Holocene raised shorelines of samos island, aegean sea, greece. Marine Geology 170(1-2):4158, DOI 10.1016/s0025-3227(00)00064-5, URL https : //doi .org/10 .1016/ s0025-3227(00) 00064-5

Styron R, Pagani M (2020) The gem global active faults database. Earthquake Spectra 36(1_suppl):160-180, DOI 10.1177/8755293020944182, URL https : //doi.org/10.1177/8755293020944182

Tan O (2013) The dense micro-earthquake activity at the boundary between the anatolian and south aegean microplates. Journal of Geodynamics 65:199-217, DOI 10.1016/j.jog.2012.05.005, URL https://doi .org/10 . $1016 / j \cdot j o g \cdot 2012.05 .005$

Taymaz T, Jackson J, McKenzie D (1991) Active tectonics of the north and central aegean sea. Geophysical Journal International 106(2):433-490, DOI 10.1111/j.1365-246x.1991.tb03906.x, URL https://doi.org/10.1111/j . 1365-246x.1991. tb03906.x

Technological Educational Institute Of Crete (2006) Seismological network of crete. DOI 10.7914/SN/HC, URL http://www.fdsn.org/doi/10.7914/ $\mathrm{SN} / \mathrm{HC}$

Toda S, Stein R, Sevilgen V, Lin J (2011) Coulomb 3.3 graphic-rich deformation and stress-change software for earthquake, tectonic, and volcano research and teaching - user guide. US Geological Survey Open-File Report 1060 
University Of Athens (2008) University of athens, seismological laboratory. DOI 10.7914/SN/HA, URL http://www.fdsn.org/doi/10.7914/SN/HA

University Of Patras GD (2000) Pslnet, permanent seismic network operated by the university of patras, greece. DOI 10.7914/SN/HP, URL http://www . fdsn.org/doi/10.7914/SN/HP

Waldhauser F, Ellsworth WL (2000) A Double-Difference Earthquake Location Algorithm: Method and Application to the Northern Hayward Fault, California. Bulletin of the Seismological Society of America 90(6):1353-1368, DOI 10.1785/0120000006, URL https://doi. org/10.1785/0120000006, https://pubs.geoscienceworld.org/bssa/ article-pdf/90/6/1353/2710256/1353\_ssa00006.pdf

Waldhauser F, Schaff DP (2008) Large-scale relocation of two decades of northern california seismicity using cross-correlation and double-difference methods. Journal of Geophysical Research: Solid Earth 113(B8), DOI 10.1029/2007jb005479, URL https://doi.org/10.1029/2007jb005479

Wessel P, Smith WHF, Scharroo R, Luis J, Wobbe F (2013) Generic mapping tools: Improved version released. Eos, Transactions American Geophysical Union 94(45):409-410, DOI 10.1002/2013eo450001

Worden CB (2016) Shakemap manual. DOI 10.5066/F7D21VPQ, URL http: //usgs.github.io/shakemap/

Worden CB, Gerstenberger MC, Rhoades DA, Wald DJ (2012) Probabilistic relationships between ground-motion parameters and modified mercalli intensity in california. Bulletin of the Seismological Society of America 102(1):204-221, DOI 10.1785/0120110156, URL https://doi.org/10. $1785 / 0120110156$

Zhang L, Mai PM, Thingbaijam KK, Razafindrakoto HN, Genton MG (2014) Analysing earthquake slip models with the spatial prediction comparison test. Geophysical Journal International 200(1):185-198, DOI 10.1093/gji/ ggu383, URL https://doi.org/10.1093/gji/ggu383 


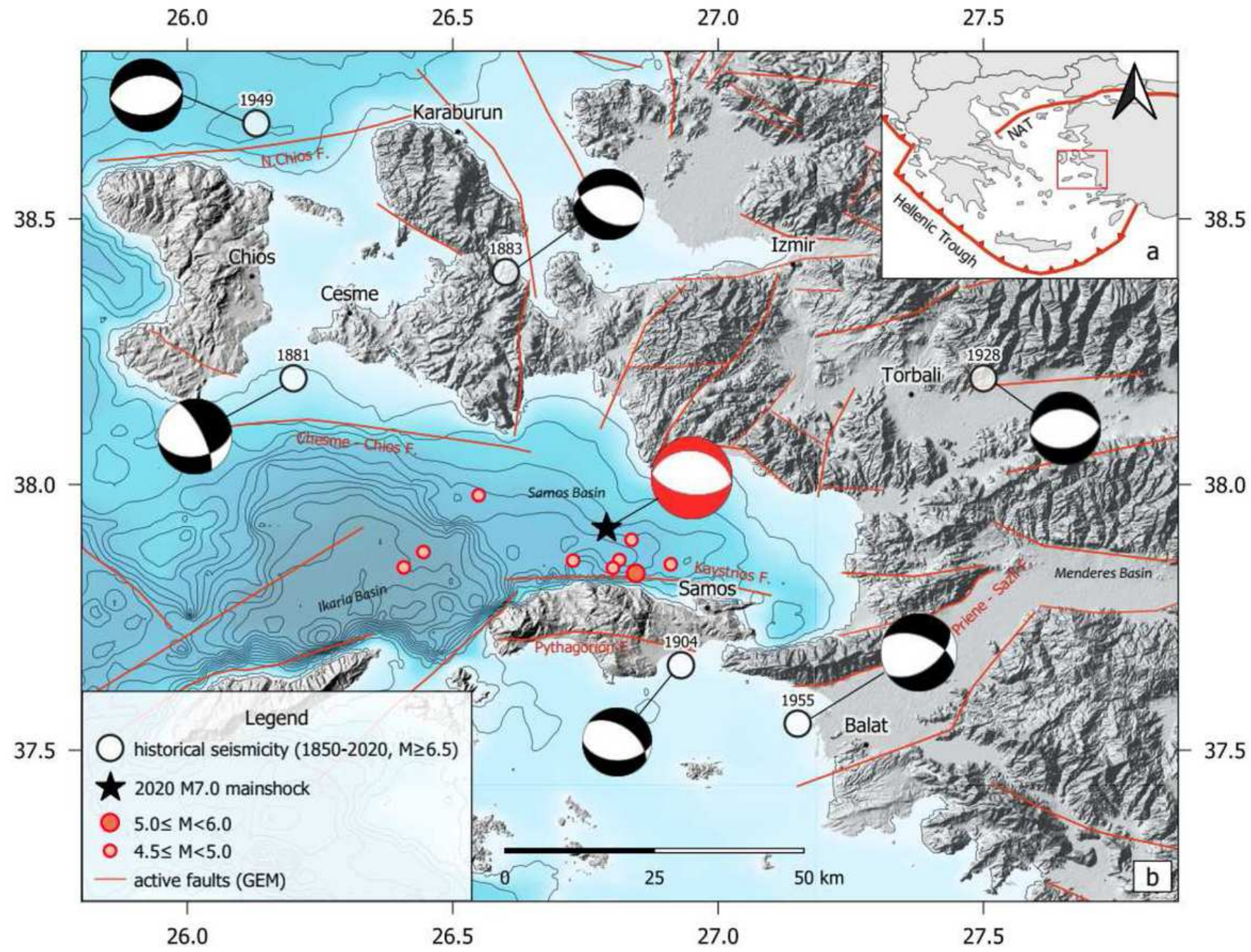

\section{Figure 1}

a: General map of the study area (enclosed by the red rectangle) within the Aegean regime in respect to the main seismotectonic features of the North Anatolian Trough (NAT) and the Hellenic Trough; $b$ : Seismotectonic map with the approximate locations of the most significant historical earthquakes ( $M \geq$ 6.5) since 1850 obtained from the historical catalogue of Papazachos and Papazachou (2003) along with their inferred fault plane solutions (details are given in Table 6). Plotted with the black star is the 2020 Samos mainshock along with the Global CMT best fitting double-couple fault plane solution, whereas the circles in red outline refer to the strongest earthquakes which occurred within four months of aftershock activity. Main active faults as reported in the GEM active fault database (Styron and Pagani, 2020) are also depicted. Note: The designations employed and the presentation of the material on this map do not imply the expression of any opinion whatsoever on the part of Research Square concerning 
the legal status of any country, territory, city or area or of its authorities, or concerning the delimitation of its frontiers or boundaries. This map has been provided by the authors.

a

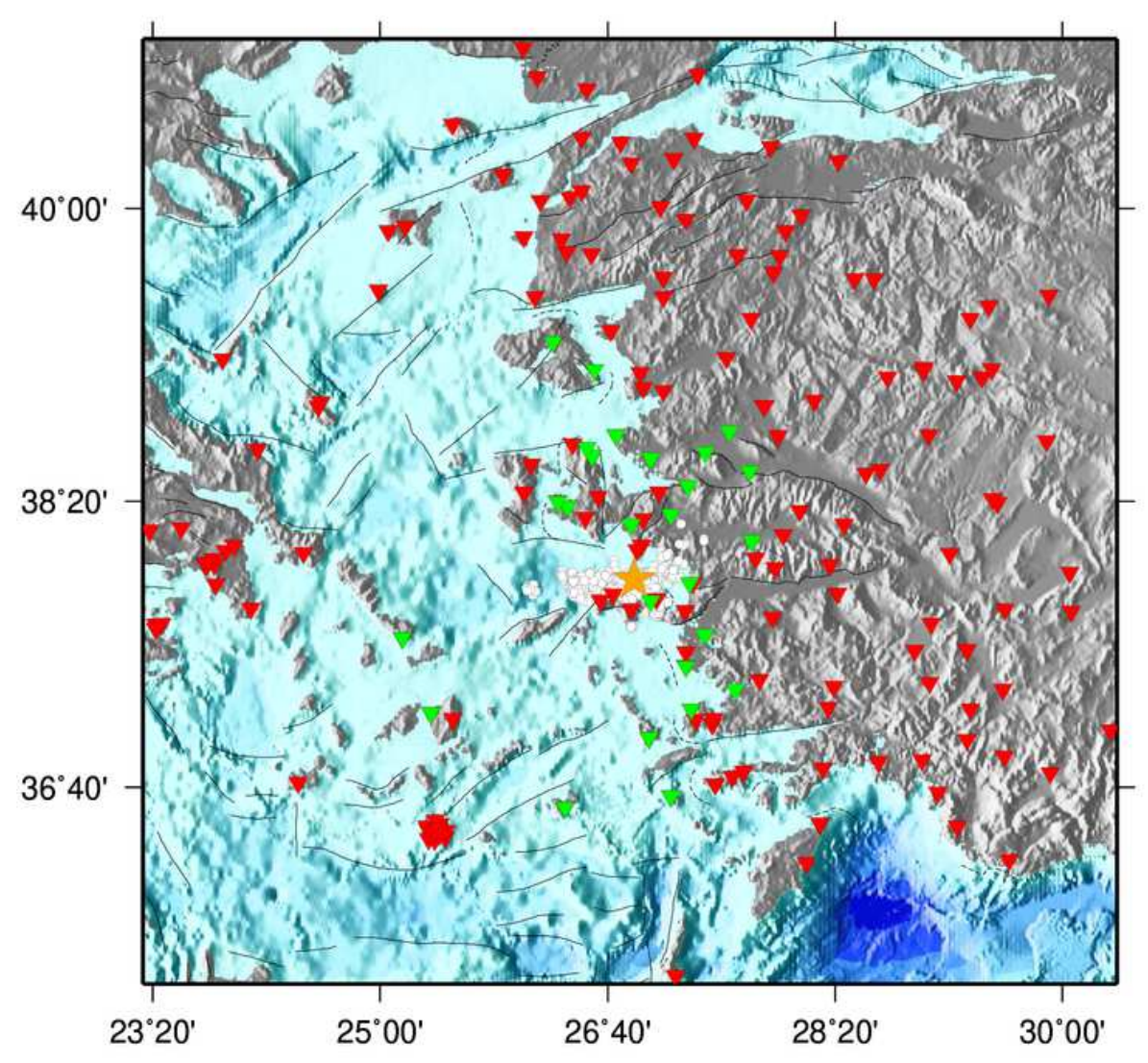

b

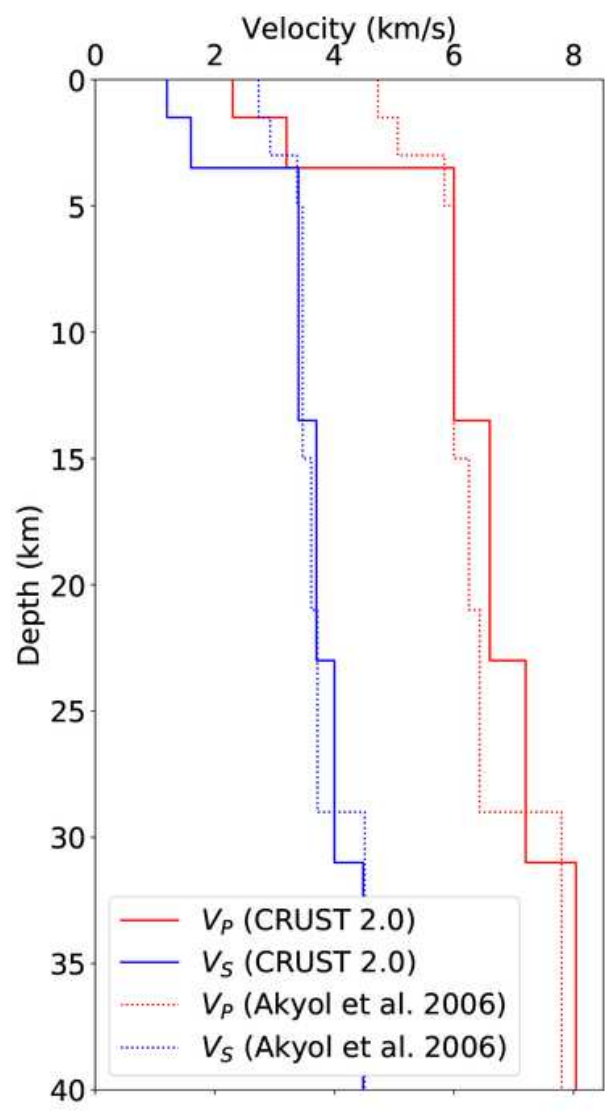

Figure 2

a: Map showing the spatial distribution of the seismic stations used in the current study with respect to the mainshock (orange star) and its aftershock sequence (white circles). Red inverse triangles show stations which have been used in earthquake relative locations, whilst green inverse triangles represent stations equipped with accelerographs whose record- ings have been used to determine the mainshock's slip model; b: comparison of 1D velocity models used for the earthquake relative locations (Akyol et al., 2006), and Earth's structure used for the determination of the mainshock's slip model, which is extracted from CRUST 2.0, 3D velocity model (Bassin et al., 2000), with respect to the $2 \varangle \times 2 \varangle$ cell, with reference to the mainshock's epicentre. Note: The designations employed and the presentation of the material on this map do not imply the expression of any opinion whatsoever on the part of Research Square concerning the legal status of any country, territory, city or area or of its authorities, or concerning the delimitation of its frontiers or boundaries. This map has been provided by the authors. 

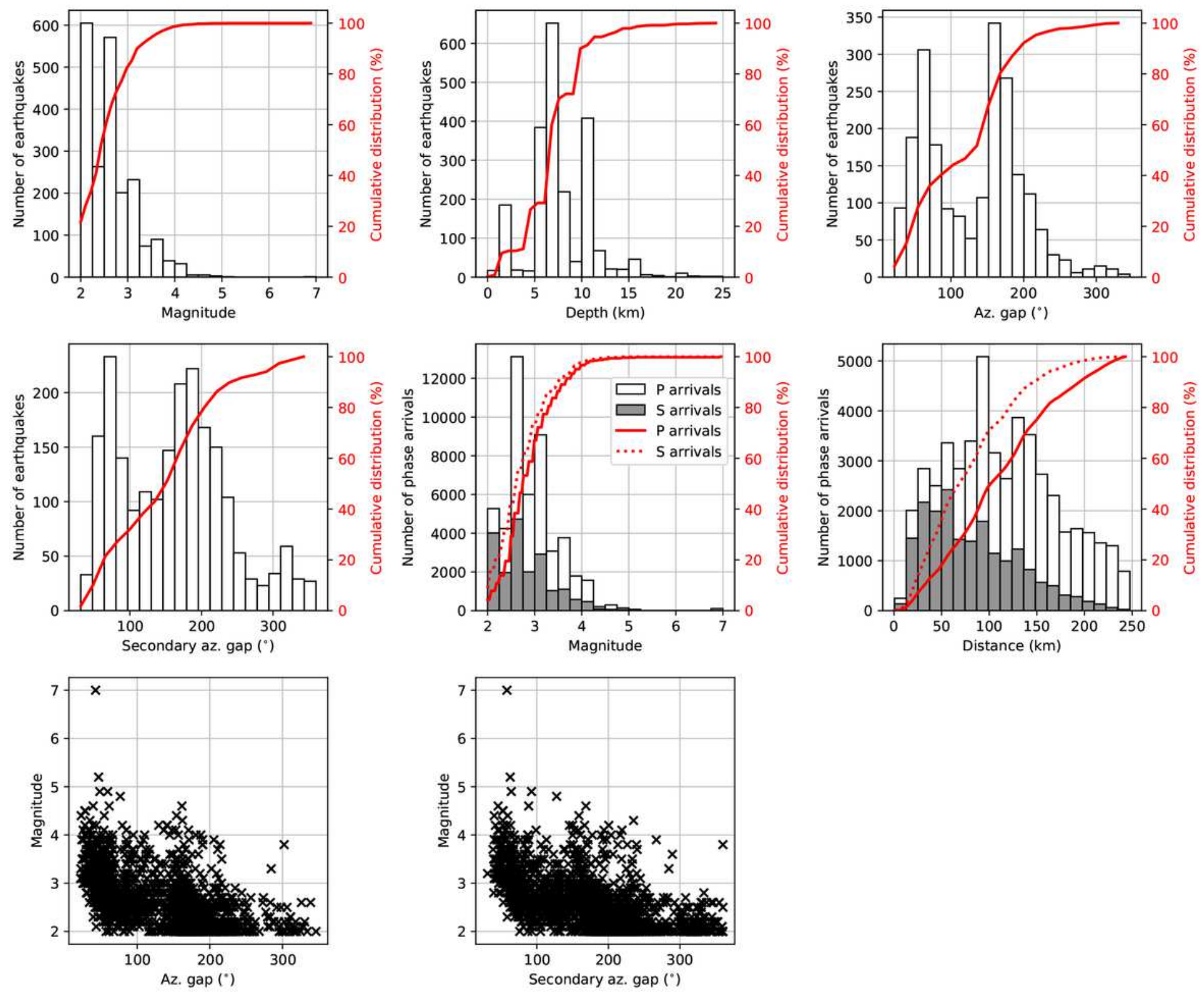

Figure 3

Histograms and scatter plots showing the distribution of magnitudes, depths, azimuthal gaps, and number of phase arrivals in the parametric data used in the current study, as well as the association of azimuthal gaps with magnitude. Red lines in histograms indicate the cumulative distribution. 

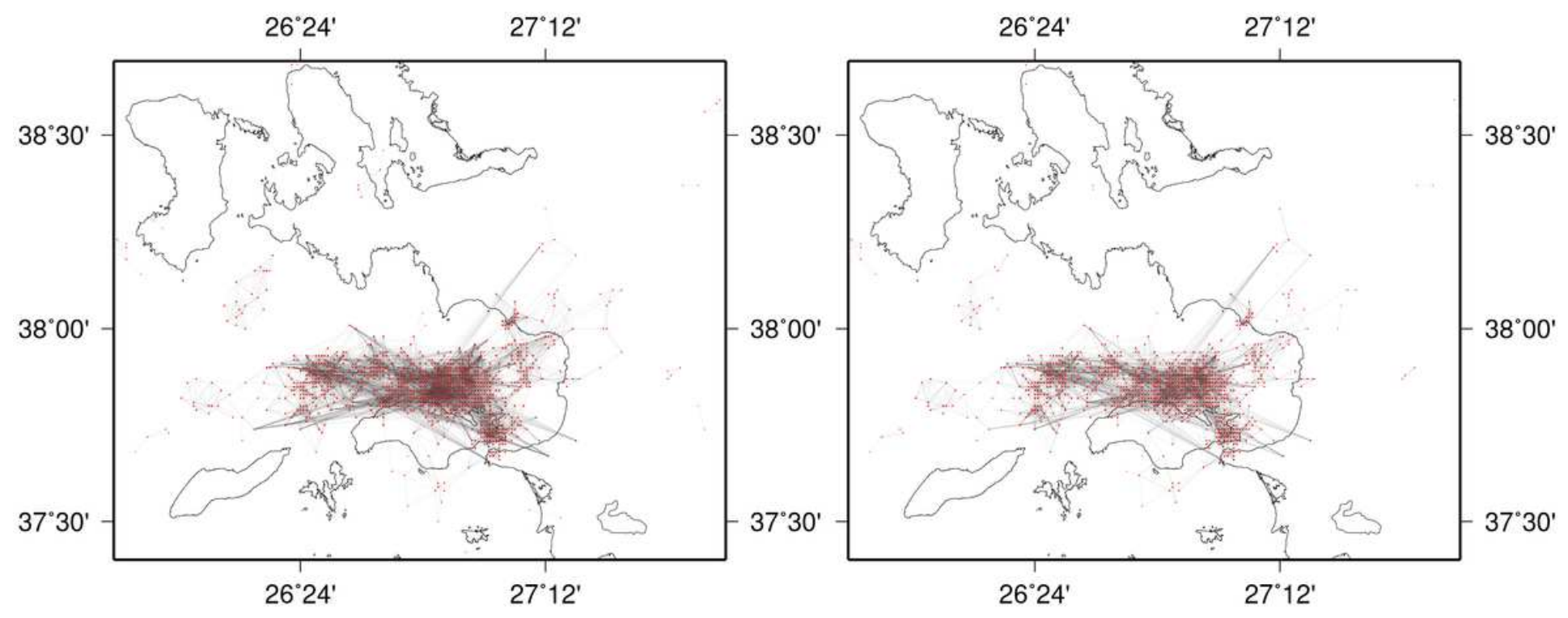

Figure 4

Maps showing the links of event pairs based on the earthquake catalogue used for the relative locations (left) and the links based on waveform cross-correlations (right). Note: The designations employed and the presentation of the material on this map do not imply the expression of any opinion whatsoever on the part of Research Square concerning the legal status of any country, territory, city or area or of its authorities, or concerning the delimitation of its frontiers or boundaries. This map has been provided by the authors. 


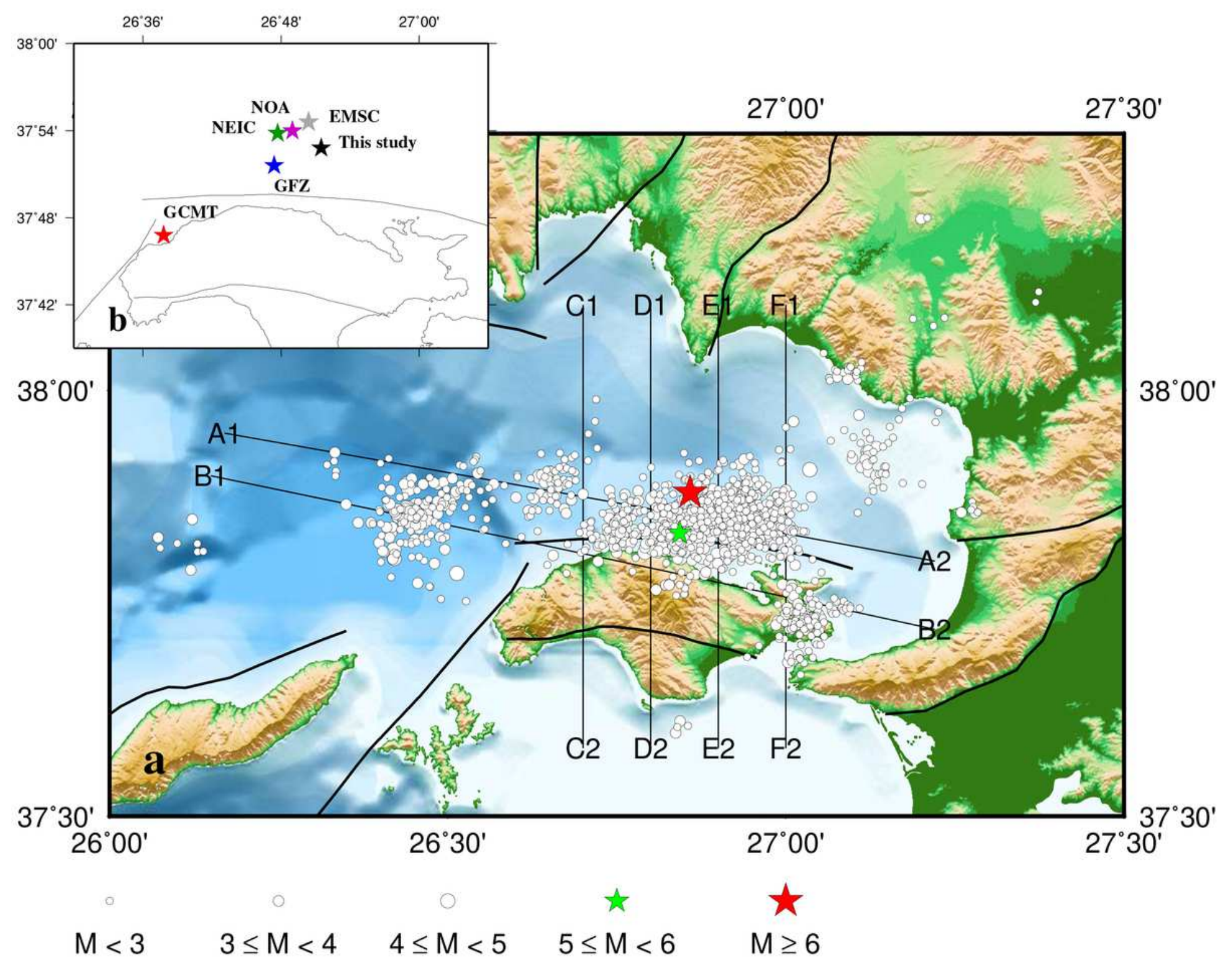

Figure 5

a: Map showing relative locations based on differential travel times from catalogue and waveform crosscorrelation data. Black thick lines represent surface traces of the main seismic faults by the GEM active fault database (Styron and Pagani, 2020). Black thin lines show cross-sections analysed in Figure 10; b: Comparison of available epicentres for the mainshock (GCMT: Global CMT, NEIC: National Earthquake Information Center, GFZ: Helmholtz Centre Potsdam, German Research Centre For Geosciences, EMSC: European- Mediterranean Seismological Centre, NOA: National Observatory of Athens) against the relocated epicentre obtained in the current study. Note: The designations employed and the presentation of the material on this map do not imply the expression of any opinion whatsoever on the part of Research Square concerning the legal status of any country, territory, city or area or of its authorities, or concerning the delimitation of its frontiers or boundaries. This map has been provided by the authors. 

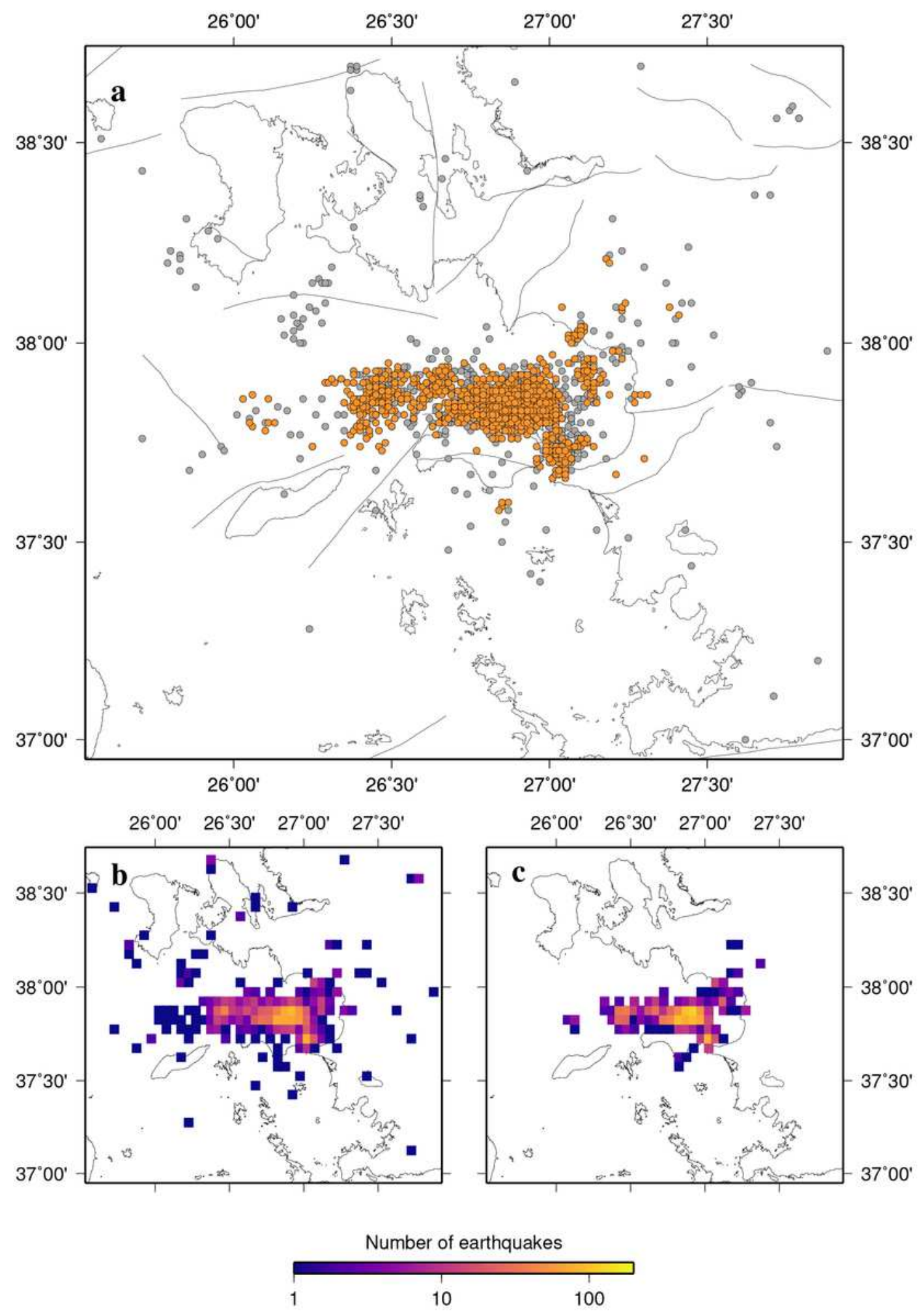

Figure 6

a: Map showing epicentre locations for all the earthquakes downloaded from EMSC (grey circles) and those that were relocated using differential travel times from catalogue and waveform cross-correlation data (orange circles); b: map showing the spatial distribution of earthquake density before the relocation on a $5 \mathrm{~km} \times 5 \mathrm{~km}$ grid; and $\mathrm{c}$ : same as in b but using the relocated epicentres. Note: The designations employed and the presentation of the material on this map do not imply the expression of any opinion 
whatsoever on the part of Research Square concerning the legal status of any country, territory, city or area or of its authorities, or concerning the delimitation of its frontiers or boundaries. This map has been provided by the authors.
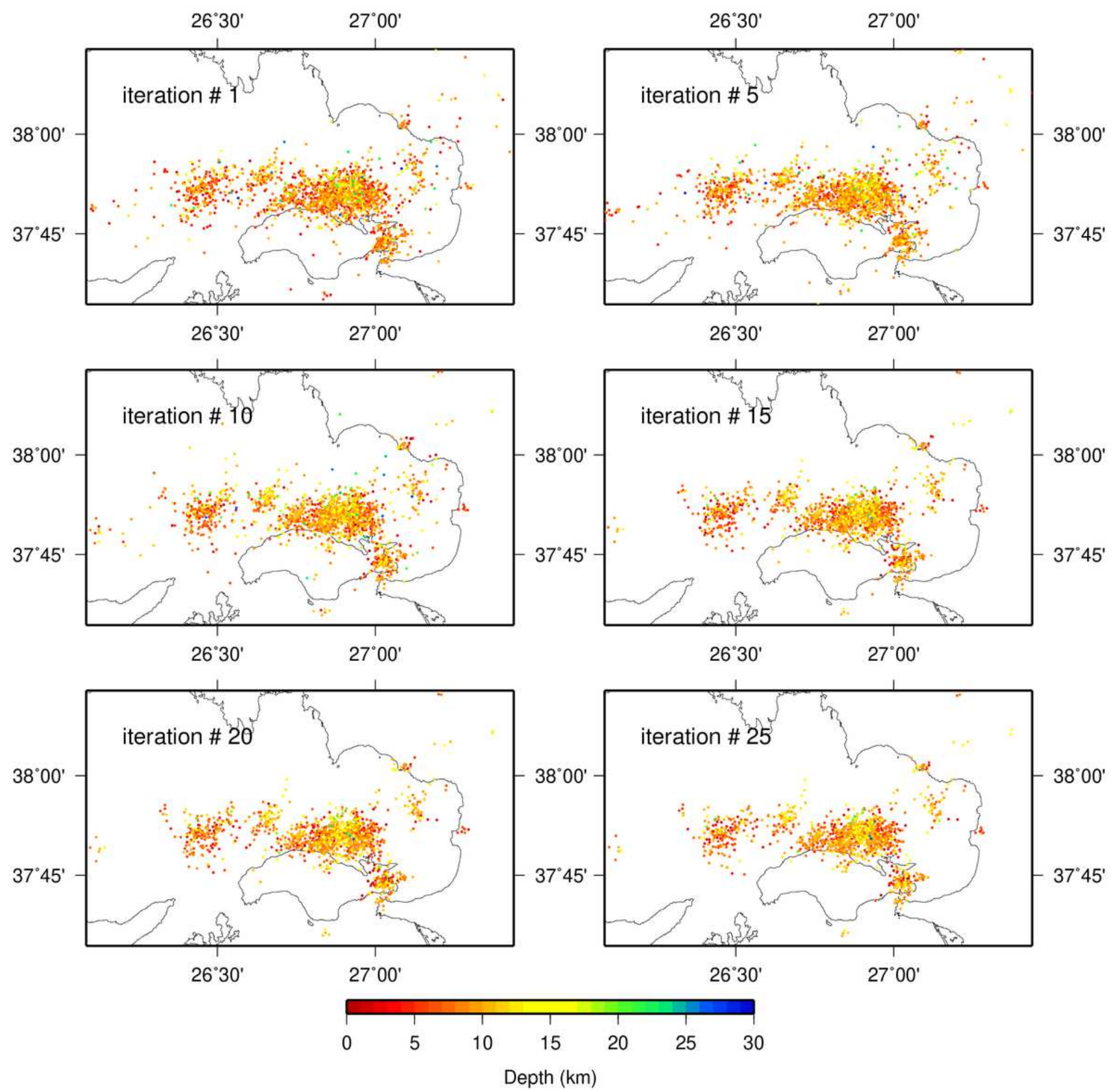

Figure 7

Maps showing the progress of the relocation inversion every five iterations when a different weighting scheme was applied to the data. Note: The designations employed and the presentation of the material on this map do not imply the expression of any opinion whatsoever on the part of Research Square 
concerning the legal status of any country, territory, city or area or of its authorities, or concerning the delimitation of its frontiers or boundaries. This map has been provided by the authors.
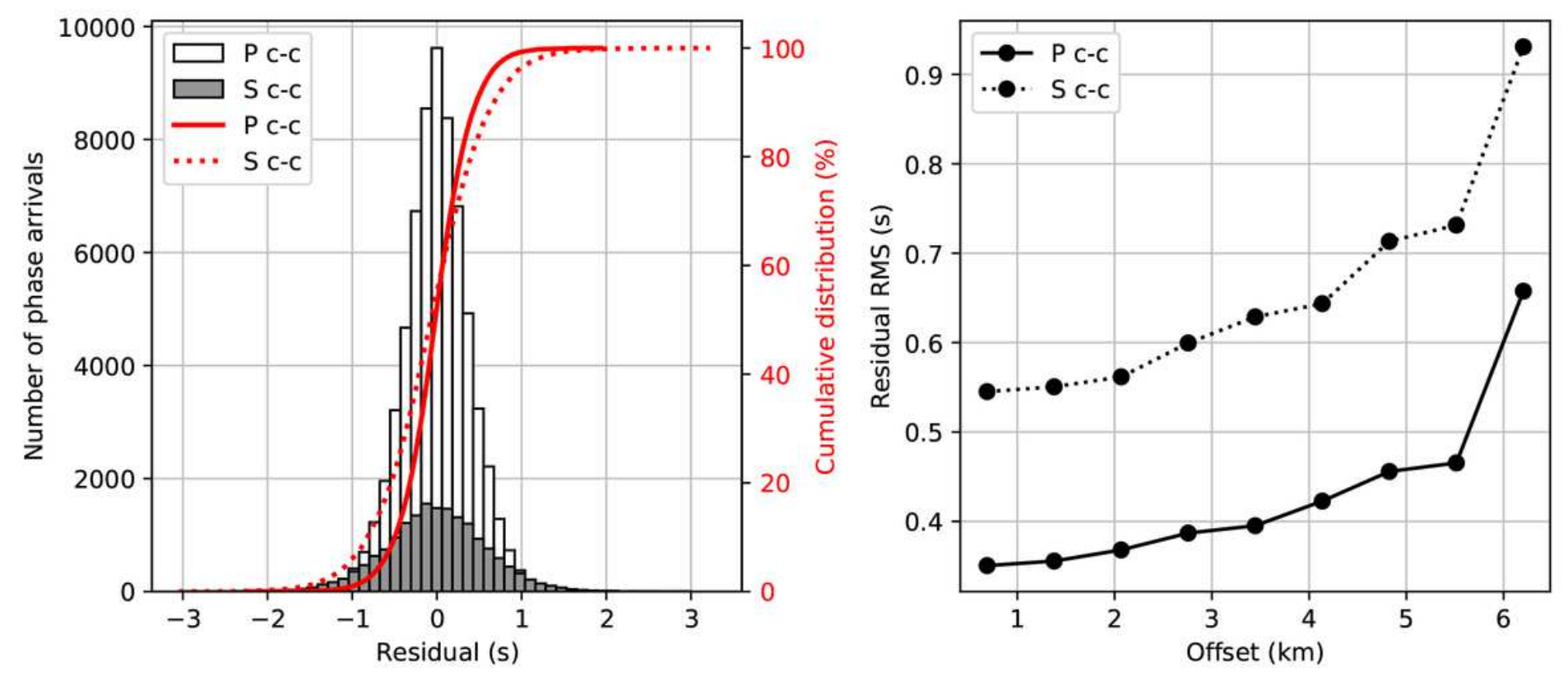

Figure 8

Histograms showing the distribution of $\mathrm{P}$ (white) and $\mathrm{S}$ (grey) cross-correlation differential travel time residuals (left). Red solid and dotted lines represent the cumulative distributions, respectively. RMS travel time residuals against the interevent distance for $\mathrm{P}$ (solid line) and $\mathrm{S}$ (dotted line) cross-correlation data are plotted in the right hand side. 


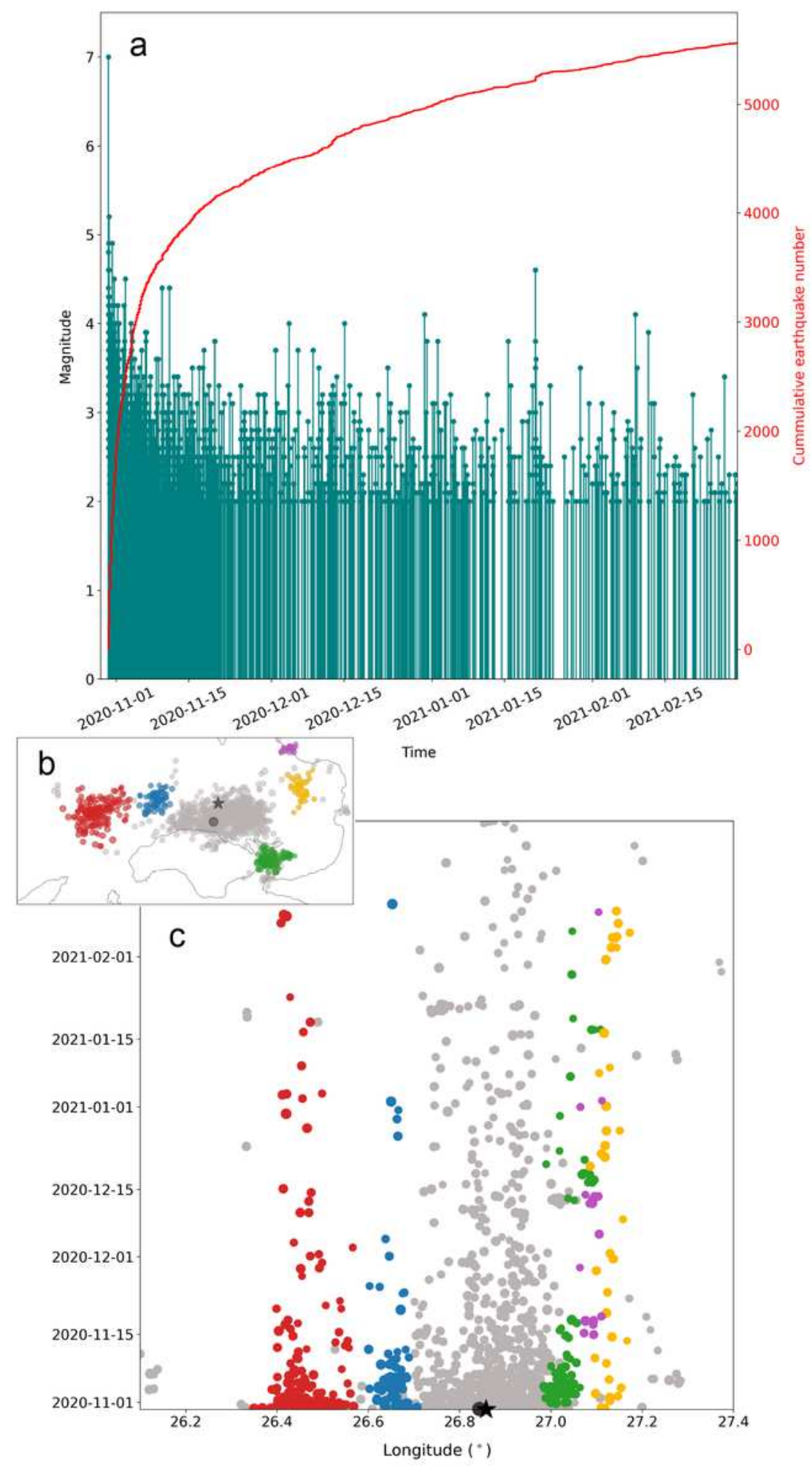

\section{Figure 9}

a: Temporal distribution of the reported seismicity for the study area, used as input to the relocation analysis from 30-10-2020 to 01-03-2021 along with the cumulative number of earthquakes in red colour; b: Map view of the relocated seismicity; and c: Spatial-temporal diagram of the relocated seismicity projected in E-W orientation. Different colouring is used to highlight distinctive earthquake clusters both in the map view and the space-time plot. 

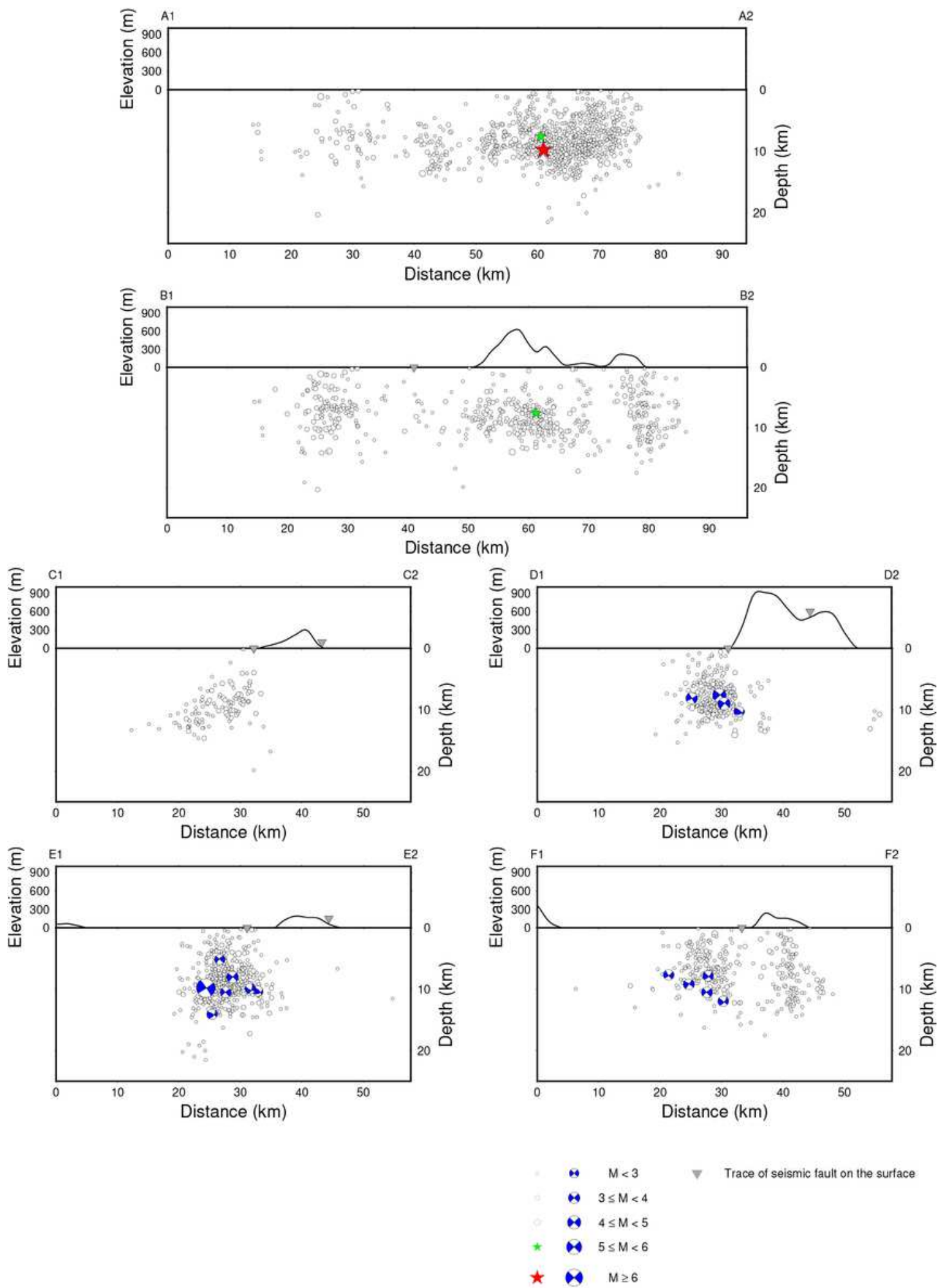

Figure 10

Cross-sections of the relocated hypocentres shown in the map of Figure 5. Available source mechanisms are also plotted in the cross-sections (C-F) oriented perpendicular to the main seismic faults in the study area. The width of each cross-section is set to $5 \mathrm{~km}$. Grey triangles indicate the surface traces of Kaystrios and Pythagorio seismic faults. 


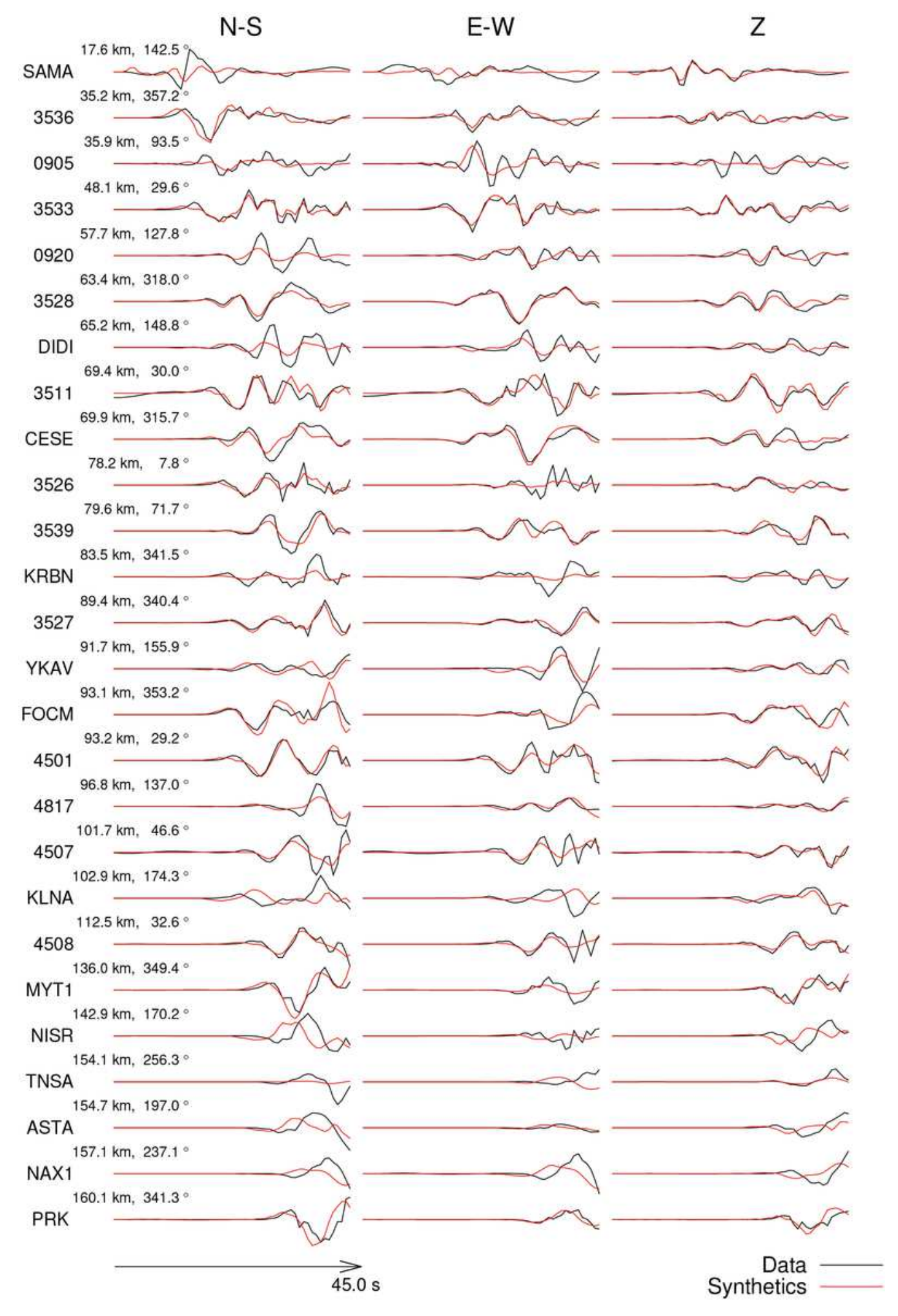

\section{Figure 11}

Three component displacement waveform data (black) compared to synthetics based on the obtained slip model (red) for each station used in the kinematic slip inversion for the mainshock. 


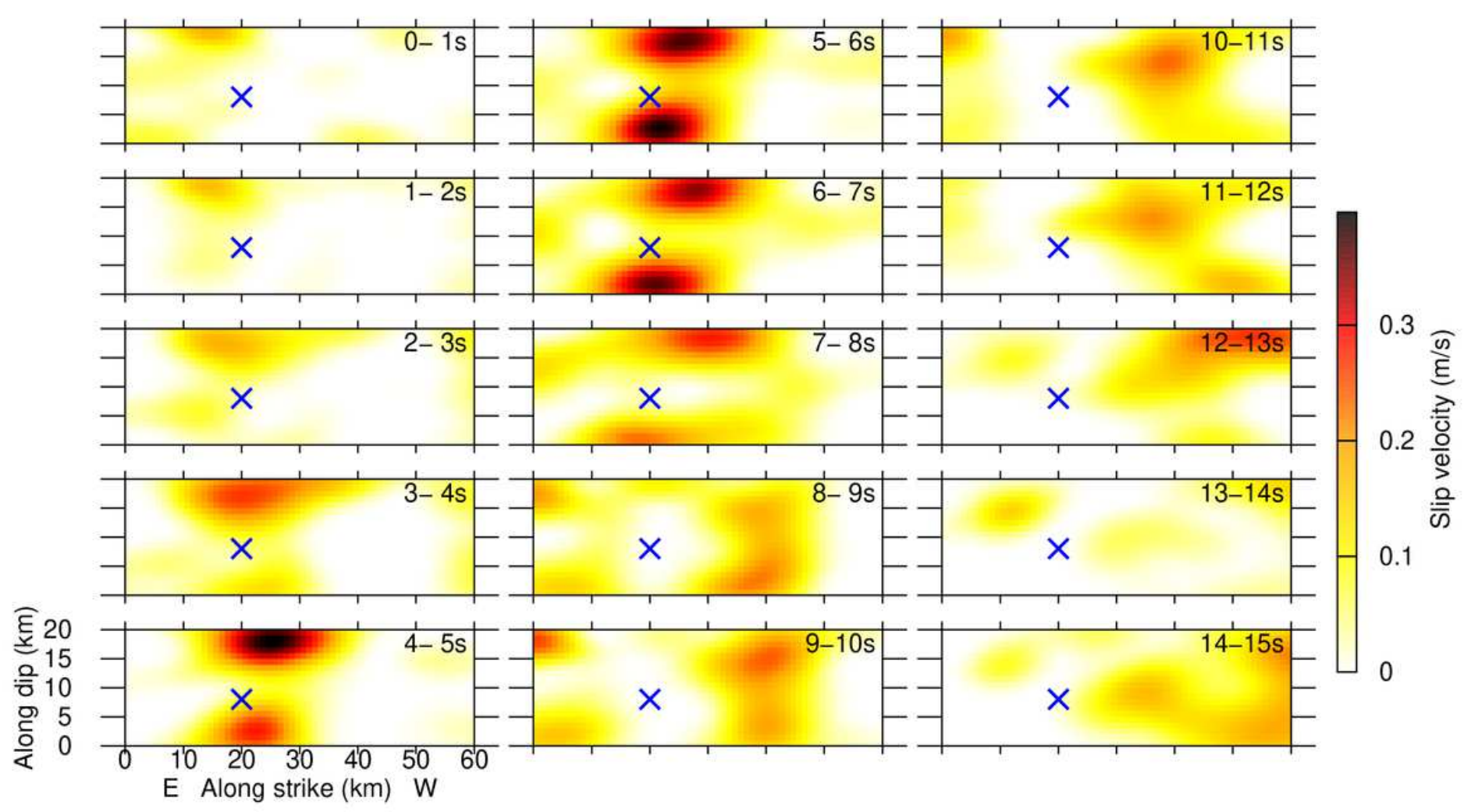

b EAST

WEST

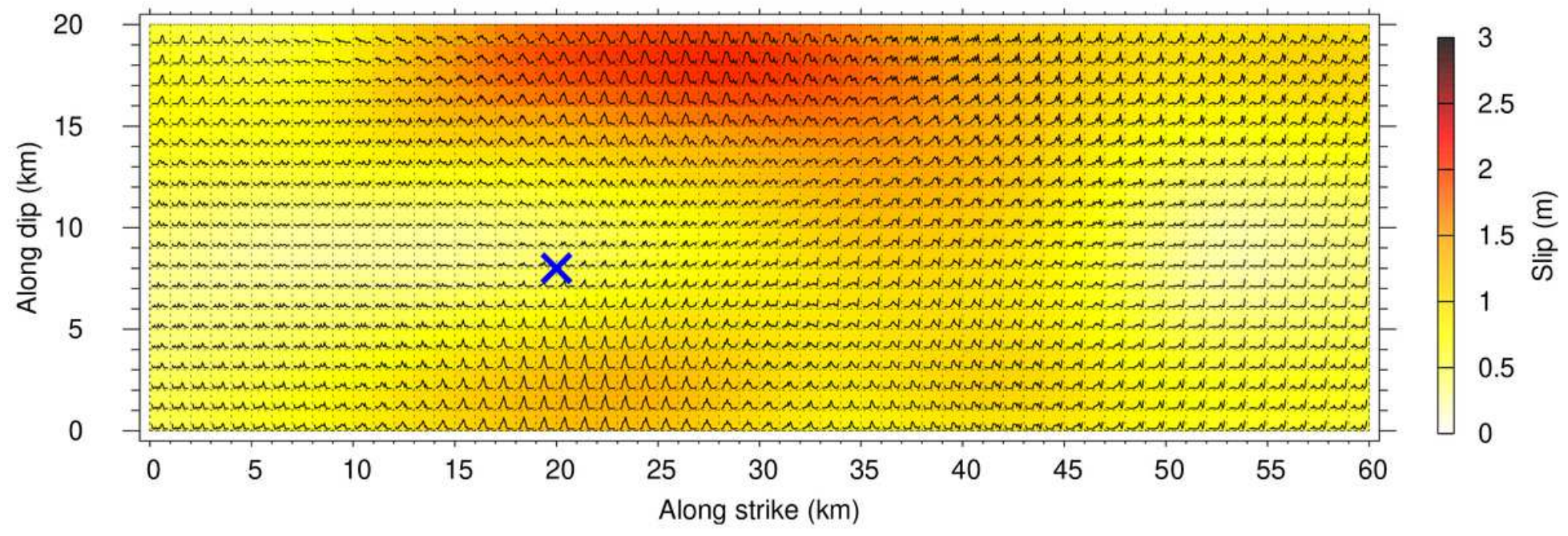

Figure 12

a: Snapshots at $1 \mathrm{~s}$ time intervals showing the rupture evolution of the mainshock obtained from the kinematic inversion described in Section 4.2. The blue cross indicates the rupture nucleation point; $b$ : composite slip model for the mainshock based on the slip history in a. Individual slip rate functions for each $1 \mathrm{~km} \times 1 \mathrm{~km}$ subfault are also shown. Details for the parameterisation of the kinematic slip inversion are given in Table 2. 

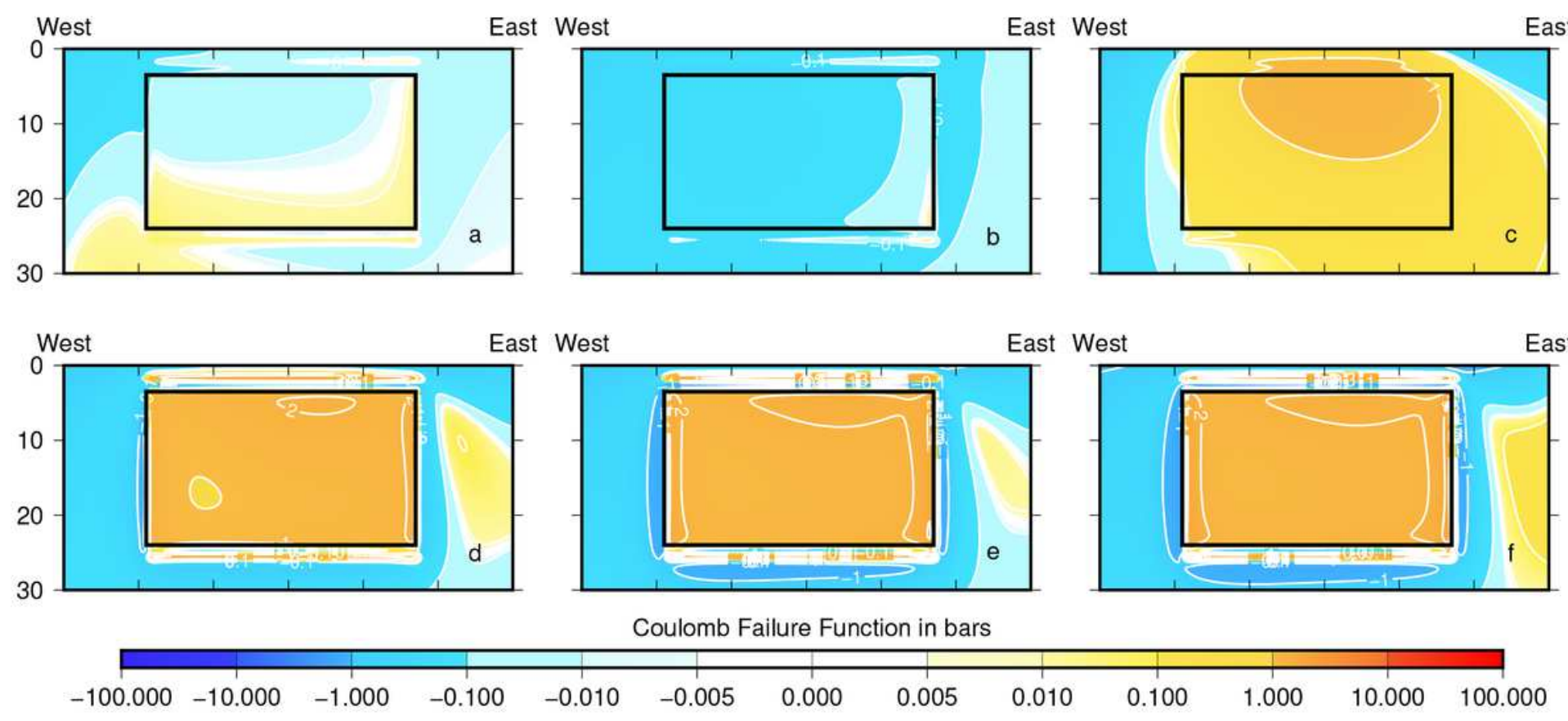

Figure 13

The accumulated $\triangle \mathrm{CFF}$ resolved onto the Kaystrios fault due to the successive tectonic loading and the coseismic stress changes impact due to a: the 1881 Chios-Cesme earthquake; $b$ : the 1883 Cesme earthquake; c: the 1904 earthquake south of Samos; d: the 1928 Torbali earthquake; e: the 1949 ChiosKaraburun earthquake and $\mathrm{f}$ : the 1955 Balat earthquake. The fault geometry is represented with a black rectangle. 


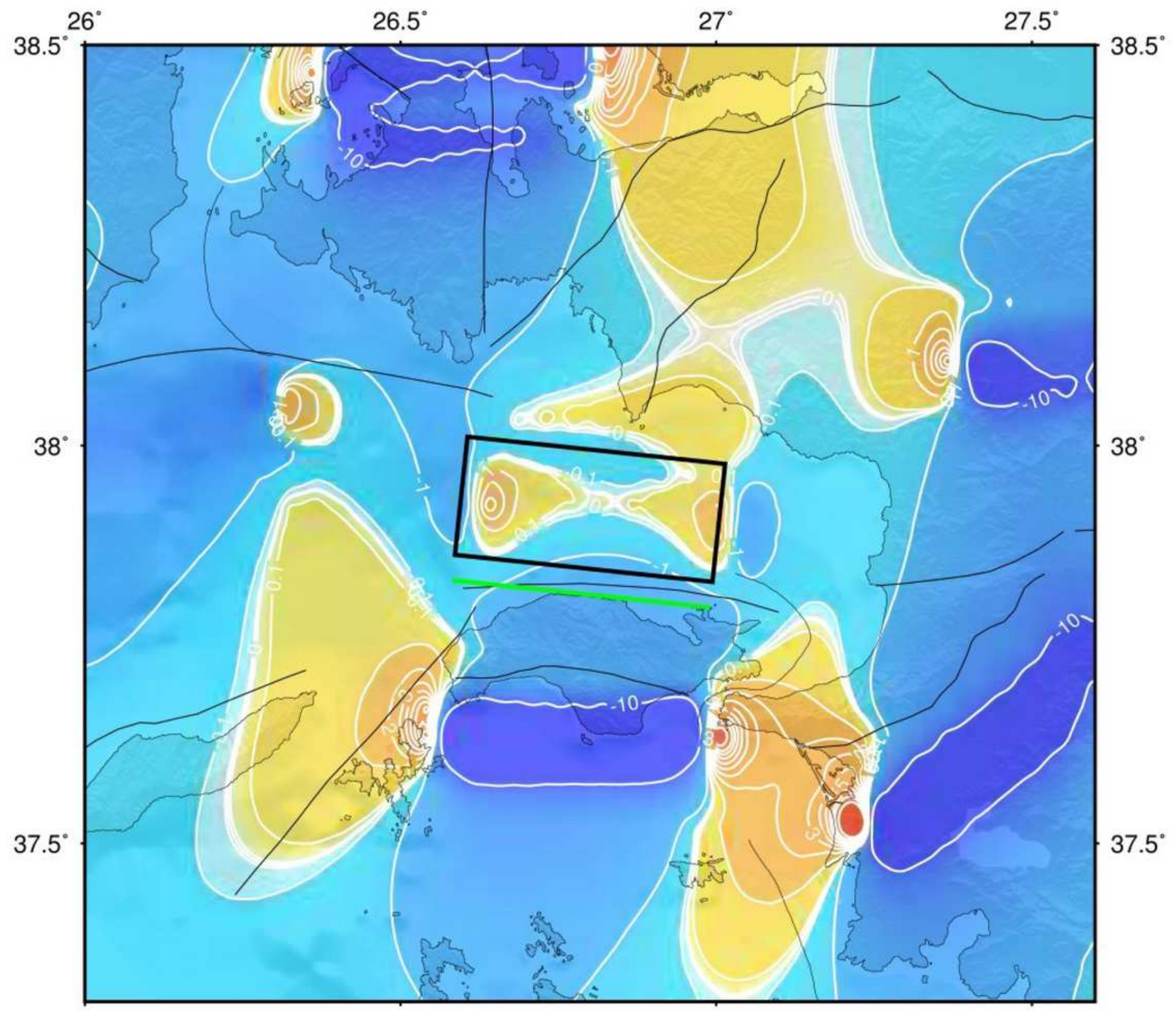

Coulomb Failure Function in bars

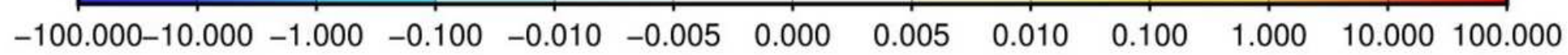

\section{Figure 14}

Stress field changes imposed by the strong earthquake occurrence and the stress loading along the Kaystrios fault, in a surface projection at $8 \mathrm{~km}$ depth. The fault is rep- resented with a black rectangle and the fault plane projection on the surface is shown as a green line. Note: The designations employed and the presentation of the material on this map do not imply the expression of any opinion whatsoever on the part of Research Square concerning the legal status of any country, territory, city or area or of its authorities, or concerning the delimitation of its frontiers or boundaries. This map has been provided by the authors. 

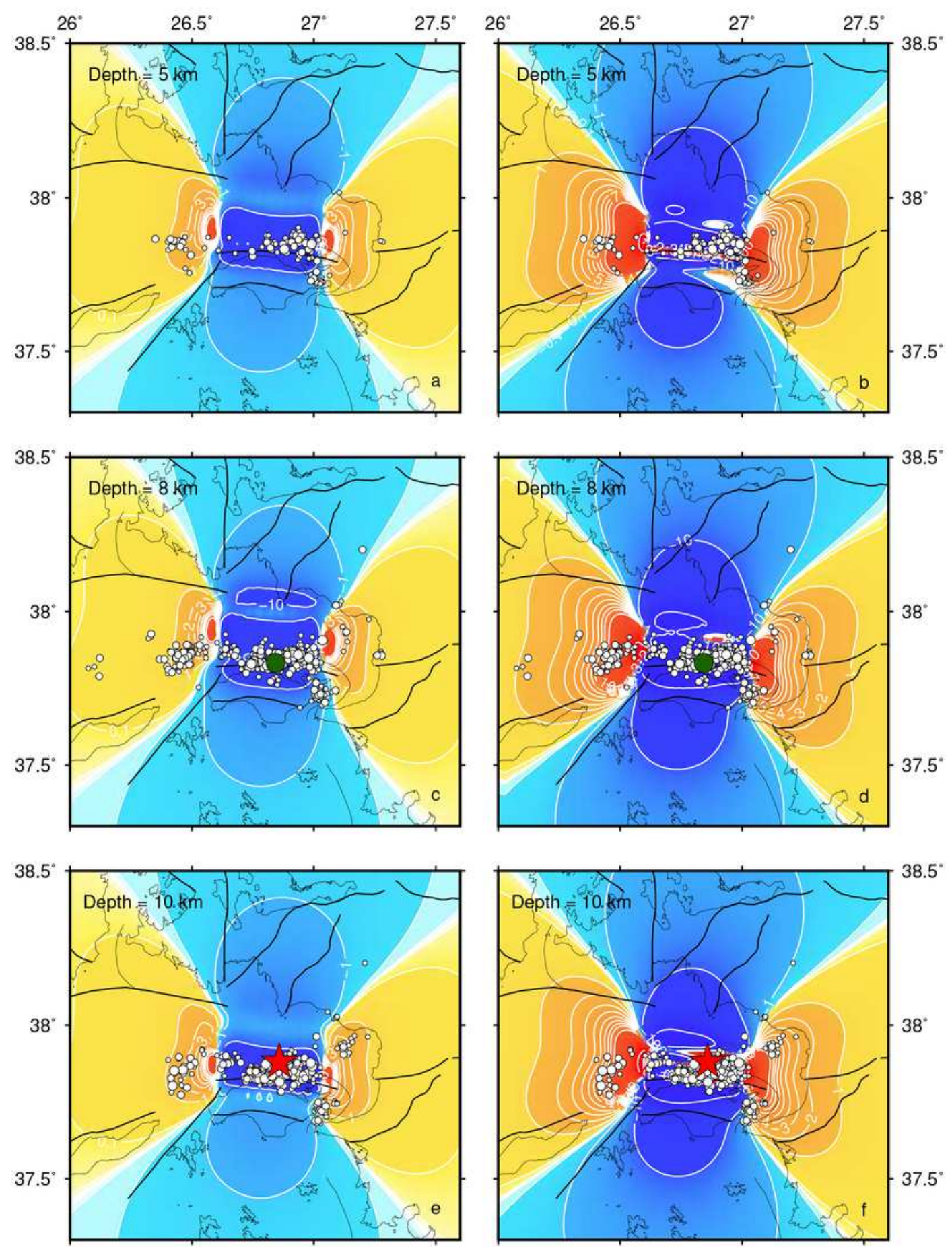

Coulomb Failure Function in bars

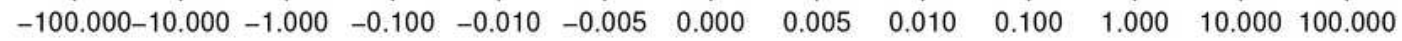

\section{Figure 15}

a: Coseismic stress changes for the uniform slip model at the horizontal layer at $5 \mathrm{~km}$ depth; b: Coseismic stress changes for the variable slip model at $5 \mathrm{~km}$ depth; c: Coseismic stress changes for the uniform slip model at $8 \mathrm{~km}$ depth; d: Coseismic stress changes for the variable slip model at $8 \mathrm{~km}$ depth; e: Coseismic stress changes for the uniform slip model at $10 \mathrm{~km}$, and f: Coseismic stress changes for the variable slip model at $10 \mathrm{~km}$ depth. Note: The designations employed and the presentation of the material on this map 
do not imply the expression of any opinion whatsoever on the part of Research Square concerning the legal status of any country, territory, city or area or of its authorities, or concerning the delimitation of its frontiers or boundaries. This map has been provided by the authors.
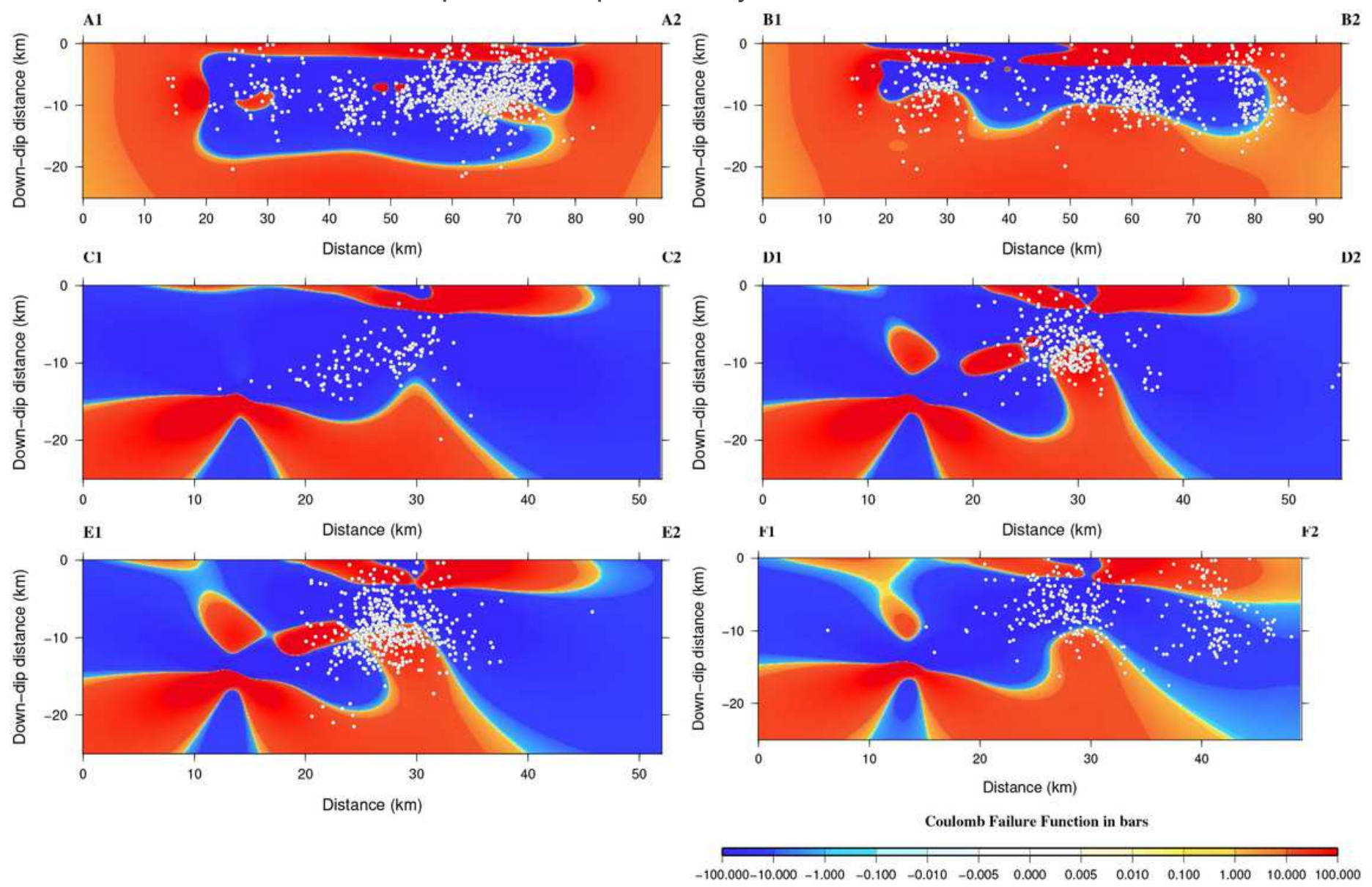

\section{Figure 16}

Cross-sections of $\triangle \mathrm{CFF}$ along vertical planes according to the cross-sections in Figure 5. White circles represent the relocated seismicity. 


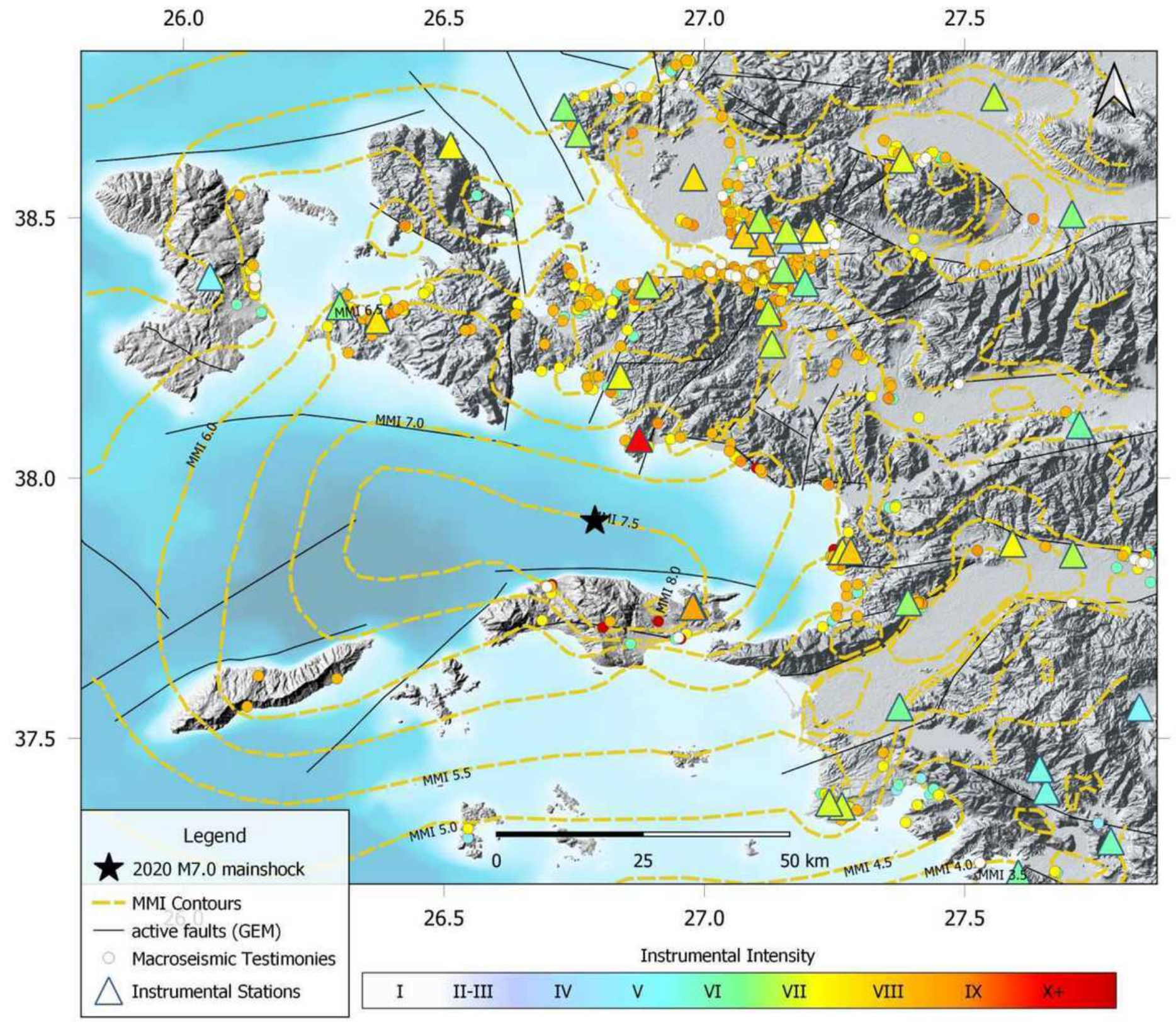

38.5

38.0

Figure 17

Estimated intensity MMI contours using the resulted rupture model, strong mo- tion maximum PGA values at recorded stations converted to $\mathrm{MMI}$ and EMSC collected testimonies. Filled triangles correspond to recorded stations and filled circles to EMSC tes- timonies. Colour following USGS MMI ShakeMap legend. Note: The designations employed and the presentation of the material on this map do not imply the expression of any opinion whatsoever on the part of Research Square concerning the legal status of any country, territory, city or area or of its authorities, or concerning the delimitation of its frontiers or boundaries. This map has been provided by the authors. 

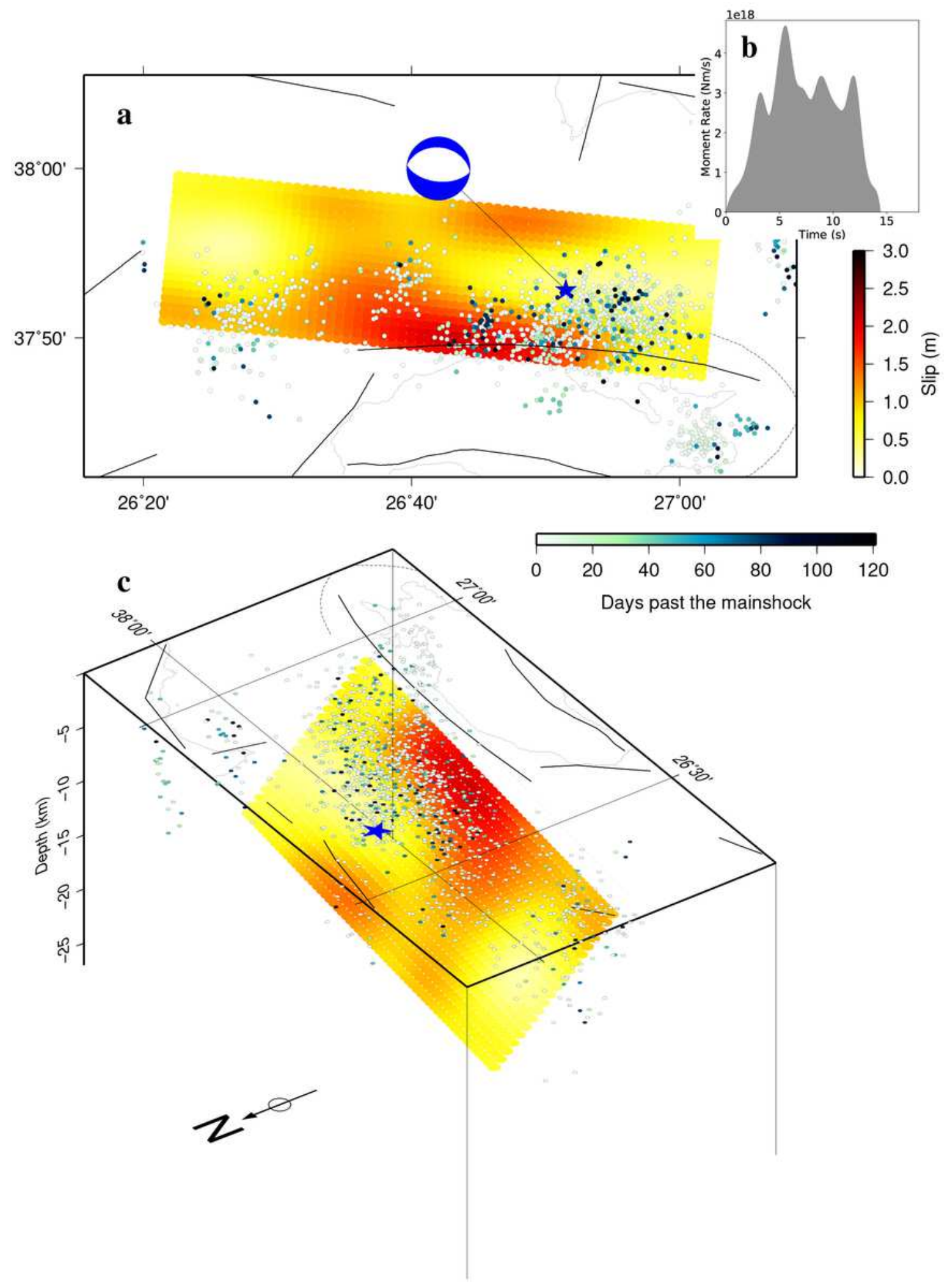

\section{Figure 18}

a: Map showing the slip model distribution in relation to the Kaystrios fault and the location of the mainshock (blue star). The GCMT best fitting double couple solution used for the determination of the slip model is also shown on the map. The relative locations of the aftershock sequence are shown as black dots; b: moment rate function determined from the kinematic slip inversion for the mainshock; $\mathrm{c}$ : 
same as in a, but in 3D plot. The surface trace of the planar fault assumed in the slip model inversion is shown in green for reference. 